\title{
REACTOR TANK UT ACCEPTANCE CRITERIA (U)
}

by W. L. Daugherty

Westinghouse Savannah Fiver Company

Savannah River Site

Aiken, South Carolina 29808

Other Authors:

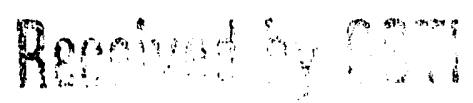

DEC 141992

\footnotetext{
This paper was prepared in connection with work done under Contract No. DE-AC09-89SR18035 with the U. S. Department of Energy. By acceptance of this paper, the publisher and/or recipient acknowledges the U. S. Government's right to retain a nonexclusive, royalty-free license in and to any copyright covering this paper, along with the right to reproduce and to authorize others to reproduce all or part oi the copyrighted paper.
} 



\title{
NRTSC
}

NUCLEAR REACTOR TECHNOLOGY

AND SCIENTIFIC COMPUTATIONS

Keywords: Uttrasonic Test In-Service Inspection IGSCC

PTERM

CAMEL

Retention - Permanent

\section{REACTOR TANK \\ UT ACCEPTANCE CRITERIA (U) \\ TASK NUMBEP: 88-001-A-1}

\author{
By \\ W. L. DAUGHERTY Materials Technology
aLDenghenty
}

ISSUED: JANUARY 30, 1990

Authorized Derivative Classifier

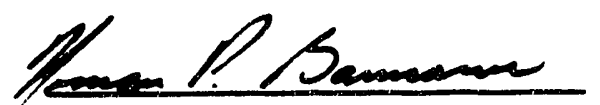

N. P. BAUMANN

$\frac{2 / 6 / 90}{\text { Date }}$

SRL SAVANNAH RIVER LABORATORY, AIKEN, SC 29808

Westinghouse Savannah River Company

Prepared for the U. S. Department of Energy under Contract DE-AC09-88SR18035

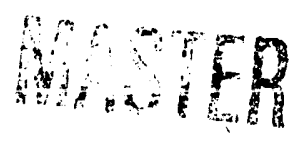


PROJECT: REACTOR MATERIALS PROGRAM

DOCUMENT: WSRC-RP-89-208-REVISION 2

TITLE: REACTOR TANK UT ACCEPTANCE CRITERIA (U)

TASK: REACTOR TANK ACCEPTANCE CRITERIA TASK 88-001-A-1

APPROVALS

$\frac{\text { P.Z. thindelar }}{\text { R.L.SINDELAR, TECHNICAL REVIEWER }}$ MATERIALS TECHNOLOGY

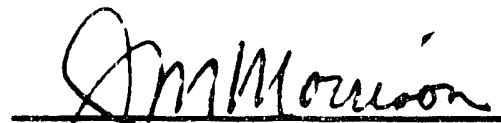

Jo. MORRISON, TECHNICAL REVIEWER REACTOR PROGRAMS

N.G. Uurdalla MATERIALS TECHNOLOGY

MoM. STONE M MANAT

J. M. ST ONE, MANAGER MATERIALS TECHNOLOGY

2.D. Spencer

JJ. SPENCER, MANAGER NUCLEAR REACTOR TECHNOLOGY \& SCIENTIFIC COMPUTATIONS

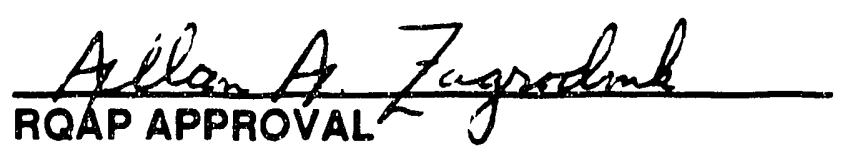

DATE: $1-30-90$

DATE: $2-\sqrt{-90}$

DATE: $2-5-90$

DATE: $\quad 2.6-e_{10}$

DATE: $2 / 6 / 90$

DATE: $2 / 7 / 90$ 


\section{Revision Summary Page}

Document No. WSRC-RP-89-208

Rev. No. 2 Issue Date: 1/30/90

Task ID No. 88-001-A-1

Effective Date: $1 / 30 / 90$

Page No.

Description of Revision

Revision 1 Revisions

1

1 st and 2nd paragraphs of Discussion;

Statements added to clarify flaw indications and required actions.

2

2nd paragraph;

New paragraphs added to clarify scope of UT Acceptance criteria.

3

Last paragraph;

Statements added io clarify scope of the UT Acceptance Criteria report (WSRC-RP-89-208).

Figure 1

"Flaw" added to title.

Chart revised for clarification and consistency with text.

Revision 2 Revisions

2

Item 4 of 2 nd paragraph; requirements for documenting weld flaws and geometric reflectors clarified.

Att. 1 Glossary Item 11; correct typographical error.

Item 13; correct typographical error and make editorial change for clarity. 


\section{INTRODUCTION}

The SRS reactor tanks are constructed of type 304 stainless steel, with 0.5 inch thick walls. An ultrasonic (UT) in-service inspection program has been developed for examination of these tanks, in accordance with the ISI Plan for the Savannah River Production Reactors Process Water System (DPSTM-88-100-1). Prior to initiation of these inspections, criteria for the disposition of any indications that might be found are required. A working group has been formed to review available information on the SRS reactor tanks and develop acceptance criteria. This working group includes nationally recognized experts in the nuclear industry. The members and their affiliation are listed below.

Members of the SRS Tank Acceptance Criteria Working Group

\author{
Name \\ D. C. Adamonis \\ N. G. Awadalla \\ N. P. Baumann \\ J. A. Begley \\ S. H. Bush \\ G. R. Caskey, Jr. \\ W. E. Cooper \\ W. L. Daugherty \\ H. S. Mehta \\ J. G. Merkle \\ S. Ranganath \\ R. L. Sindelar \\ J. C. Tobin \\ S. Yukawa
}

\author{
Organization \\ Westinghouse Electric Corporation \\ SRS \\ SRS \\ Westinghouse Electric Corporation \\ Review \& Synthesis Associates \\ SRS \\ Teledyne Engineering Services \\ SRS \\ General Electric Company \\ Oak Ridge National Laboratory \\ General Electric Company \\ SRS \\ SRS Consultant \\ SRS Consultant
}

The working group has met three times and produced three documents describing the proposed acceptance criteria, the technical basis for the criteria and a proposed initial sampling plan. This report transmits these three documents, which were prepared in accordance with the technical task plan and quality assurance plan for this task, task 88-001-A-1. In addition, this report summarizes the acceptance criteria and proposed sampling plan, and provides further interpretation of the intent of these three documents where necessary.

\section{DISCUSSION}

The acceptance criteria are contained in EDG-89.47, provided as Attachment 1 to this report. These criteria define two standards for characterizing UT indications. With the exception of geometric reflectors, an indication greater than or equal to $20 \%$ through wall in depth is considered a flaw. Detection of flaws smaller than those used for UT qualification $\left(3.0^{\prime \prime} \pm 0.5^{\prime \prime}\right.$ in length and $0.2^{\prime \prime} \pm 0.1^{\prime \prime}$ in depth) is not required. However, if smaller indications are detected, they shall be recorded and considered by the analyst for combination with adjacent indications. This statement does not constitute a requirement for the UT inspector to detect flaws smaller than those used for qualification.

Flaws which are smaller than the reexamination standard (5 inches) are acceptable for continued operation until the next normal inspection in 5 years. Flaws greater than or equal to the reexamination standard, but less than the acceptance standard are acceptable for continued operation for a period of 18 months. Flaws greater than or equal to the acceptance standard (10 inches) require additional analysis and evaluation using flaw, material, and operating conditions specific to the flaw location to 
determirie acceptability for continued operation. The acceptability of a flaw exceeding the acceptance standard will be reviewed and approved by WSRC and DOE management. Flaws greater than or equal to the acceptance standard will also require an expansion of the sample size of the present inspection. Finally, indications less than $20 \%$ through wall in depth, and longer than twice the acceptance standard, are subject to additional evaluation, flaw specific analysis, and/or examination. These criteria are illustrated in Figure 1.

The Reactor Tank UT Acceptance Criteria were developed for use in evaluating and dispositioning indications found in the heat affected zone or base metal surrounding tank assembly welds. This is consistent with DPSTM-88-100-1, which identifies specific IGSCC categories for each type of weldment in the reactor tank. Only the heat affected zone portions of these weldments are susceptible to IGSCC. The weld metal is not susceptible to IGSCC. Beyond the guidelines developed for IGSCC by the working group, the following guidance is provided for addressing any indications that might be found within the weld metal or UT signals resulting from geometric reflectors:

1. Any UT signal that is interpreted by the level III inspectors as a reflector due to weld geometry is acceptable. It should be documented for future reference (see item 4 below).

2. Any UT signal that is interpreted by the level III inspectors as a discontinuity which is embedded entirely within the weld and does not penetrate the tank surface is acceptable as is. Such discontinuities are assumed to be a result of tank fabrication. As such, these weld imperfections would have been accepted by the code of record enforced during tank fabrication. There is no known mechanism for the propagation of weld flaws in the SRS reactor tanks. Thus, they present no concern to the structural integrity of the tank. These indications should be documented for future reference (see item 4 below).

3. Any UT signal that is interpreted by the level III inspectors as a discontinuity within the weld volume which penetrates the ta surface should be evaluated in accordance with the acceptance criteria of this document.

4. Since the UT qualification is based on cracks of $3.0^{\prime \prime} \pm 0.5^{\prime \prime}$, shorter cracks may not be detected. Similarly, geometric or embedded weld reflectors shorter than $2.5^{\prime \prime}$ may not be detected. These weld reflectors need not be considered for combination with adjacent indications. Embedded weld flaws whose length is greater than or equal to $2.5^{\prime \prime}$ shall be documented for future reference and should include, to the extent to which the equipment and inspectors are qualified, the location coordinates and a cross-sectional plot showing the location of the reflector with respect to the weld. Hard copy data from an automatic data acquisition system (such as the Intraspect 98) which is capable of providing an overlay for direct comparisons with subsequent inspections is considered adequate for this purpose.

Attachment 2 (EDG-89.48) contains the technical bases considered in developing these criteria. A vailable information on iank stress analyses. matenal properties, IGSCC behavior, the UT examination program and fracture mechanics analy ses is summarized.

A sampling plan is described in EDG-89.49. provided as Attachment 3. This sampling plan applies only to the initial inspection. The scope of subsequent inspections will depend in part on the results of the first inspection. The proposed sampling plan calls for inspection of all tank shell longitudinal welds, one-third of the tank shell circumferential welds, portions of the T weld that are accessible. base metal regions and identified areas of repair work. 
The proposed sampling plan does not specifically identify the regions of base metal to be inspected during the initial inspection. It is not the intent of the working group that all base metal in the accessible regions be examined. Rather, only selected portions need be examined. Specifically, it is proposed that the initial examination cover the narrow regions of base metal bounded by (1) lines extending from each tank shell longitudinal weld, (2) a circumferential line 12 inches above the center girth weld, and ( 3 ) a circumferential line 12 inches below the center girth weld. This gives coverage of two narrow strips of base metal, two feet in height, with the circumferential girth weld dividing each strip in half. Inspection of these regions will provide assurance that no defects are propagating from the longitudinal welds into the base metal.

The three documents provide the necessary acceptance criteria for the disposition of UT indications that might arise during inspection of the SRS reactor tanks. The criteria control acceptance of flaws based on length as sized by UT measurement; no restrictions are placed on the depth of the flaw. The considerations used to develop these criteria and the sampling plan provide confidence that any flaw of significant size will be detected in a timely manner and dispositioned in such a way as to preserve the structural integrity of the reactor tanks and provide confidence in the continued safe, reliable operation of the SRS reactors. The disposition of flaws at a measured depth less than or equal to the tank wall thickness is handled as an operational decision with leakage limits controlled per the site Technical Specification 3.3.2. This Technical Specification precludes reactor operation with leakage from the process water system pressure boundary, as defined in the Specification.

WLD:sgm

SRL-EDG-890166 
Figure 1. Flow Diagram of LT Flaw Indication Disposition Procedure

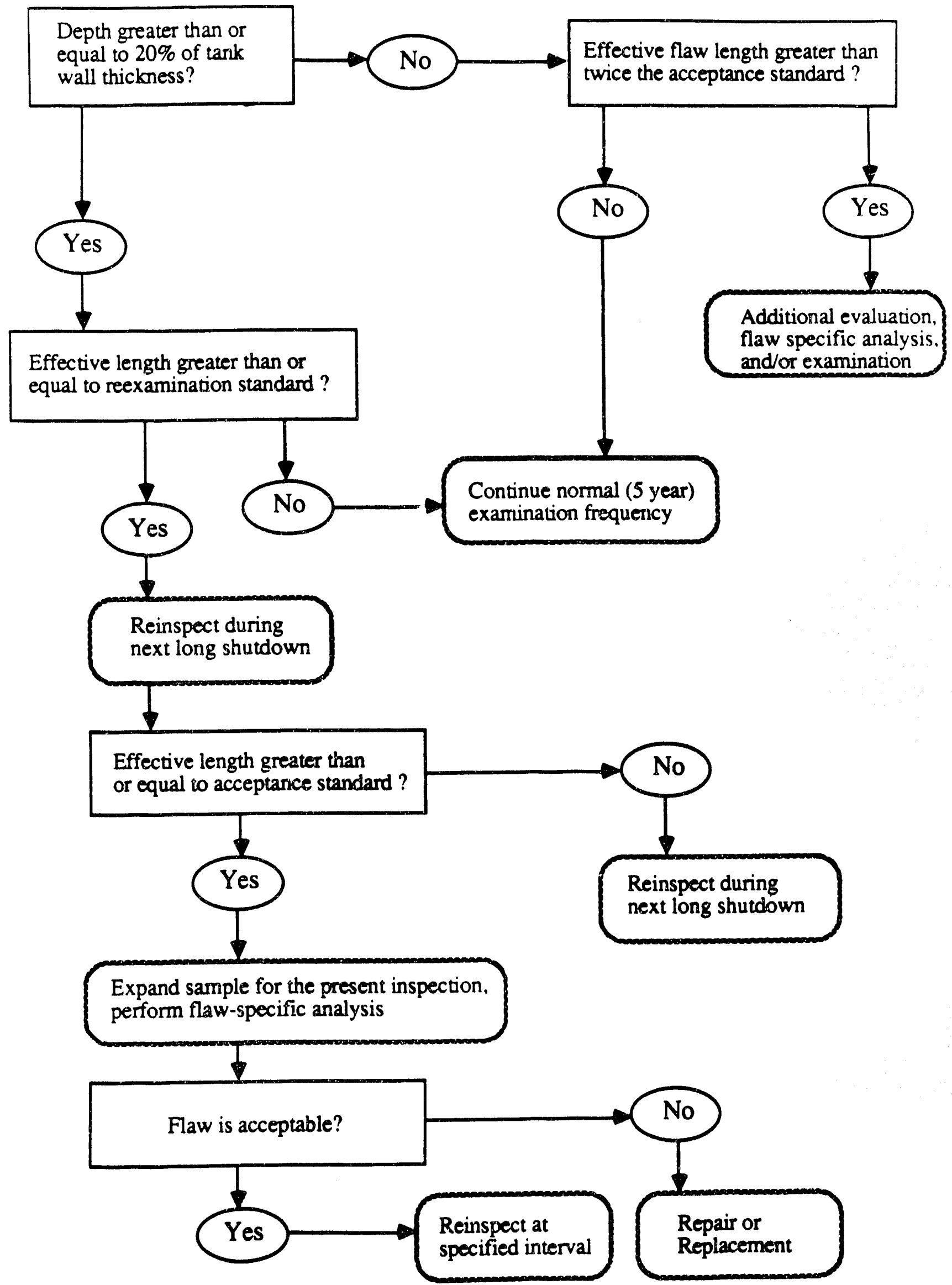


J. M. Stone

Page 4

January 30, 1990
WSRC-RP-89-208-Revision ?

Task Number 88-001-A-1

ATTACHMENT NO. 1 


\section{PROCEDURE FOR EVALUATION OE REACTOR TANK INSPECTION RESULTS (U)}

\section{DECEMBER 1989}

\section{Patent Status}

This internal management report is being transmitted without DOE patent clearance. and no further dissemination or publication shall be made of the report without prior approval of the DOE-SR patent counsel.

Westinghouse Savannah River Company Savannah River Laboratory P. O. Box 616 Aiken, SC 29802 PREPARED FOR THE U.S. DEPARTMENT OF ENERGY UNDER CONTRACT DE-ACO9-88SR18035 


\section{TULE: PROCEDURE FOR EVALUATION OE REACTOR TANK_INSPECTION_RESULTS (U)}

\section{DOCUMENT: EDG-89.47-REVISION1}

\section{REVISION 1}

PREPARED BY:

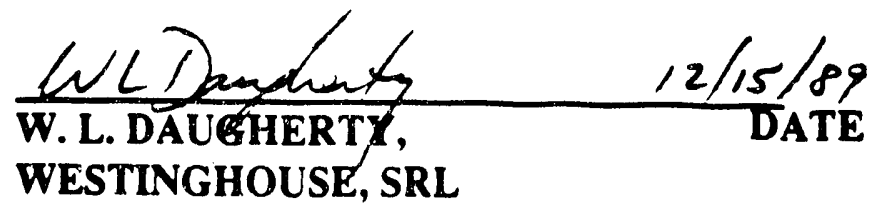

REVISION1 REVIEWED BY:
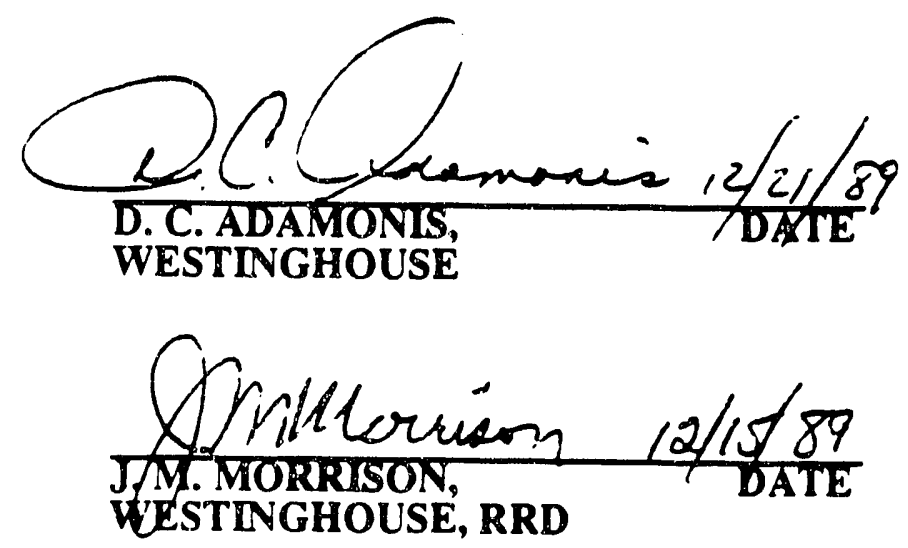
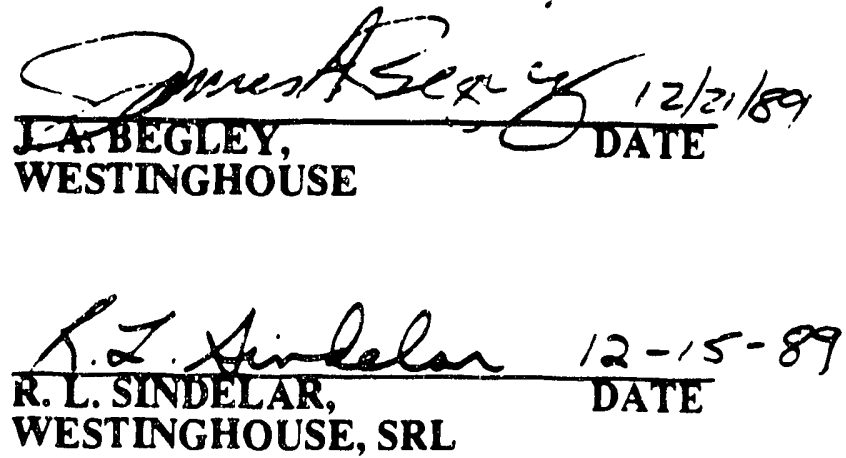
This approval page from the original issue of the Reactor Tank LT Acceptance Criteria by the Tank Acceptance Criteria Working Group is included in Revision 1 as a record of the technical expertise behind these acceptance criteria. Revision 1 to this document was made to clarify the criteria and not to alter the technical contents.

TILE: PROCEDURE FOR EVALUATION OF REACTOR TAN̄K_INSPECTION RESULTS

PREPARED BY:
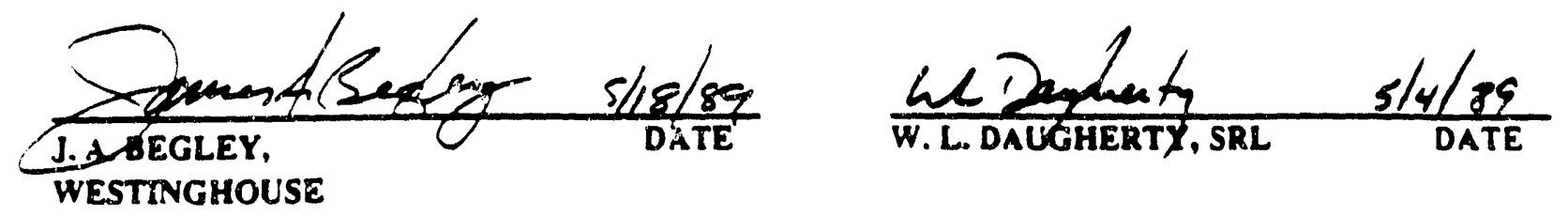

REVIEWED BY:

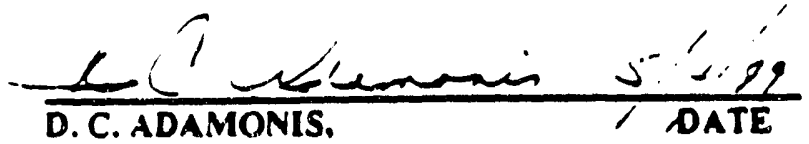

WESTINGHOUSE'
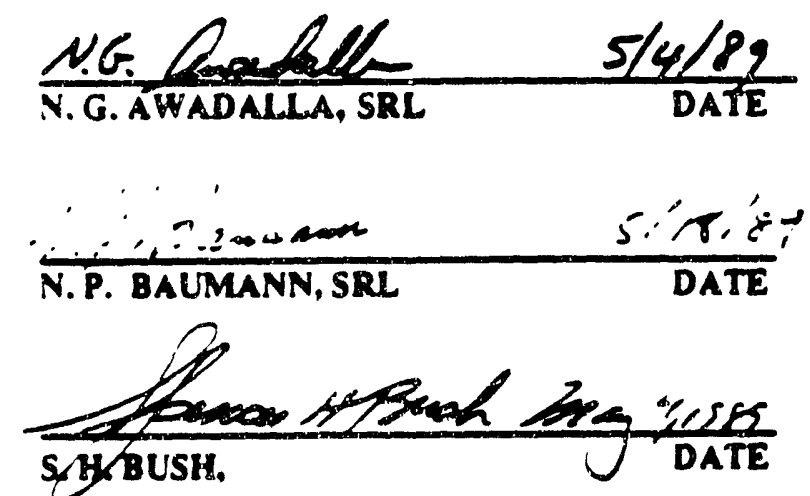

REVIEW \& SYNTHESIS ASSOCIATES
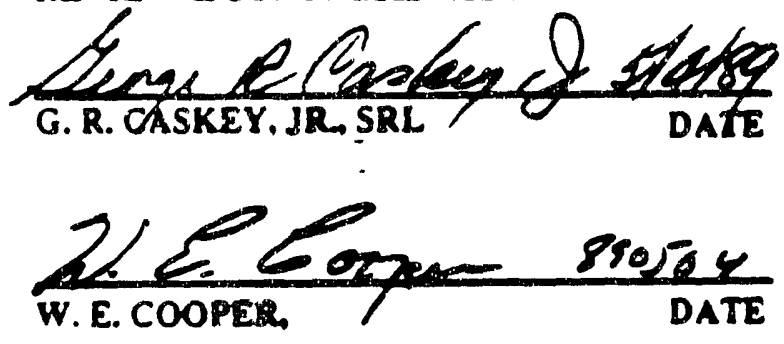

TELEDYNE ENGINEERiNG SERVICES

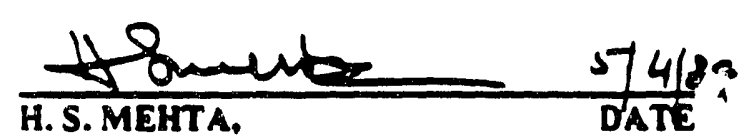

GENERAL ELECTRIC COMPANY
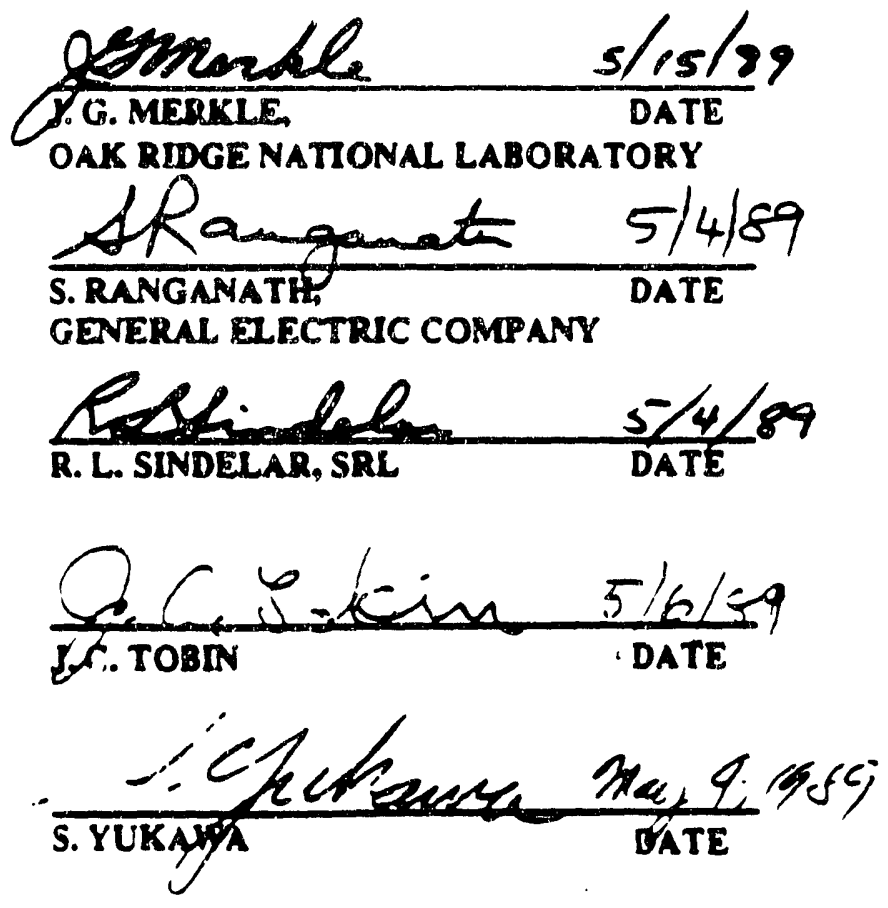


\section{TABLE OF CONTENTS}

I. INTRODUCTION AND APPROACH $\ldots \ldots \ldots \ldots \ldots \ldots \ldots \ldots \ldots$

II. FLAW CHARACTERIZATION $\ldots \ldots \ldots \ldots \ldots \ldots \ldots \ldots \ldots \ldots$

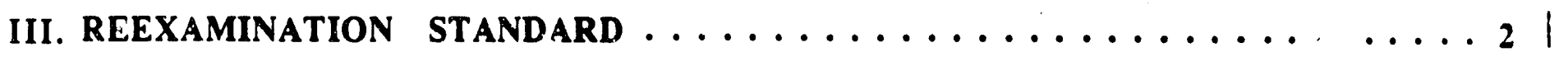

IV. ACCEPTANCE STANDARD FOR EXAMINATION $\ldots \ldots \ldots \ldots \ldots \ldots \ldots$

v. PROCEDURE FOR ACCEPTANCE BY ANALYSIS $\ldots \ldots \ldots \ldots \ldots \ldots \ldots$

VI. REFERENCES $\ldots \ldots \ldots \ldots \ldots \ldots \ldots \ldots \ldots \ldots \ldots \ldots \ldots \ldots \ldots \ldots$

VII.GLOSSARY $\ldots \ldots \ldots \ldots \ldots \ldots \ldots \ldots \ldots \ldots \ldots \ldots \ldots \ldots \ldots \ldots \ldots \ldots \ldots$ 


\section{Rexision Summary Page}

Document No. ED̄G-89.47

Rev. No. 1 Issue Date: 12/20/89

Task ID No. 88-001-A-1

Effective Date: $12 / 20 / 89$

Page No.

Descriprion of Revision

i

1

1

1

2

2

2

Glossary
Updated to reflect revised page numbering.

1st paragraph:

Revised to clarify applicability to IGSCC.

2nd paragraph added to clarify management treatment of leakage from the Process Water System Pressure Bcundary.

Last paragraph;

Editorial changes made.

2nd paragrapin;

Rules for crack combination are clarified.

Section II. "Reexamination Standard", 2nd paragraph;

Word "crack" deleted.

Section IV, "Acceptance Standard for Examination", 1st paragraph; Words "..identification and..." added for clarification.

Changes/additions made in items 5, 9, and 12; New item 14 added: Balance of numbers changed to reflect this addition.

These changes provide further clarification of the test discussion. 


\section{INTRODUCTION AND APPROACH}

The ISI Plan for the Savannah River Reactor Process Water System (1) specifies an ultrasonic inspection of the reactor tanks on a nominal five year frequency. The procedure for the evaluation of reactor tank inspection results is described in the following paragraphs. The scope of this procedure is limited to the disposition of planar flaws with an approach that parallels that of Section XI of the ASME Boiler and Pressure Vessel Code. This procedure was also developed specifically for evaluating and dispositioning indications found in the heat affected zone or base metal surrounding tank assembly welds. This is consistent with reference (1), which identifies specific IGSCC categories for each type of weldment in the reactor tank. The weld metal is not susceptible to IGSCC.

The evaluation of planar flaws is performed with the assumed condition of a through wall flaw depth along the entire length of any UT indication with reported depth greater than or equal to $20 \%$ through wall. The flaws are dispositioned based on flaw length only thereby addressing the structural safety significance of the flaw. Ultrasonic inspection results of flaws greater than or equal to $20 \%$ through wall in depth including through wall flaws are controlled by management decisions in regands to reactor operation. Leakage limits from potential through wall flaws are governed by the site Technical Specification 3.3.2. In addition to placing specific limits on normal process water losses, this Technical Specification does not permit reactor operation with leakage from the process water system pressure boundary, as defined in the Specification.

Rules for the characterization of flaw sizes are presented, including interaction effects. The evaluation procedure is based on comparing the effective size of an indication with two size criteria; a reexamination standard and an acceptance standard. The effective flaw length is a parameter that treats flaws as if they were through wall and provides for the combination of cracks in close proximity. Both the reexamination standard and the acceptance standard provide reasonable assurance that a crack will not exceed one-half the allowable flaw size prior to the next inspection.

All UT inspection results are recorded and available for future reference. Background information, crack growth and fracture analyses and safety margins which provide the technical bases for this flaw disposition procedure are included in Reference 2 . In particular, the Reference 2 discussion of UT detection and sizing capabilities provides a basis for the evaluation procedures.

The general approach for evaluation of the UT inspection results is outlined in Table 1. Sections II through V provide details for the evaluation.

\section{EIAW CHARACTERIZATUON}

A flaw is defined as a planar indication (geometric indications are not considered planar indications) with a depth greater than or equal to $20 \%$ of the reactor tank wall thickness. An indication less than $20 \%$ through wall in depth but greater than twice the acceptance standard in length is subject to supplemental examination. Detection of flaws shorter than those used for UT qualification $\left(3.0^{\prime \prime} \pm 0.5^{\prime \prime}\right)$ is not assured. However, if shorter flaw indications are detected, they shall be recorded and considered by the analyst for combination with adjacent indications. 
Page 2

December 20, 1989

A flaw is characterized by its effective length as defined below. Limitations are placed upon effective flaw length. No limitations are placed upon flaw depth. Limitations on acceptable effective flaw length are based on the conservative assumption of $100 \%$ depth along the full effective flaw length.

If the distance between a pair of colinear flaws is less than or equal to 2.6 inches, the pair of flaws shall be considered to be a single flaw of effective length equal to the distance between the farthest flaw ends. If two flaws are parallel but not colinear and the perpendicular distance between them is less than or equal to 0.5 inches, then the above rule shall also apply to determine the effective flaw length. This procedure may result in the combination of several pairs of flaws into a single flaw.

\section{REEXAMINATION STANDARD}

Flaws with an effective length less than 5 inches do not exceed the reexamination standard. For these flaws, the original examination frequency is maintained.

Flaws with an effective length greater than or equal to 5 inches exceed the reexamination standard. The physical flaw length and depth are to be reported as well as the location. These flaws shall be reinspected during the next three inspection outages. In the event an indication remains essentially unchanged during these subsequent three inspections, future inspections will revert to the original schedule.

\section{ACCEETANCE STANDARD FOR EXAMINATION}

Flaws with an effective length greater than or equal to 10 inches exceed the acceptance standard. Supplementary examinations shall be considered to assist in the identification and characterization of the flaw. Unless such supplementary examinations result in recharacterization of the flaw as one which has an effective length of less than 10 inches, the tank shall be subject to additional examination and evaluation for acceptance by analysis.

The additional examinations shall be performed on welds within the same inspection category, with the total length of welds for which the additional examination is performed being no less than that originally scheduled for the current exim ninations. If the additional examinations reveal any flaws with effective length greater than the acceptance standard, the additional examination shall be expanded to include $100 \%$ of all welds within that examination category.

The procedure for acceptance by analysis is presented in Section V.

\section{PROCEDURE FORACCEPTANCEBYANALYSIS}

This section describes the general approach and requirements to be followed in the acceptance by analysis evaluation required for flaws with an effective flaw length in excess of the acceptance standard. If the criteria for acceptance by evaluation are satisfied, continued tank operation for the defined evaluation period is permissible.

The technical approach and significant elements are described in Reference 1. The basic approach of the fracture safety analysis is as follows:

1. Consider the measured physical dimensions of the flaw or flaws included in the effective flaw length as determined by Section $I$.

2. Incorporate an allowance for inspection measurement error. 
3. Define the interval for the next inspection of the flaw.

4. Incorporate a flaw growth allowance for SCC based on a selected time to the next inspection.

5. For the crack length at the end of the evaluation period, compute the loading intensity based on the principles of linear elastic and elastic plastic fracture mechanics. Plasticity effects must be included or shown to be negligible. Applied and welding residual stresses must be included.

6. Using a crack growth resistance curve approach, determine if appropriate safety margins are available for protection against unstable crack growth. In computing the loading intensity in terms of $\mathrm{K}$ or $\mathrm{J}$, multiply the pressure loading by a factor of 3.0 for normal and upset conditions or the pressure and seismic loading by a factor of 1.4 for accident conditions. As a check of the degree of extrapolation of fracture testing data evaluate crack stability in both $J$ vs. $T$ and $J$ vs. a plots using mathernatically equivalent fits as illustrated in Figure 1.

7. The criteria for acceptance by evaluation are satisfied for the evaluation period if no unstable crack growth is predicted.

Key factors in the analysis have been delineated and the safety margins with respect to tank loading have been specified. Fracture toughness and associated crack growth resistance curve properties depend on position in the tank as the fluence depends sensitively on location. Location and tank specific values, if available, should be used. Flaw grow th allowances for IGSCC should consider, to the extent meaningful results are attainable, the past performance of the Savannah River reactor systems and a growing database of laboratory observations. A summary of information currently available in these areas is presented in Reference 2.

\section{REFERENCES:}

1. DPSTM-88-100-1, "ISI Plan for the Savannah River Production Reactors Process Water System," P. R. Vormelker, R. L. Sindelar and W. L. Daugherty, Savannah River Laboratory, December 1988.

2. EDG-89.48, "Technical Basis For The Savannah River Reactor Tank Acceptance Criteria," D. C. Adamonis et al., May 1989 
Tablē 1. General Approach for Evaluation of UT Inspection Results

\begin{tabular}{|c|c|c|c|c|c|c|c|}
\hline \multicolumn{5}{|c|}{ BEEXAMINATION STANDARD } & \multicolumn{3}{|c|}{ ACCEPTANCESTANDARD } \\
\hline & $<$ & $=$ & $>$ & $<$ & $<$ & $=$ & $>$ \\
\hline RECORD & YES & YES & YES & & YES & YES & YES \\
\hline ACC. NDE (EACH OUTAGE) & NO & YES & YES & & YES & YES* & YES* \\
\hline $\begin{array}{c}\text { ACC. NDE + EXPANDED } \\
\text { SAMPLE }\end{array}$ & NO & NO & NO & & NO & YES* & YES* \\
\hline EVALUATION (ANALYSIS) & NO & NO & NO & & NO & YES* & YES* \\
\hline YES = action required & & & & & & & \\
\hline NO = no action required & & & & & & & \\
\hline$A C C=$ accelerated & & & & & & & \\
\hline
\end{tabular}




\section{GLOSSABY}

1. Acceptable Effective

Flaw Length

2. Acceptance Standard

3. Allowable Flaw Size

4. Effective Flaw Length

5. Effective Flaw Size/ Characterization

6. Evaluation Procedure

7. Examination Category

8. Factor(s) of Safety

9. Flaw

10. Flaw Growth

11. Flaw Growth Allowance

12. Fla:v Indication (Or Indication)

13. Inspection Measurement Error

14. Flaw Identification

15. Inspection Outage

16. Physical Flaw Length

17. Reexamination Standard

18. Residual Stress

19. Resistance Curve

20. Unstable Crack Growth
See Acceptance Standard.

Flaws with an effective length less than or equal to 10 inches but equal to or greater than 5 inches.

Critical (unstable) flaw size calculated by fracture mechanics after multiplying normal operating stress by 3 and faulted stresses $(\mathrm{P}+\mathrm{DBE})$ by 1.4 .

Total length of a flaw or combination of flaws when separated by no more than 2.6 inches.

Measured flaw length and depth, including proximity considerations for adjacent flaws.

Comparison of effective flaw size to reexamination standard and acceptance standard.

See Ref. 1 (to dec. 1). For tanks the longitudinal and circumferential welds plus regions of repair if they exist.

Factors of 3.0 on pressure for normal and upset condition or 1.4 on pressure plus design basis earthquake for accident (faulted) conditions.

Any planar indication with a depth greater than $20 \%$ of the reactor tank wall (geometric indications excluded).

Flaw growth due to IGSCC (or other mechanisms such as fatigue) occurring in a specified time interval.

See flaw growth; where time interval is that to next inspection.

Ultrasonic response determined to be a discontinuity other than geometric.

Possible error in length measurement for a given ultrasonic procedure wherein underprediction of length is assumed. The magnitude is assumed to be 0.5 inches.

A prosess which identifies the type or source of the flaw including, but not limited to, fabrication volumetric flaws or service-induced flaws.

Long shutdown used to conduct UT; nominally assume 18 months between inspection outages.

Length of a discrete flaw.

Flaws having an effective length equal to 5 inches.

Those stresses usually resulting from contraction during welding and weldment restraint.

Fracture mechanics technique to determine margins against unstable crack growth.

A combination of flaw length and loads calculated to lead to flaw instability. 


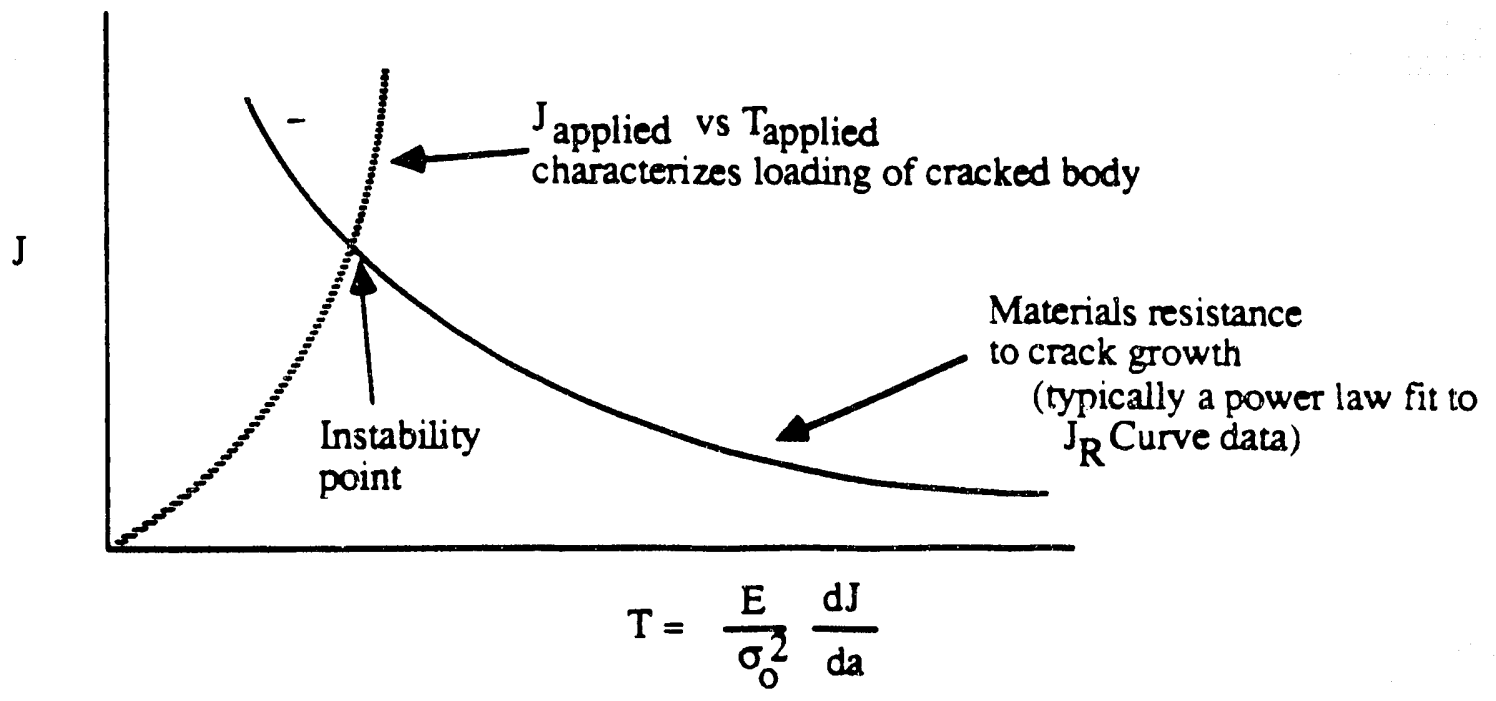

\section{ATINSTABחITY}

$\mathrm{J}_{\text {applied }}=\mathrm{J}_{\text {material }}$

$\mathrm{T}_{\text {applied }}=\mathrm{T}_{\text {material }}$

$\frac{\mathrm{dJ}}{\mathrm{da}} \int_{\text {applied }}=\frac{\mathrm{dI}}{\mathrm{da}} \int_{\text {material }}$

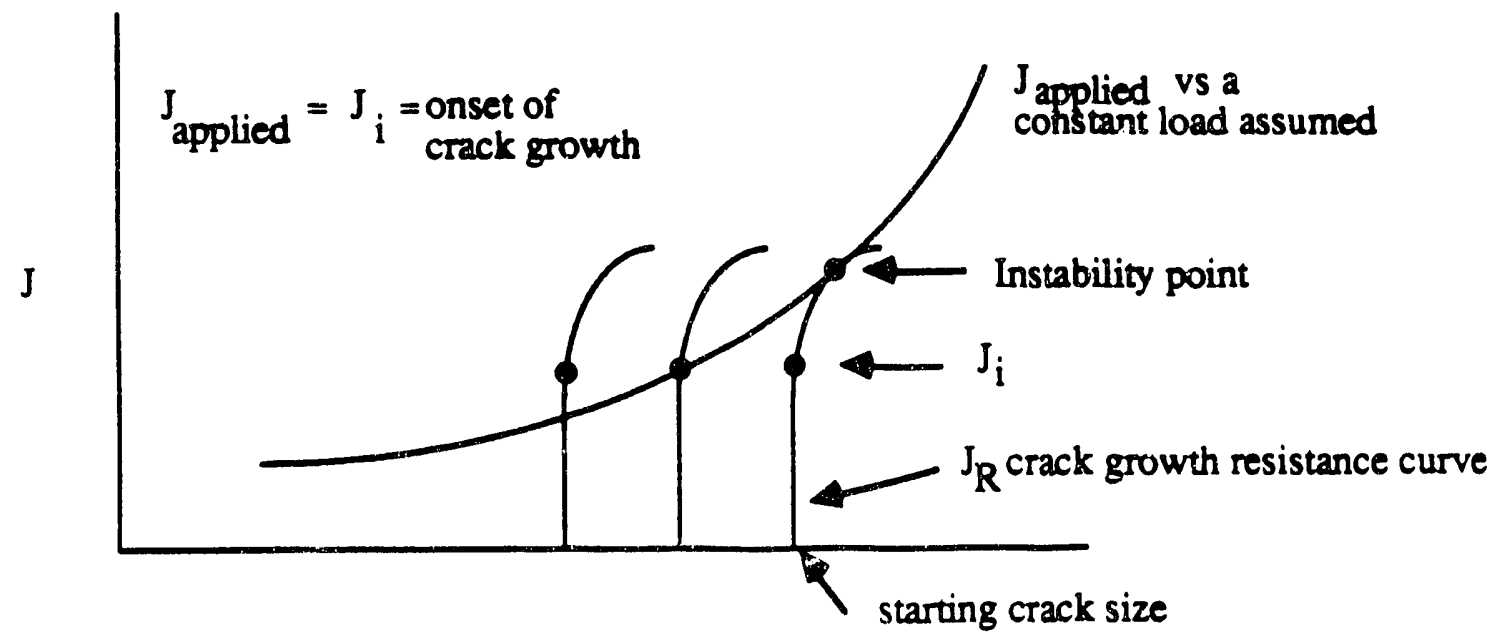

a, crack size

Figure 1. Equivalent J - T, J - a Illustrations of Crack Growth Stability 
J. M. Stone

Page 5

January 30, 1990
WSRC.RP-89-208-Revision 2

Task Number 88-001-A-1

ATTACHMENT NO. 2 


\section{TECHNICAL BASIS EOR THE SAVANNAH RIVER REACTOR TANK ACCEPTANCE,CRJTERIA (U)}

\section{DECEMBER 1989}

\section{Patent Status}

This internal management report is being transmitted without DOE patent clearance, and no further dissemination or publication shall be made of the report without prior approval of the DOE-SR patent counsel.

Westinghouse Savannah River Company 


\section{TILEE TECHNICAL BASIS FOR THE SAVANNAH RIVER REACTOR TANK ACCEPTANCE CRITERIA (U)}

DOCUMENT: EDG-89.48-REVISION 1

\section{REVISION 1 \\ PREPARED BY:}

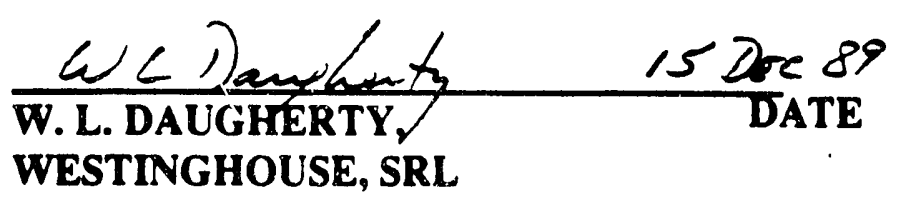

REVISION1 REVIEWED BY:

$\ell=1$

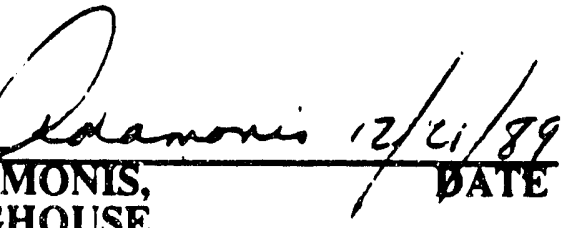
WESTINGHOUSE
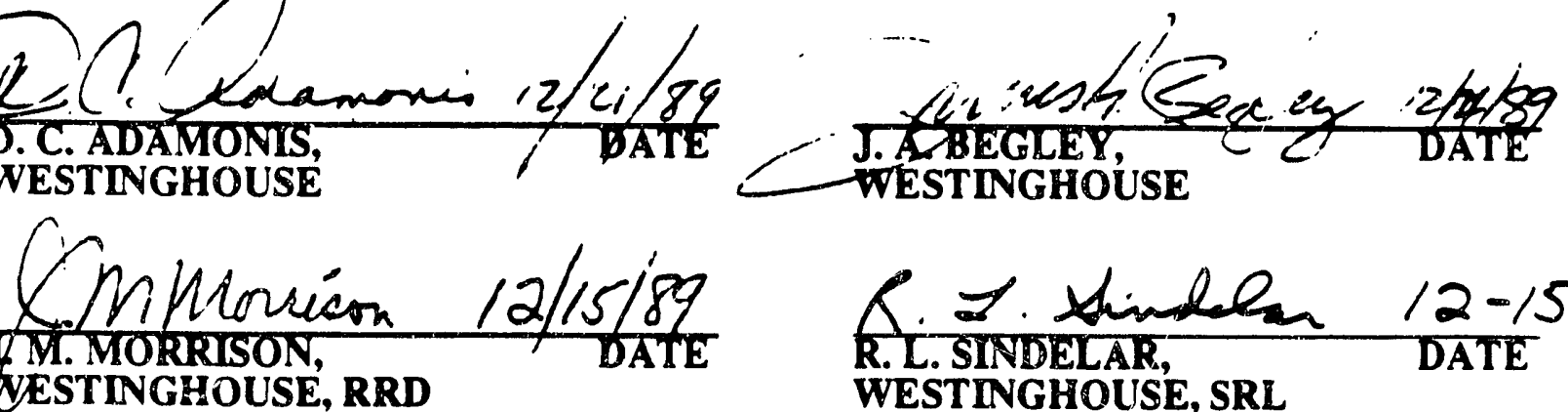
A.I. thinglan 12-15-89 R.L.SINDELAR, WESTINGHOUSE, SRL DATE EESTINGHOUSE, RRD 
This approval page from the original issue of the Reactor Tank LT Acceptance Criteria by the Tank Acceptance Criteria Working Group is included in Revision 1 as a record of the technical expertise behind these acceptance criteria. Revision 1 to this document was made to clarify the criteria and not to alter the technical contents.

\section{TOCLE: TECHNICALBASIS FOR THE SAVANNAHLRIVER BEACTOR TANK ACCEPTA NCE CRITERIA}

\section{PREPARED BY:}
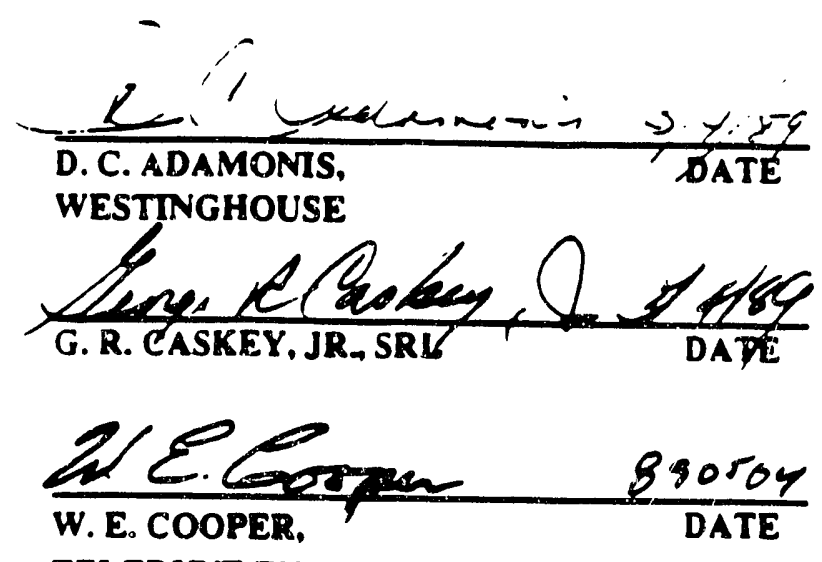

TELEDYNE ENGINEERING SERVICES
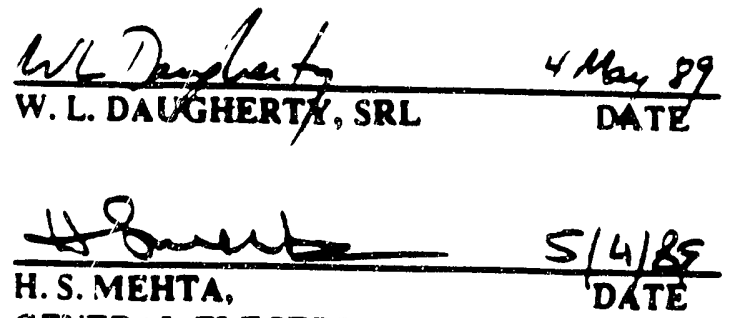
GENERAL ELECTRIC COMPANY

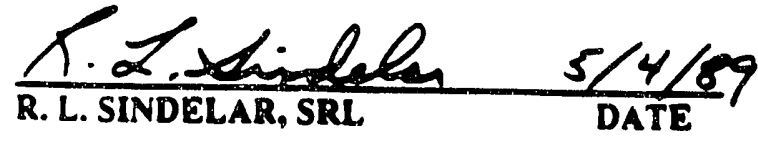

\section{REVIEWED BY:}
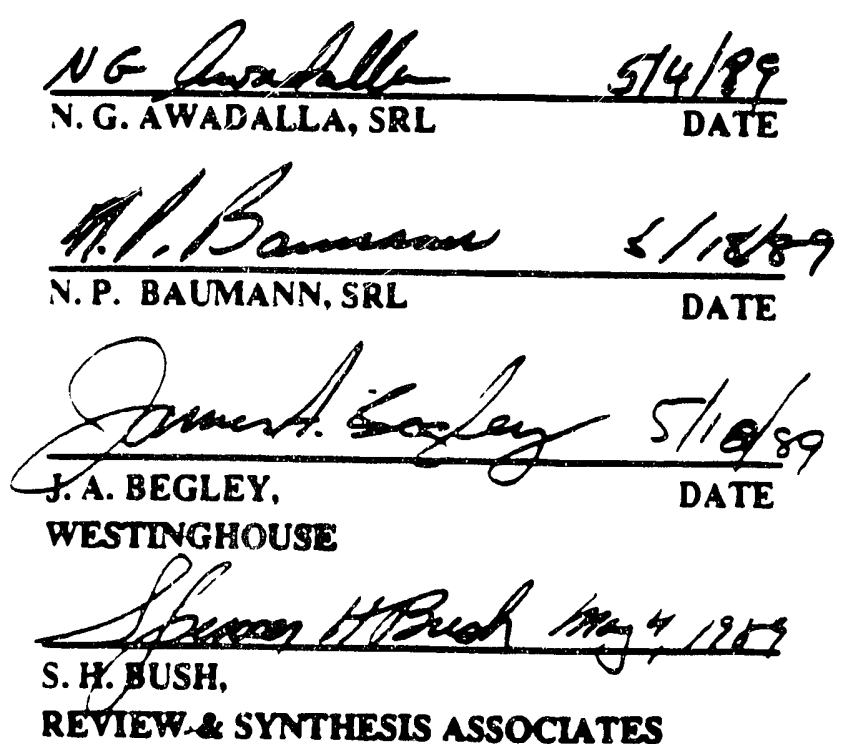

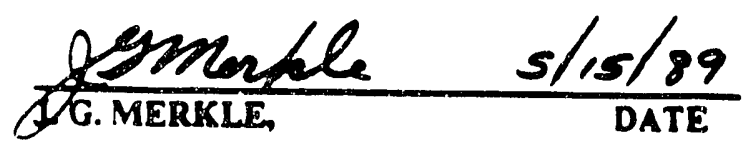

OAK RIDGS NATIONAL LABORATORY

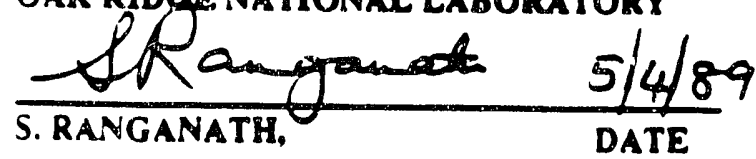

GENERAL ELECTRIC COMPANY
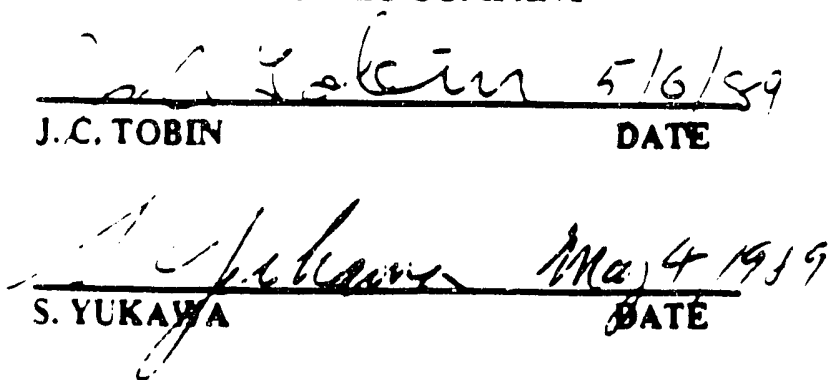


\section{TABLE OF CONTENTS}

I. INTRODUCTION

II. DISCUSSION

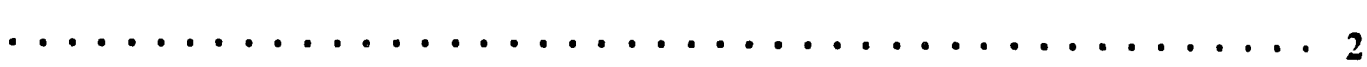

Stress and Structural Evaluation Fracture Toughness Properties IGSCC Behavior

UT Examination Program $\ldots \ldots \ldots \ldots \ldots \ldots \ldots \ldots \ldots \ldots \ldots \ldots$

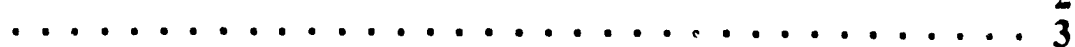

Examination Methodology Detection and Sizing Capabilities 


\section{Bevision Summary Page}

Document No. EDG-89.48

Rev. No. 1 Issue Date: 12/20/89

Task ID No. 88-001-A-1

Effective Date: $12 / 20 / 89$

Page No.

Description of Revision
i
Updated to reflect revised page numbering.
1
4th paragraph:
Statement in pareathesis added for clarification; last sentence changed for consisteacy with EDG-89.47.
$1 \quad$ Last paragraph, item $\# 2$;
Chauge made for clarification and consistency with ASME Code. Section XI.
5
1st line:
Corrected reference citation.
1 st and 2nd paragraphs; last sentence in 3rd paragraph;
Information added to document material properties.
2nd paragraph under "IGSCC Behavior";
Weid cracking frequency revised based on new data.
2ad paragraph; item 1; Terminology corrected.
8
3rd paragraph;
Last sentence added to clarifiy UT examination requirements.
Last paragraph:
Last sentence added to clarify UT acceptance criteria applicability.
3rd paragrapti:
2nd sentence added for clarification of basis for selecting locations $A$ and $B$.
6th paragraph;
Section added to address long shallow flaws.
References $* 16$ and $* 23$ updated.

Figure 4

A. 1

A-2, A-3

A.5 (sec) deleted from the captions of both diagrams.

4th paragraph:

Sentences added to clarify residual stress distribution.

Additional information added to address circumferential cracks.

References i.S. and A6. added. 


\section{Revision Summary Page}

Document No. EDG-89.48

Rev. No. 1 Issue Date: 12/20/89

Task ID No. 88-001-A-1

Effective Datc: $12 / 20 / 89$

Page No Description of Revision

Figure A2 Labels to the right of each diagram corrected.

Figures A5, A6 Curve labels added. 


\section{INTRODUCTION}

The tank of a Savannah River Site reactor is a cylinder approximately 16 feet in diameter and 14 feet high and is not pressurized except for a 5 psig helium blanket gas in addition to the hydrostatic head of the heavy water $\left(\mathrm{D}_{2} \mathrm{O}\right)$ moderator. The tanks are made of American Iron and Steel Institute Type 304 stainless steel fabricated into cylindrical shells with four to six wrought plates per vessel, 0.5 inches thick. The shells were made up in two flat half-sections for later rolling and welding. The tank bottom section containing the moderator effluent nozzles was welded to the shell in a $T$-joint configuration. All joining was performed with multipass Metal Inert Gas (MIG) welding.

An ultrasonic in-service inspection program has been implemented for the Savannah River Site (SRS) reactor tanks. The rationale for implementation of this program is to 1) provide information conceming tank status necessary for life extension studies and planning preventive maintenance and 2) provide additional assurance conceming the continued safe and reliable operation of the tank over and above that already established by design, analysis, prior examinations and operating experience. The approach of this periodic in-service inspection program is consistent with Section XI of the ASME Boiler and Pressure Vessel Code and the "ISI Plan for the Savannah River Production Reactors Process Water System". Baseline examinations will be accomplished during scheduled outages over the next five years of operation and "in-service" examinations will be performed during subsequent five year intervals.

A key step in preparing for the reactor tank examination program is development of appropriate acceptance criteria, criteria for more frequent surveillance of acceptable flaws, and the threshold flaw size above which the examination sample size must be expanded. A working group was formed to review available information and develop these criteria. The criteria are contained in a companion document (1). This document summarizes the technical information and approach on which the criteria are based. Although these criteria are based on reasonable interpretation of the best information available, they are subject to change as additional experience is developed.

The acceptance criteria provide three response levels to the ultrasonic testing (UT) results based on effective length standards. If an indication is greater than or equal to $20 \%$ through wall, it is considered a flaw (excluding geometric indications). An indication less than $20 \%$ through wall but more than twice the acceptance standard in length is subject to additional evaluation, flaw specific analysis and/or examination.

If a flaw is found which is less than the reexamination standard, it is recorded along with the other inspection documentation and no other action is necessary.

If a flaw equals or exceeds the reexamination standard. but is less than the acceptance standard, two actions are taken:

1. The flaw is reported as acceptable, and

2. The flaw is subject to an increased inspection frequency in the future.

Finally, if a flaw equals or exceeds the acceptance standard, five actions are taken:

1. The flaw is reported,

2. Supplemental examinations using other methods and techniques may be considered to optimize flaw identification and characterization.

3. The sample size for the current examination is expanded,

4. The flaw is analyzed for acceptance, and

5. The flaw is subject to an increased inspection frequency in the future. 


\section{DISCUSSION -}

Several elements were combined in developing the acceptance criteria. These are discussed separately in this section. The elements include tank stress analyses, fracture toughness properties. intergranular stress corrosion crack (IGSCC) behavior, and details of the planned inspection procedure. The combination of these elements is then illustrated with sample calculations.

\section{Stress and Structural Evaluation}

Over the history of the SRS reactor program, several structural evaluations have been performed to characterize the response of the reactor tank under various design, operating and accident conditions. The tank designs for $P, K$ and $L$ reactors are identical. The earliest analyses were consistent with the Construction Code for the tanks, Section VIII - Division 1. Although there was only one Division of Section VIII at that time, the qualification is useful to later developments. These evaluations, consistent with the Code requirements and with the specifications, considered only a Design Pressure at a Design Ternperature.

A complete stress analysis and structural evaluation of tank stresses was performed by Quadrex Corporation in 1985 (2). These analyses included normal operating conditions and seismic loadings, and applied the criteria of the 1983 Edition of Section VIII - Division 2. Division 2, first issued in 1968 , provides "altemative" rules, alternative to those of Division 1, for the design of pressure vessels. The difference is often characterized in terms of the basic approach to design: Division 1 applying a "design-by-rule" approach, traditional to the design of pressure equipment for specified Design Pressures and Design Temperatures; and, Division 2 applying a "design-by-analysis" approach, utilizing modern engineering capabilities, including evaluation of complex operating conditions and geornetries. Use of the alternative rules was necessary for the Quadrex evaluation of the complex geometries of the tanks when subjected to service and seismic loadings. Quadrex concluded that the applicable Code allowable stress criteria were satisfied.

Of more significance in the context of the present report is the similarity between the ASME Section III (III) rules for the design of Class 1 nuclear components, such as reactor pressure vessels, and those of Section VIII - Division 2 (VIII-2). The "design-by-analysis" meti.odology is imposed in both. The major difference lies in the method for evaluation of stresses which result from abnormal operating conditions, such as earthquakes. III provides for four different sets of allowable stress levels, Service Levels A, B, C and D. The lowest, Service Level A, uses allowable values identical to the basic values of VIII-2. VIII-2 permits a 20\% increase in cercain of the allowable stresses when seismic loadings are considered, an increase greater than that generally used with III for Design Basis Earthquakes (DBE) and less than that generally used with III for Safe Shutdown Earthquakes (SSE). Since the Quadrex evaluations included seismic stresses, advantage was taken of the $20 \%$ increase in certain allowable values.

The tank is generally divided into several regions for analyucal purposes. The major portion of the tank wall is a thin-walled cylinder with no structural discontinuities. The bottom tube sheet assembly is treated as a composite flat plate incorporating the stiffness of the piping penetrations as well as the perforated top and bottom plates comprising the bottom shield surfaces. The outlet nozzles and other local areas of complex configuration are currently analyzed by finite element techniques. This approach was followed by Quadrex, considering the stress effects of the following normal operating and seismic loadings:

1. 5 psi overpressure (plenum gas) plus 7.3 psi hydrostatic pressure ( 15.5 feet of $D_{2} O$ ).

2. 1.32 psi equivalent hydrodynamic pressure applied to the tank wall from vertical seismic excitation. 
3. Vertical loads on the bottom tube sheet of $224,600 \mathrm{lbs}$. (deadweight) and $126,820 \mathrm{lbs}$. (seismic).

4. Combined maximum horizontal direct shear and overall bending moment from horizontal seismic motions (E-W and $\mathrm{N}-\mathrm{S}$ directions).

5. 5 psi internal pressure on the bottom tube sheet assembly.

Quadrex compared their calculated stress intensities with the VIII-2 allowable stress intensities, including the $20 \%$ increase in allowable values when appropriate. All stresses were found to meet the requirements specified in VIII-2. Table 1 of the present report copies the information contained in Table 6-2 of the Quadrex report with respect to calculated stress intensity and location, but instead of comparing the calculated values with the VIII-2 values, the III Service Level A values are used. All calculated stress intensities are less than the allowable values.

In order to complete the tank structural evaluation, Quadrex also evaluated three modes of tank buckling: general compression, general shear and toe buckling. The safety margins against buckling were determiried by dividing the critical buckling stress by the calculated compressive stress for each of the three buckling modes considered. In all cases, the safety margins were estimated to be greater than 10 .

These evaluations clearly show that the tank stresses under normal and seismic conditions meet the criteria of Section III of the Boiler and Pressure Vessel Code applicable to nuclear reactor vessels. Therefore, it is consistent in developing an inspection program, including acceptance criteria, to follow the philosophy of the Section XI rules of the Code applicable to the preservice and inservice inspection of nuclear vessels.

\section{Fracture Toughness Properties}

Irradiation programs conducted as part of the Reactor Materials Program (RMP) provide mechanical property data for fast fluence $\left(E_{n}>0.1 \mathrm{MeV}\right)$ and displacement damage levels at and above tank wall fluence levels. The irradiated mechanical property results, with attention to the application of fracture toughness to the SRS tank sidewall regions, are discussed in this section.

Over 1000 Type 304 stainless steel mechanical and corrosion properties specimens were obtained from the R-Reactor process water piping for the RMP studies, approximately one-third of which were selected for irradiated properties testing. The archival material selected from eight separate rings of 16-inch diameter piping each contained a circumferential weld. This provided potentially 16 different heats of 1950's vintage stainless steel. The composition of this material is consistent with that of the plates used to fabricate the reactor tanks (3). The specimens were machined into tensile bars $(T)$, Charpy $V$-notch $\left(C_{v}\right)$ and compact tension (CT) specimens. Separate specimens sampled base metal, weld metal and weld heat-affected-zone material. A total of 283 specimens (86 CTs, $119 \mathrm{C}_{\mathrm{v}}$ 's and $78 \mathrm{~T}$ 's) have been tested in the unirradiated properties or baseline testing program. A total of 325 specimens have been allocated for the irradiated properties testing program. This includes 93 specimens $\left(81 \mathrm{C}_{\mathrm{V}}\right.$ 's and $12 \mathrm{Ts}$ ) in the screening irradiation program; 72 specimens (36 CT's, $18 \mathrm{C}_{v}$ 's and $18 \mathrm{~T}$ 's) in the full-term irradiation in the HFIR; and 160 specimens (60 CT's, $60 \mathrm{C}_{V}$ 's and $40 \mathrm{~T}$ 's) in the surveillance irradiation in the Savannah River K-Reactor. The conclusions drawn in this section are based on the irradiated property results of the screening irradiation (UBR) and the HFIR irradiations as discussed below. 
Two of the RMP irradiation programs have been completed. A low fluence, screening irradiation was conducted in the University of Buffalo Reactor (UBR) (4) to assess composition and weldment component sensitivity to irradiation. Eighty-one Charpy V-notch specimens and 12 tensile specimens were irradiated to a fast fluence $\left(E_{n}>0.1 \mathrm{MeV}\right)$ of $1.0 \times 10^{20} \mathrm{n} / \mathrm{cm}^{2}$ or $0.07 \mathrm{dpa}$ at a temperature of $120{ }^{\circ} \mathrm{C}$. The residual absorbed impact energies are approximately $60 \%$ of the preirradiation levels. The average of all impact energies of base, weld and HAZ material following irradiation and testing at 25 and $125^{\circ} \mathrm{C}$ are 73 and $81 \mathrm{ft}-\mathrm{lb}$, respectively. The lowest absolute irradiated value of $54 \mathrm{ft}$-lb occurred in a heat-affected-zone specimen tested at $25^{\circ} \mathrm{C}$ and oriented with the fracture plane parallel to the pipe axis and rolling direction of the stock. Fractography examinations of the UBR specimens have shown the failure mode to be $100 \%$ ductile rupture (5). Test results (6) show no composition sensitivity to irradiation.

The second irradiation program was conducted in the High Flux Isotope Reactor (HFIR) at Oak Ridge National Laboratory. The irradiation and mechanical testing of two of the three mechanical capsules from the HFIR has been completed. The mechanical capsules, labeled 1Q, $4 \mathrm{M}$ and $12 \mathrm{M}$, each contained a complement of 18 compact tension specimens, 9 Charpy V-notch specimens and 9 tensile specimens. The $1 Q$ capsule contained a reference heat of Type 304 stainless steel supplied by Materials Engineering Associates (MEA). The 1Q capsule was extensively instrumented with thermocouples to qualify the capsule thermal-hydraulic design. Irradiation temperatures for the mechanical capsule ranged from approximately $80^{\circ} \mathrm{C}$ in the capsule end specimens to $160^{\circ} \mathrm{C}$ in the mid-plane specimens. The $4 \mathrm{M}$ capsule specimens were selected to provide base metal, weld and HAZ specimens in the L-C and C-L orientation to the original pipe and material with differing compositions (7). The $1 \mathrm{Q}$ and $4 \mathrm{M}$ specimens were irradiated to fast fluence $\left(\mathrm{E}_{\mathrm{n}}>0.1 \mathrm{MeV}\right)$ levels of 5 to $40 \times 10^{20} \mathrm{n} / \mathrm{cm}^{2}$ and dpa levels of 0.3 to 2.2. This range brackets current and future SRS tank wall maximum values $(8,9)$. The $12 \mathrm{M}$ irradiation has not been completed as yet due to an interruption in the HFIR schedule. Post-irradiation testing of the $1 \mathrm{Q}$ and $4 \mathrm{M}$ specimens was performed at $125^{\circ} \mathrm{C}(10,11)$.

The tensile results and fracture tougnness (as measured by $J_{D}$ at $1 \mathrm{~mm}$ of crack extension) results are shown in Figures $1 \mathrm{~A}$ and $1 \mathrm{~B}$. Figure $1 \mathrm{~A}$ shows the irradiated yield strengths of base, weld and HAZ material are approximately 65 to $80 \mathrm{ksi}$ with limited sensitivity to fluence at the exposure conditions. The irradiated toughness response is similar. Irradiated toughness levels range from 40 to $80 \%$ of the corresponding unirradiated levels; the toughness continues to decrease slightly as fluence increases at the SRS tank wall maximum exposures. The residual $1 Q$ and $4 \mathrm{M}$ impact energies are approximately $50 \%$. These results are consistent with the trend of saturation of radiation hardening observed in austenitic stainless steels irradiated at temperatures below $300^{\circ} \mathrm{C}$.

The assessment of flaw stability requires the material J-T properties of the section of the reactor tank containing the flaw. Figure 2 shows the fast fluence and dpa exposure parameters of a $60^{\circ}$ sector of the $\mathrm{P}$ and $\mathrm{K}$ tank side wall. (The tank wall has a six-fold symmetry of neutron exposure.) Within the range of HFIR irradiation exposures, tank wall conditions are spanned and little decrease in toughness is seen. Base metal, weld and $\mathrm{HAZ}$ specimens $4 \mathrm{BB}, 5 \mathrm{BA}, 2 \mathrm{~W}, 3 \mathrm{HA}$ and $3 \mathrm{HB}$ are grouped with similar toughness values (see Figure 3 ). Specimen $1 B B$ has a toughness exceeding the nominal value while specimens of $7 \mathrm{HA}$ heat-affected-zone material exhibit the lowest toughness.

As a grouping of material type and orientation. HAZ material tested in the C-L orientation displayed the lowest mechanical properties. Overall, the $7 \mathrm{HA}$ material, tested in the C-L direction or parallel to the rolling direction, is observed to have the lowest toughness properties in both the unirradiated and irradiated material condition. The unirradiated baseline testing results are applied to effectively extend the database of the HFIR high fluence specimens. Of the $27 \mathrm{CT}$ specimens tested at $125^{\circ} \mathrm{C}$ in the 
unirradiated (baseline) condition, the average $\mathrm{J}_{\mathrm{IC}}$ (Deformation J, power law fit (6)) is 2825 in-lb/in ${ }^{2}$ and the $\mathrm{J}$ at $1 \mathrm{~mm}$ varue is $3058 \mathrm{in}-\mathrm{lb} / \mathrm{in}^{2}$ collectively for base, weld and $\mathrm{HAZ}$ material in the $\mathrm{L}-\mathrm{C}$ and $C$ - $L$ test directions. Two sperimens of the $7 \mathrm{HA}$ material, designated $7 \mathrm{HA}-5$ and $7 \mathrm{HA}-7$, were irradiated to a fast fluence level of $3.6 \times 10^{21} \mathrm{n} / \mathrm{cm}^{2}$ at a specimen center temperarure of $150^{\circ} \mathrm{C}$. The fracture toughness results as measured by ${ }_{D}$ at $1 \mathrm{~mm}$ of crack extension were 633 and 753 in- $1 \mathrm{~b} / \mathrm{in}^{2}$ ( 42 and $50 \%$ of the unirradiated toughness) for the $7 \mathrm{HA}-5$ and $7 \mathrm{HA}-7$ specimens. respectively. In terms of $J_{I C}$, the toughness was 443 and 414 in- $1 \mathrm{~b} / \mathrm{in}^{2}(51$ and $47 \%$ of the unirradiated toughness) for the 7HA-5 and 7HA-7 specimens, respectively. The flow stress used to determine $\mathrm{J}_{\text {IC }}$ was 58 and 85 ksi for the unirradiated and irradiated conditions, respectively.

The irradiated toughness data of the THA-5 specimen was applied in the crack stability analysis (Appendix A). A review of Figure A2 shows that the J-Resistance curve goes through an apparent inflection point after which its slope appears to increase with crack extension. The inflection point corresponds approximately to a $J_{D}$ value of $650 \mathrm{in}-\mathrm{lb} / \mathrm{in}^{2}$. Therefore, only the data up to a $J_{D}$ value of $650 \mathrm{in}-\mathrm{lb} / \mathrm{in}^{2}$ were used in determining the material $\mathrm{J}-\mathrm{T}$ curves.

Due to the limited sensitivity of the material toughness to neutron exposure from 5 to $40 \times 10^{20}$ $\mathrm{n} / \mathrm{cm}^{2}$, the $\mathrm{J}-\mathrm{T}$ values of specimen $7 \mathrm{HA}$ and the values from specimen $2 \mathrm{~W}$ are used as lower bound and nominal irradiated properties, respectively for the fluence range. For expesure levels less than $5 \times 10^{20} \mathrm{n} / \mathrm{cm}^{2}$, the trend in material properties vs exposure is taken from tensile data generated at SRS in 1960 (12). Figure 4, reproduced from Reference 12, indicates radiation hardering effects have not quite reached maximum levels at $3 \times 10^{20} \mathrm{~N} / \mathrm{cm}^{2}$. Irradiation levels less than $0.1 \times 10^{20}$ $\mathrm{n} / \mathrm{cm}^{2}$ would show little hardening effects and the material properties are nearly equivalent to the unirradiated properties.

\section{IGSCC Behavior}

The austenitic stainless steel of the SRS reactor tanks can be susceptible to IGSCC. Three conditions must be present in order for IGSCC to occur (13):

1. A sensitized microstructure, typically present in the heat affected zones of structural welds.

2. A tensile stress in the sensitized region, generally provided by weld residual stresses and operating stresses.

3. An environment that promotes corrosion. such as the oxygenated water in the SRS reactor system (14).

The only known IGSCC of a reactor tank has occurred in the $\mathrm{C}$ tank knuckle region. The $\mathrm{C}$ reactor experience is not relevant to the other reactors due to the unique configuration and fabrication history of the knuckle region. The piping has expenenced isolated cases of IGSCC in the weld heat affected zones and flame washed areas (15). These cases have occurred in about $7 \%$ of the welds, and approximately $0.4 \%$ of the total length of heat affected zones have actually cracked (16).

Because IGSCC is driven by the presence of tensıle stress. given the presence of sensitization and oxygen, it would generally $\propto c c u r$ preferentially in areas of relatively high stress. In the process water piping and reactor tanks, the operating stresses are quite low; weld residual stresses are expected to be the primary driving force for IGSCC. Due to the nature of the welding process, considerable local variation is expected in weld residual stresses, leading to localized regions that are most susceptible to IGSCC. Adding to this tendency is the variation in degree of sensitization within the heat affected zone. These factors are evidenced by the localized nature of cracking observed to date. 
Three sources of information are available from which to infer crack growth rates for the reactor tanks: literature data, laboratory data generated specific to Savannah River reactor conditions and field measurements made on IGSCC in the reactor process 'vater piping. Reference (17) reviews and summarizes the literature data for non-1тradiated Type 304 stainless steel. This reference identifies the data developed by Ford and Silverman (18), as most applicable to Savannah River reactor conditions and indicates a maximum crack up extension rate of $1 \times 10^{-4} \mathrm{inch} / \mathrm{hour}$ in sensitized material. The Ford and Silverman data are summarized in Figure 5.

Laboratory studies of crack growth rate at SRS conditions were conducted under both constant load and slow cyslic load with compact tension specimens. The specimens were furnace sensitized and had not been irradiated. Specimens were precracked and then the crack was aliowed to grow under applied load wi hin a controlled aqueous environment that duplicated the temperature and chemistry conditions of the process water system (19). One limitation of this test is the uncertainty in applying results from sinall non-irradiated specimens to a larger reactor tank of irradiated stainless steel. On the other hand, the observation of trends and sensitivities in the laboratory tests can be extrapolated more reliably.

Crack growth rates on the order of $10^{-6}$ inch hour have been observed in laboratory tests under simulated Savannah River reactor environment at steady state loading. Under transient conditions (change in load, temperature, etc.) an effecuve crack tip extension rate between $10^{-5}$ to $10^{-4}$ inch/hour is inferred from similar laboratory tests (19).

The field data are based on the results or UT examinations performed on the process water piping. Periodic UT examinations were begun in 1984. Welds that contain IGSCC are reinspected annually. A rough estimate of crack growth rate can be inferred from changes in measured crack length. Due to the limited UT data available and the combination of uncertainties inherent in extracting growth rate information from the data, a reliable growth rate for individual cracks can not be estimated. However. the UT data taken from the large process water piping (20) suggest an average growth rate of about 3 $x 10^{-6}$ inch/hour.

Given the agreement between the laboratory and literature data, and the lack of disagreement from the field data, an upper bound crack tip extension rate of $1 \times 10^{-4} \mathrm{inch} /$ hour is chosen. For a crack growing at both ends, this produces a growth rate of $1.75 \mathrm{inch} / y e a r$. However, given the variable nature of local stresses and material conditions, the average growth rate should be considerably lower, as evidenced by the field data. Therefore, over the long term, the assumption that a crack grows at the upper bound rate is conservative.

\section{UT Examination Program}

Ultrasonic inspection techniques provide a proven technology for detection and sizing of IGSCC. They have been applied extensively to address the issue of IGSCC in stainless steel components. The lessons leamed from this experience in detection and sizing of IGSCC are, in general. directly applicable to the SRS tank inspection program. Experience has shown that essential elements in the successful inspection for IGSCC are adequate training and qualification of inspection personnel, appropriate use of advanced inspection methodologies such as crack tip diffraction and application of automated ultrasonic data acquisition equipment. All of these elements are incorporated into the SRS tank inspection program.

A review of the tank inspection methodology has been conducted to assess flaw detection and sizing capabilities in terms of the acceptance criteria. The sizing capabilities of the techniques have been compared to others commonly applied in the commercial nuclear industry. Based upon this review it is concluded that the detection and sizing capabilities of the methodology selected for the 
SRS tank inspection program are commensurate with those applied in the commercial nuclear industry, provide a high degree of confidence that flaws exceeding the examination frequency standard will be detected and possess a sizing tolerance of $\pm 0.5^{\prime \prime}$ on length.

\section{Examination Methodology}

Cltrasonic examinations of the tank weld heat affected zones will be accomplished from the tank inside diameter surface utilizing a remote inspection robot developed by the Equipment Engineering Division of the Savannah River Laboratory. Features of the robot include:

1. The ability to access the tank through 4-3/8" diameter permanent sleeves through the upper plenum,

2. The ability to provide $360^{\circ}$ coverage of the tank by placement in 18 different USH locations.

3. The ability to reach most tank surfaces of interest,

4. Computer-based control of examination and data acquisition functions,

5. A positioning accuracy at the tank wall of \pm 0.030 inch,

6. Absolute tank position feedback, and

7. Fully automated scan capability.

Other equipment is integrated into the system to permit visual observation of scanning activities in the tank; application of eddy current techniques for weld location and flaw confirmation; in-tank calibration; and recording the ultrasonic, eddy current, and visual data on magnetic media. The system is operated from a mobile control center which houses all ultrasonic, eddy current, audiovisual, robot control and communication equipment.

The examination protocol is as follows:

1. Set up equipment at the first USH position and test to assure all systems are functioning properly.

2. Circumferential and axial scans are then performed with the eddy current system to provide accurate location of the tank welds.

3. Eddy current and tool position data are fed to the host computer where a weld map is generated automatically.

4. The ultrasonic examination scan parameters are input to the host computer.

5. The host computer then controls the scan motion of the robot arm, operation of the ultrasonic system, and recovery of data.

When the accessible weld heat affected zones in this tank sector have been completely examined, the equipment is moved to the next tank section and the process repeated.

All data from the ultrasonic examination will be digitized and recorded using an Intraspect/98 Automated Ultrasonic Imaging System. The Intraspect/98 Automated Ultrasonic Imaging System is a Hewlett Packard HP9836 based ultrasonic data acquisition and analysis system. The system features a fully programmable front end, data storage and data analysis capability. Digitized RF waveforms can be collected at sampling rates up to $80 \mathrm{MHz}$. Transducer position is stored with each waveform. As waveforms are acquired, real time C-scans are displayed. Data can be stored on hard disk drive and transferred to magnetic tape for archival storage. Review of the data is conducted off-line at a data analysis station. 


\section{Detection and Sizinḡ Capabilities}

Ultrasonic examinations will be performed using dual element $45^{\circ}$ shear wave. $2.0 \mathrm{MHz}$ transducers in a full vee application (21). Reference sensitivity is established on notches having depths equal to $5 \%$ of the tank wall thickness. Examinations will be performed at a sensitivity at least $8 \mathrm{~dB}$ above the reference level. Scanning is conducted in both directions along a line parallel to the welds and both directions along a line perpendicular to the welds where access permits. Scan speed will be selected such that A-scan data is sampled at intervals no greater than 0.1 inch along the scan line. The maximum increment between scan lines is 0.5 inch. The entire examination system, including inspection personnel, will be qualified for flaw detection and sizing on representative samples containing IGSCC. This qualification program is modeled after the Boiling Water Reactor piping inspection requirements and will be administered by personnel from the EPRI NDE Center. Training will be conducted prior to qualification on a full-scale mockup of the tank.

Application of $45^{\circ}$ shear wave techniques is very effective for detecting surface initiating cracks due to comer trap effects and because there are no energy losses due to mode conversion. While the majority of commercial experience has involved examinations performed from the surface opposite the crack initiation point (half vee configuration), $45^{\circ}$ transducers of identical design to those proposed for the current SRS tank inspections were qualified and demonstrated in a full vee configuration for examinations of the C Tank sidewall region in 1985.

The C Tank ultrasonic procedure qualification specification required that notches greater than 0.2 inch deep $\times 0.2$ inch long be reliably detected (22). The $45^{\circ}$ dual element, full vee technique met this requirement when scan increments were 0.1 inch. Considering the scan increment proposed for the current SRS tank inspection program is 0.5 inch and calibration sensitivity is established on a $5 \%$ deep notch ( 0.025 inch), cracks having lengths of 1.0 inch and depths on the order of 0.1 inch should be detected with a high degree of reliability. This indicates that the equipment and procedures to be used for this inspection are more sensitive than required for the qualification standards of $3.0^{\prime \prime} \pm 0.5^{\prime \prime}$.

Length sizing is typically performed using a " $\mathrm{dB}$ drop" technique; i.e. $6 \mathrm{~dB}, 12 \mathrm{~dB}$, vanishing echo. etc. These techniques are highly dependent upon beam spread in the lateral plane, the configuration of the flaw at the terminal ends, and proximity of the flaw to other reflectors. For inspections of $C$ Tank, length sizing was performed using a $6 \mathrm{~dB}$ drop (half maximum amplitude) technique. Length sizing tolerances as determined on EDM norches were \pm 0.4 inch. Notches are ideal reflectors in the sense that they provide a target where depth is constant over the entire length. Observation of IGSCC in the SRG process water piping system suggests that cracks resulting from this phenomenon are generally "thumbnail" in shape with depth equal to half the length. As these crack shapes are not ideal targets, length sizing accuracies are expected to be somewhat less than those determined on notches. For these cases, length sizing tolerances are esumated to be \pm 0.5 inch.

\section{Sample Calculation and Acceptance Criteria}

Sample calculations have been made for two postulated through-wall cracks. The details of these calculations are presented in Appendix A. Figure 6 shows the locations of these postulated cracks. Crack $A$ is oriented in the axial direction and crack $B$ is circumferentially oriented. Since the UT equipment will have access only to the cylindrical portions of the tank wall, the acceptance criteria were developed specifically for this region of the tanks ranging from the T-weld up to the expansion ring. 
Three steps involved in the calculation are:

1. determine the applied and residual stresses,

2. determine the appropriate irradiated condition J-Resistance and J-T curves and

3. calculate instability and allowable crack lengths.

Each of these steps is developed in detail in Appendix A. Table 2 shows the instability and allowable crack lengths at the two postulated crack locations.

\section{Acceptance Standard}

Based on reference (23) calculations for a wide range of tank locations, the locations chosen for the sample calculations include the most limiting in terms of allowable crack length. Specifically, postulated location $A$ is the most limiting location in the tank in terms of instability length. Since crack $A$ is oriented axially, crack $B$ was chosen as a typical circumferential crack for comparison. In order to account for uncertainties in the mathematical mode!s, materials property data and the analytical techniques, the minimum allowable crack length is further reduced by a factor of 2 . This produces a value of 12.5 inches. Any indication which is shorter than the acceptance standard, but equal to or longer than the reexamination standard, will be reinspected on an increased frequency (18 months maximum inspection interval), but will be acceptable for further operation. During this 18 month period, a crack is predicted to grow a maximum of:

$$
(1.75 \text { inches } / \text { year }) \times(1.5 \text { years })=2.6 \text { inches. }
$$

Subtracting this maximum growth allowance from 12.5 inches produces 9.9 inches. Therefore the acceptance standard is chosen as 10 inches. Any flaw which is less than this acceptance standard is not expected to grow to a length exceeding one-half the allowable flaw size prior to the next inspection.

\section{Reexamination Standard}

The reexamination standard is specified as one-half the acceptance standard, or 5 inches. Any indication shorter than the reexamination standard will be documented in the inspection records but does not warrant any further action.

\section{Long Shallow Indications}

Indications that are less than or equal to $20 \%$ through wall, but more than twice the acceptance standard in length, are subject to additional evaluation, flaw specific analysis and/or examination. Indications which do not exceed this criterion are judged to maintain ample margin to the minimum ASME Code allowable length of 25 inches for a through wall crack. Any analysis performed for such indications should follow the general methodology outlined in Appendix A. However, the analyst shall use available detailed information to direct the details of such analysis.

\section{Crack Combination Rules}

Cracks in close proximity to each other may not behave independently, depending on crack size and the stresses in the surrounding material. Therefore, it is necessary to identify appropriate rules for combining cracks to obtain an effective flaw length. If acceptance by analysis of individual or 
multiple cracks is required, the analyst has the option of using more sophisticated techniques to refine these rules, as appropriate. The definition of effective flaw length is summarized as follows:

1. If the distance between the closest tips of a pair of colinear flaws is less than or equal to 2.6 inches, the pair of flaws shall be considered to be a single flaw of effective length equal to the distance between the farthest flaw tips. This procedure may result in the combination of several pairs of flaws into a single flaw.

2. For two cracks in different planes, they shall be considered a single crack if the interplanar gap between them is less than or equal to 0.5 inch.

The criteria for flaw combination are based on judgment in consideration of the variabilities in UT, future crack growth, and the basis of the proximity rules of Section XI.

\section{Summary of Conservatisms and Assumptions}

This section summarizes the various assumptions and conservatisms used in developing both the acceptance standard and the reexamination standard. Specific conservatisms used in these analyses include:

1. The more limiting of a factor of 3 increase in the normal operating stresses, or a factor of 1.4 increase in the normal plus accident stresses, is used to calculate the allowable flaw size. This is consistent with the ASME Code.

2. A factor of 2 reduction from the allowable flaw size, plus an upper bound allowance for crack growth rate and measurement uncertainty are used to produce the acceptance standard.

3. All cracks are assumed to be through-wall in calculating instability lengths.

4. The lowest material toughness data measured on SRS material is used. This is a factor of 3 below the nominal irradiated material toughness.

5. The crack growth rates used here bound all relevant literature data and the laboratory data.

\section{CONCLUSIONS}

A procedure for evaluation of reactor tank inspection results has been developed. The procedure includes rules for flaw characterization, reexamination and acceptance criteria and procedures for acceptance by analysis. The technical basis for the evaluation procedure is described in this document. The procedure itself is given in Reference 1.

Several elements were considered in developing the evaluation procedure. These elements include stress analysis and structural evaluation, stress corrosion crack behavior, the ultrasonic examination program and fracture mechanics techniques. The stress analysis has identified the operating and upset loads in the SRS reactor tanks. These stresses are combined with lower bound material properties to predict the behavior of postulated flaws. Information on crack growth rates and the UT inspection methodology is incorporated to develop conservative acceptance criteria and flaw characterization rules.

Rules have been developed regarding the combination of two or more cracks in close proximity to one another. If the closest tips of two colinear cracks are separated by 2.6 inches or less, they shall be considered a single flaw, with an effective length equal to the distance between the farthest flaw tips. This rule may result in the combination of several pairs of flaws into a single flaw. 
The acceptance standard is set at 10 inches. Any flaw whose effective length equals or exceeds this value will require supplemental examination and/or analysis for disposition. Such a flaw will also be subject to an increased inspection frequency and will trigger an increase in the sample size during the current inspection outage. The reexamination standard is set at 5 inches. A flaw whose effective length equals or exceeds this value, but is less than the acceptance standard, is acceptable for continued operation. However, it will be reinspected during the next long shutdown. A flaw whose effective length is less than the reexamination standard is acceptable for continued operation. No additional actions are required; inspections will continued at the origisal frequency.

Conservatisms inherent in the tank acceptance procedures have been summarized. The considerations that are used in developing these procedures provide confidence that any flaw detected will be dispositioned in a manner that will preserve the integrity of the reactor tanks and provide confidence in the continued safe and reliable operation of the SRS reactors. 


\section{REFERENCES}

1. EDG-89.47, "Procedure for Evaluation of Reactor Tank Inspection Results," J. A. Begley et al., May 1989.

2. QUAD-1-85-017, "Seismic Analysis and Evaluation of 105-L Reactor Tank Savannah River Plant," Quadrex Corporation, 12/85.

3. DPST-88-1010, "Reactor Materials Program - Materials Source History for Type 304 Stainless Steel Testing Program," K. J. Stoner, Savannah River Laboratory, December 1988.

4. J. R. Hawthome, et al., "Experimental Assessments of Notch Ductility and Tensile Strength of Stainless Steel Weldments After $120^{\circ} \mathrm{C}$ Neutron Irradiation," ASTM STP 956, Amencan Society for Testing and Materials, 1987 pp. 191-206.

5. DP-MS-87-91, "Fractographic and Microstructural Aspects of Fracture Toughness Testing in Iradiated 304 Stainless Steel," W. H. Cullen et al., Materials Engineering Associates, Inc. and Savannah River Laboratory, presented at ASME Annual Winter Meeting, Boston, Mass.. December 1987.

6. J. R. Hawthorne, et al., "Sample Preparation, Irradiation, and Testing of 304 Stainless Steel Specimens - Final Report," Materials Engineering Associates, Inc. Report MEA-2221, prepared for E. I. du Pont de Nemours \& Co., Inc., Savannah River Laboratory, August 1987.

7. DPST-86-418, "Selection of HFIR Specimens for SRP Reactor Materials Program," R. L. Sindelar, G. A. Abramczyk and K. R. O'I la Savannah River Laboratory, April 1987.

8. DP-MS-88-143, "Life Extension Approach to the Reactor Vessel of a Nuclear Production Reactor," R. L. Sindelar to be presented at ASME/JSME Pressure Vessel and Piping Conference, July 23-27, 1989.

9. DPST-86-793, "Neutron fluence in SRP Reactor Tank Walls," N. P. Baumann, Savannah River Laboratory, November 1986.

10. MEA-2.214, "Fracture Toughness Characterization of Stainiess Steel Plate F50 Irradiated in HFIR Assembly 1Q," A. L. Hiser, B. H. Menke and J. R. Hawthorne, MEA Progress Report to Savannah River Laboratory.

11. MEA-2241, "Fracture Toughness Characterization of Type 304 Stainiess Steel Piping Materials Irradiated in HFIR Assembly 4M," A. L. Hiser, B. H. Menke and J. R. Hawthorne, MEA Progress Report to Savannah River Laboratory.

12. DP-534, "Mechanical Properties of Irradiated Welds in Stainless Steel," J. W. Joseph, Jr., Savannah River Laboratory, December 1960.

13. Int. Joumal of Pressure Vessels and Piping, Vol. 30, "Environment Sensitive Cracking in Pressure Boundary Materials of Light Water Reactors," H. Hanninen, I. 4ho-Mantila and K. Torronen, pp. 253-291, 1987. 
14. DP-MS-88-177, "Aqueous Impurity Effects on Stainless Steel IGSCC: A Central Composite Matrix Analysis," R. S. Ondrejcin et al, Savannah River Laboratory, to be issued.

15. DPST-87-469, "Incidence of IGSCC in Reactor Tanks and Piping", G. R. Caskey et al, Savannah River Laboratory, December 1987.

16. SRL-MTD-890069. "Locations and Sizes of Stress Corrosion Cracks in Savannah River Reactor Piping and Tanks," G. R. Caskey, Savannah River Laboratory, September 1989.

17. NEDC-30837, "Stress Corrosion Cracking Literature Review and Analysis for the Savannah River Plant," B. M. Gordon and H. S. Mehta, General Electric, December 1984.

18. "The Prediction of Stress Corrosion Cracking of Sensitized 304 Stainless Steel in $0.01 \mathrm{M}$ $\mathrm{Na}_{4} \mathrm{SO}_{4}$ at $97^{\circ} \mathrm{C} "$. F. P. Ford and M. Silverman, Comosion, Vol. 34, No. 5, May 1978.

19. GE 88-06, General Electric Monthly Progress Letter \#35, P. Aldred, March 1988, and GE 88-20, General Electric Monthly Progress Letter \#40, P. Aldred, August 1988.

20. Area Metallurgical Reports for process water piping UT inspections, 1984 to 1989.

21. Draft RTIP Prucedure; "Robotically Assisted, Automated Ultrasonic Examination for the Detection of Sizing of Crack Like Reflectors in the Heat Affected Zones of SRP's Reastor Tank Weldments;" 008, Rev.0; March 5, 1989.

22. Westinghouse Nuclear Services Integration Division' "Ultrasonic Testing (UT) Qualification Procedure," SEAP85061, Rev. 1; June 1985.

23. SASR \#86-64, Fracture Mechanics Evaluation of Potential Flaw Indications in the Savannah River L, P and K Taniks," General Electric, October 1989. 
Table 1. Comparison of Calculated Stress Intensities with the Class 1, Service Level A Allowable Stress Intensities of Section III

Location or Component

Tank shell away from bottom tube sheet and outlet nozzle opening

Tank shell at intersection with bottom rube sheet but away from outlet nozzle opening

Tank shell near outlet nozzle opening

(a) at intersection with bottom tube sheet

(b) at the upper comer of outlet nozzle wall

Outlet nozzle wall near intersection with tank shell

Outlet nozzle cross-section perpendicular to nozzle axis away from the intersection

Bottom tube sheet

(a) at center of top \& bottom plates

(b) near edge of top \& bottom plates

(c) outer circular ring

(d) tubes connecting top \& bottom plates

(e) welding of tubes to top \& bottom plates
Primary

Membrane

(ksi)

(Allowable $=20$ )

$5.58^{*}$

- .

5.4

Primary

Membrane plus

Bending (ksi)

(Allowable $=30$ )

Primary plus

Secondary

(ksi)

(Allowable $=60$ )

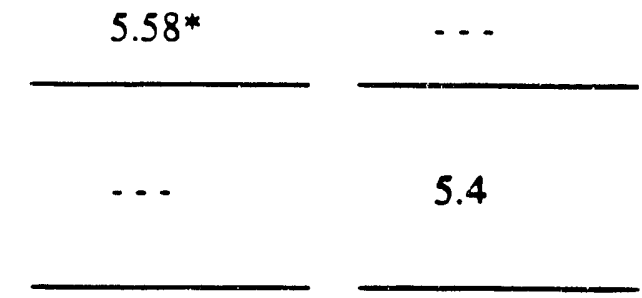

17.7

50.1

(43.7)

26.0

39.6

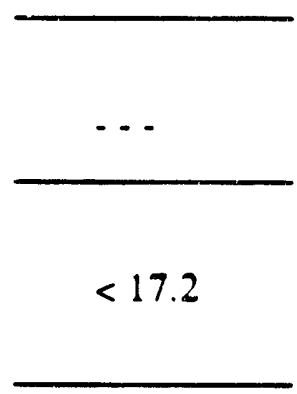

25.5

37.3

2.76

5.1

19.7

21.0

8.96

13.1

$<3.06$

3.06

$<3.47$

3.47

Values in brackets do not include thermal effects.

Values not given are either non-applicable or not critical.

* This location is comparable to location A used in the sample calculation. However, this stress intensity differs from that given in Table Al since seismic loads are included here. 
TABLE 2

\section{CALCULATED INSTABIITY AND ALLOW ABLE CRACK LENGTHS}

\begin{tabular}{ccccc} 
& \multicolumn{5}{c}{ J-R Lower Bound Data } \\
$\begin{array}{l}\text { Postulated } \\
\text { Crack Location }\end{array}$ & No & Level D & No Lllowable & Level D \\
& 58 & 32 & 26 & 25 \\
A & - & 50 & & 40 \\
B & & & & \\
\hline
\end{tabular}

Notes: All crack lengths are in inches

NO - Normal Operation 

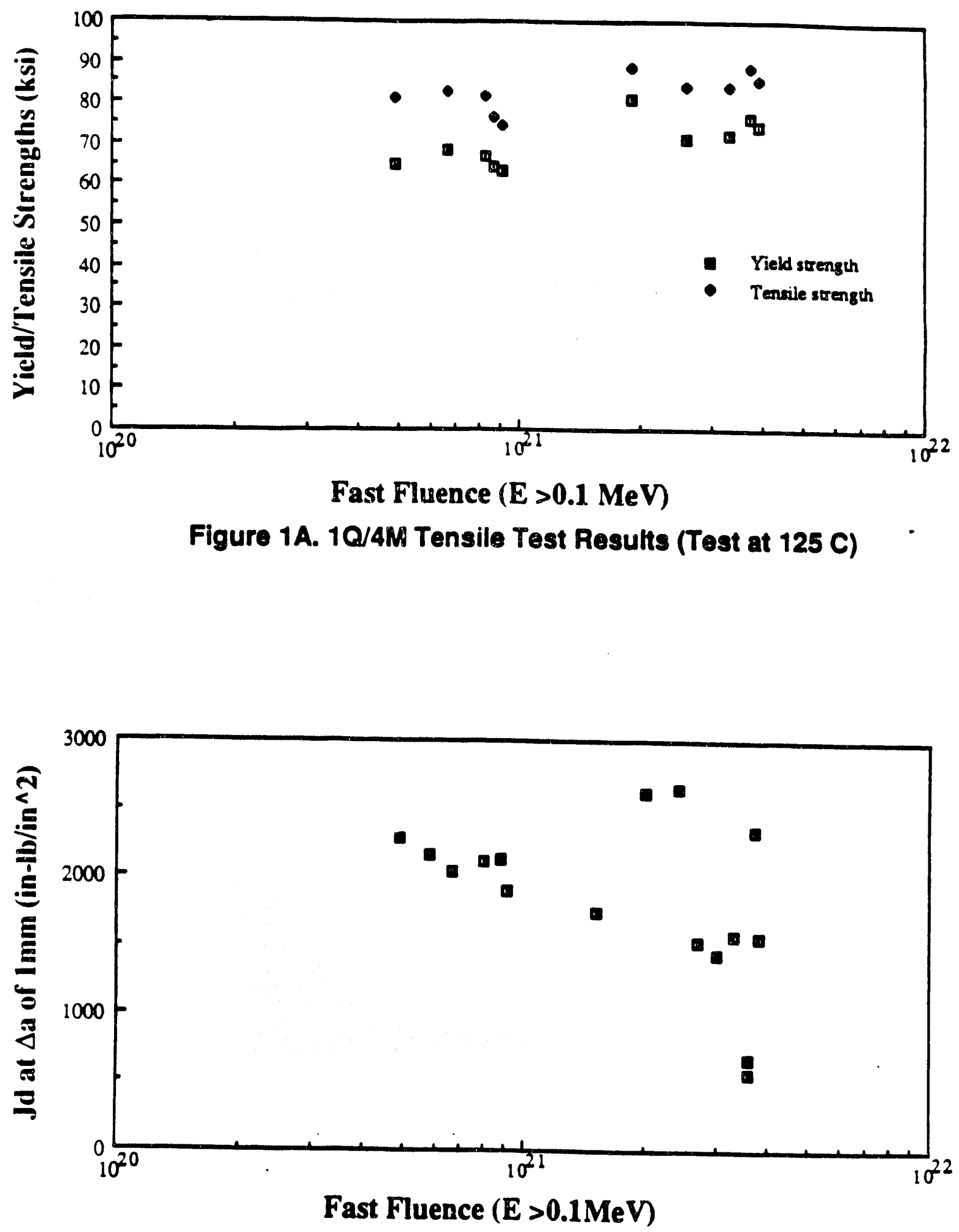

Figure 1B. 1Q/4M Toughness Test Results (Test at $125 \mathrm{C}$ ) 
Fig 2 Fast Fluence and DPA in Sector Vertical distance, per cent

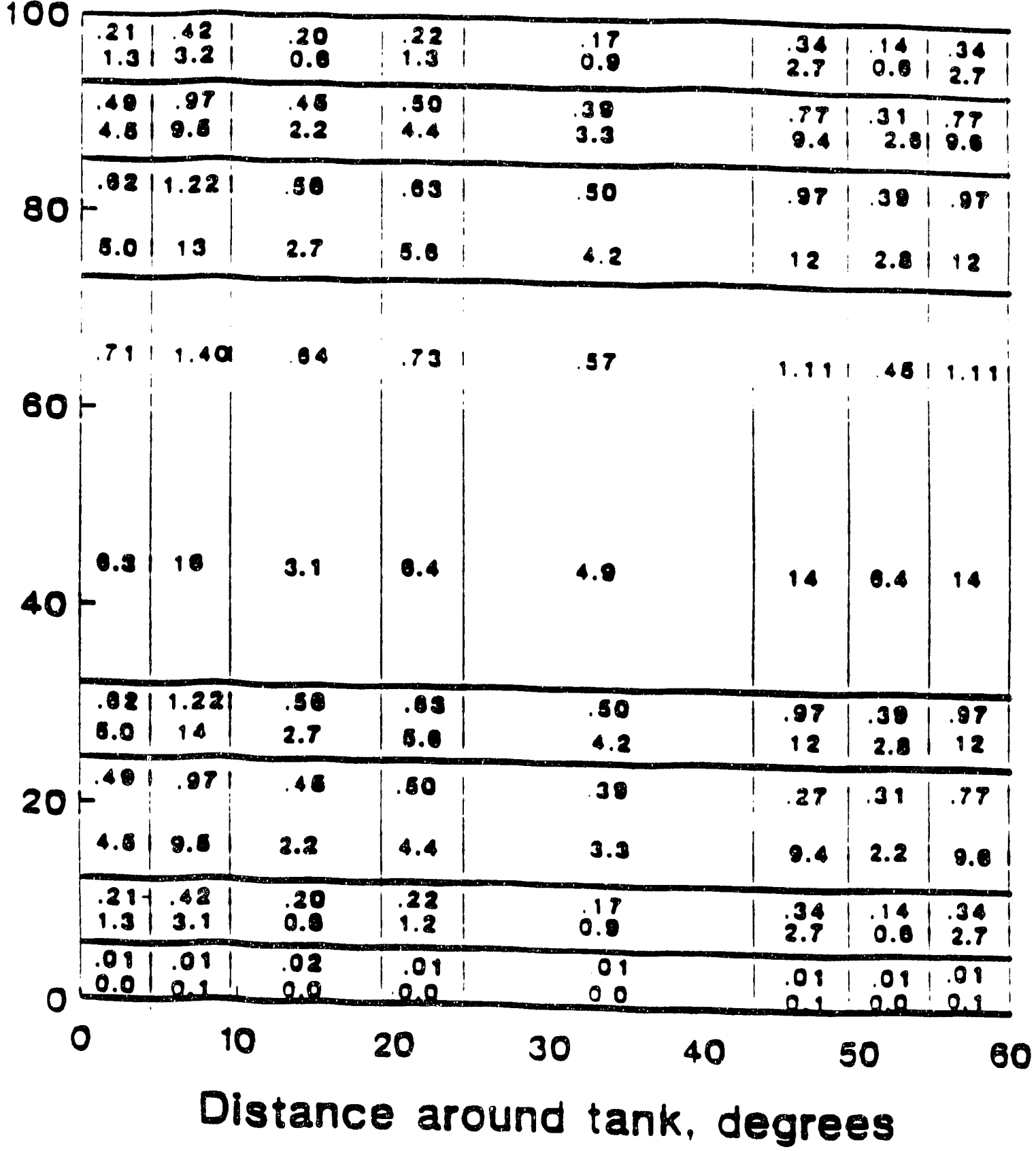

Fast fluence (r0.1 MeV) in units of $10^{20} \mathrm{n} / \mathrm{cm}^{2}$ DPA is too entry in exen box 


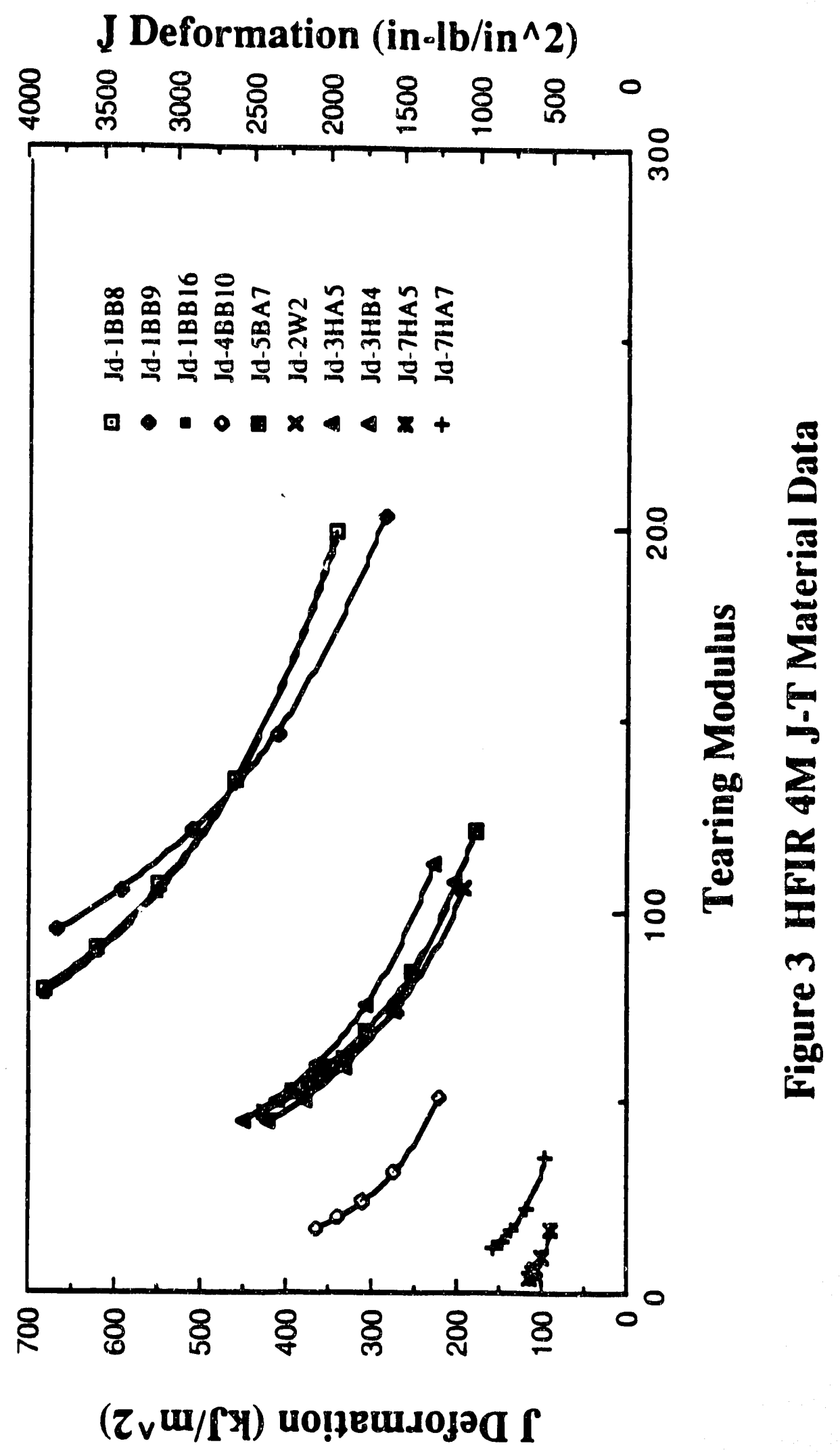




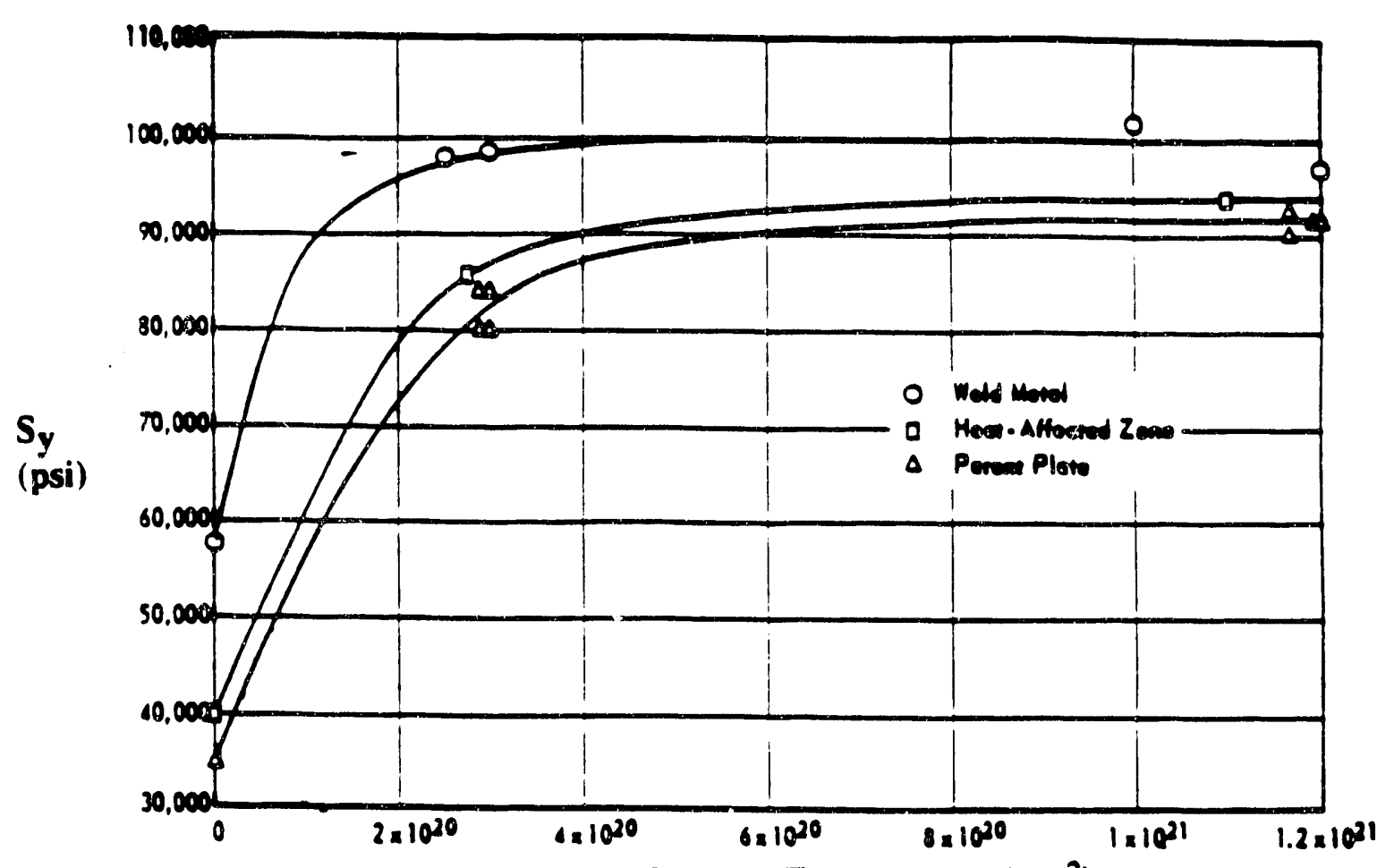

Fast Neutron Exposure, $\mathrm{n} /\left(\mathrm{cm}^{2}\right)$

(a)

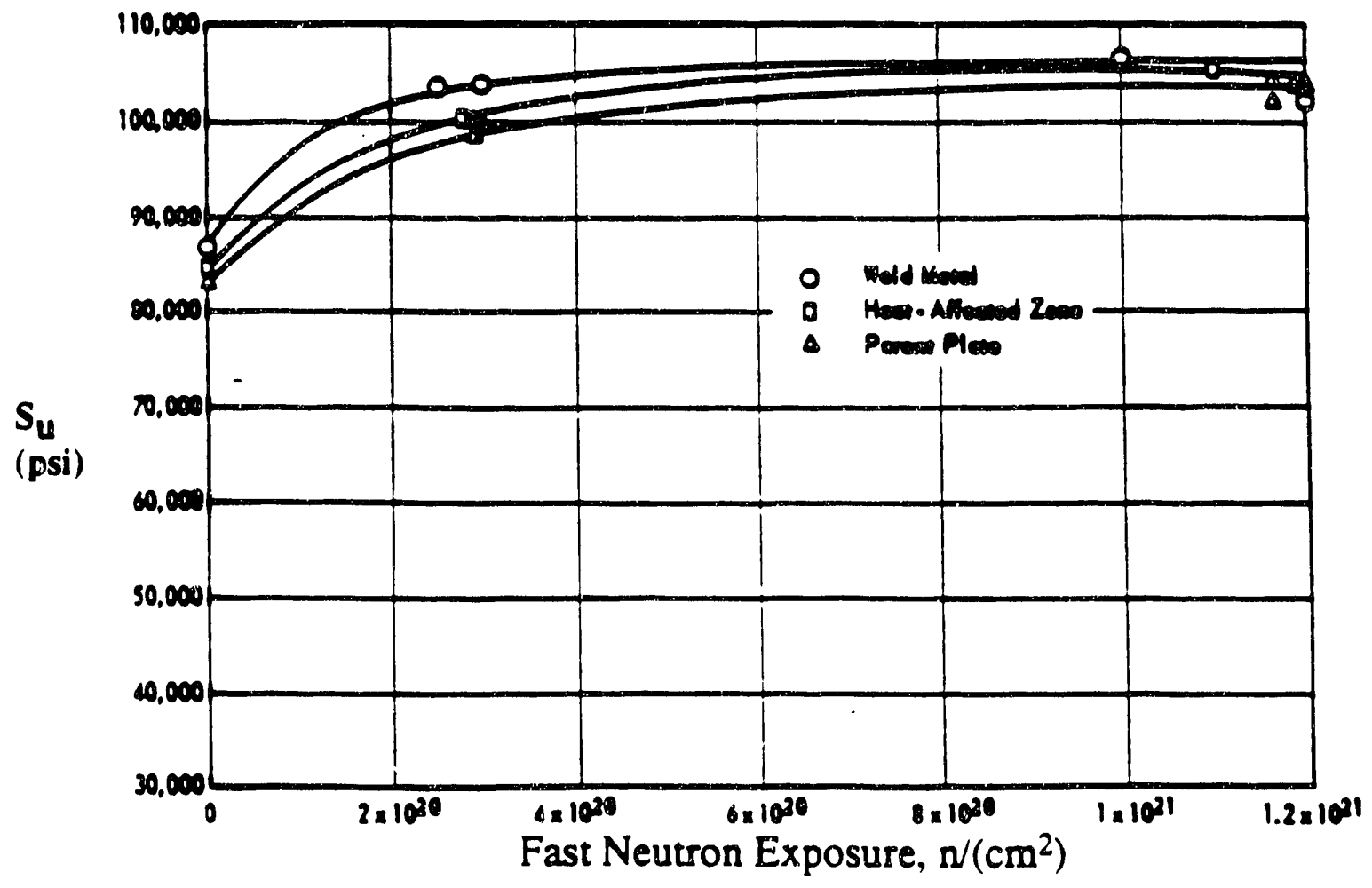

(b)

Figure 4. Yield and Ultimate Strengths of 304 Stainless Steel as a Function of Fast Fluence. 


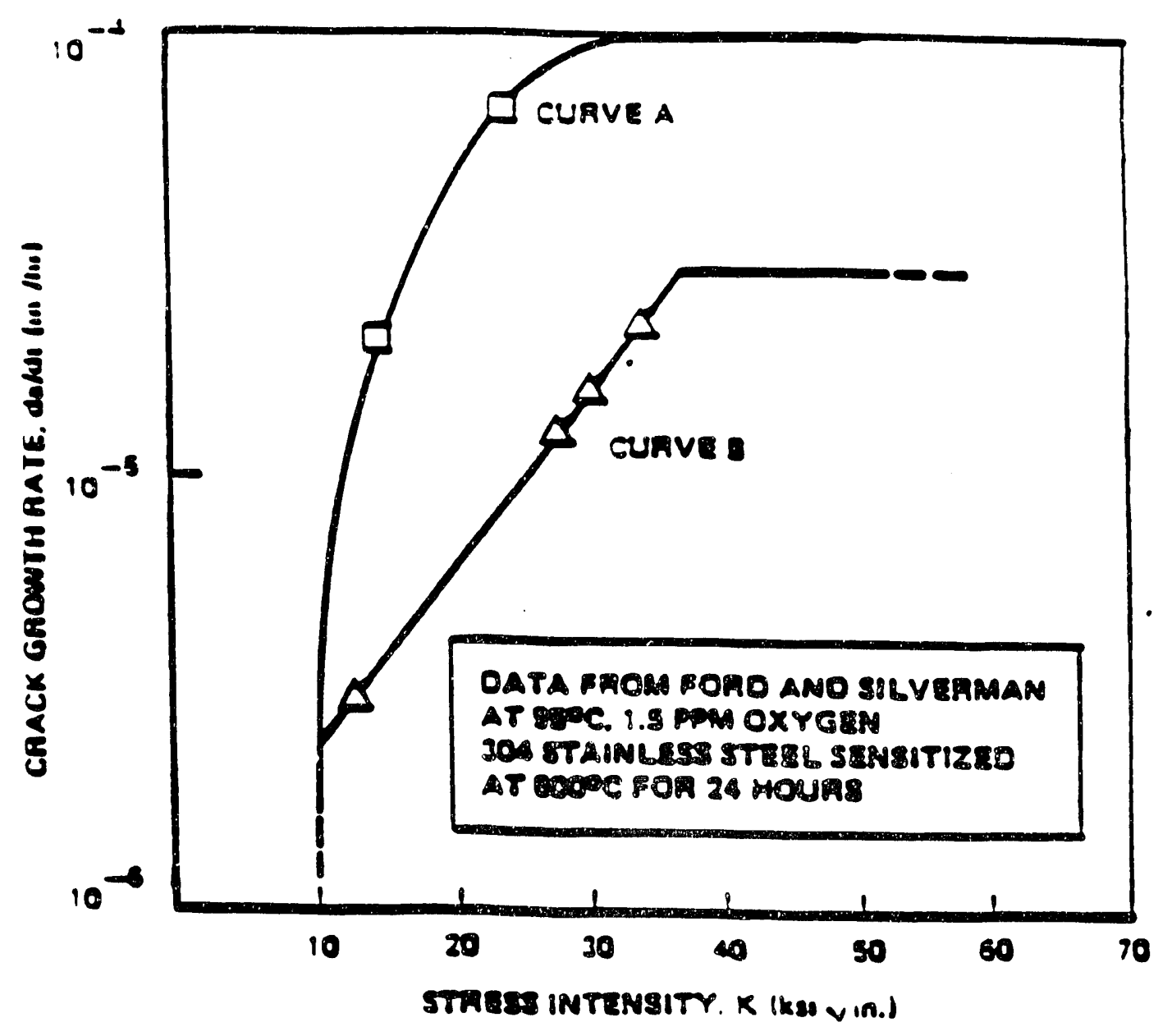

Figure 5. Literature data on IGSCC growth rate relevant to SRS Reactors 


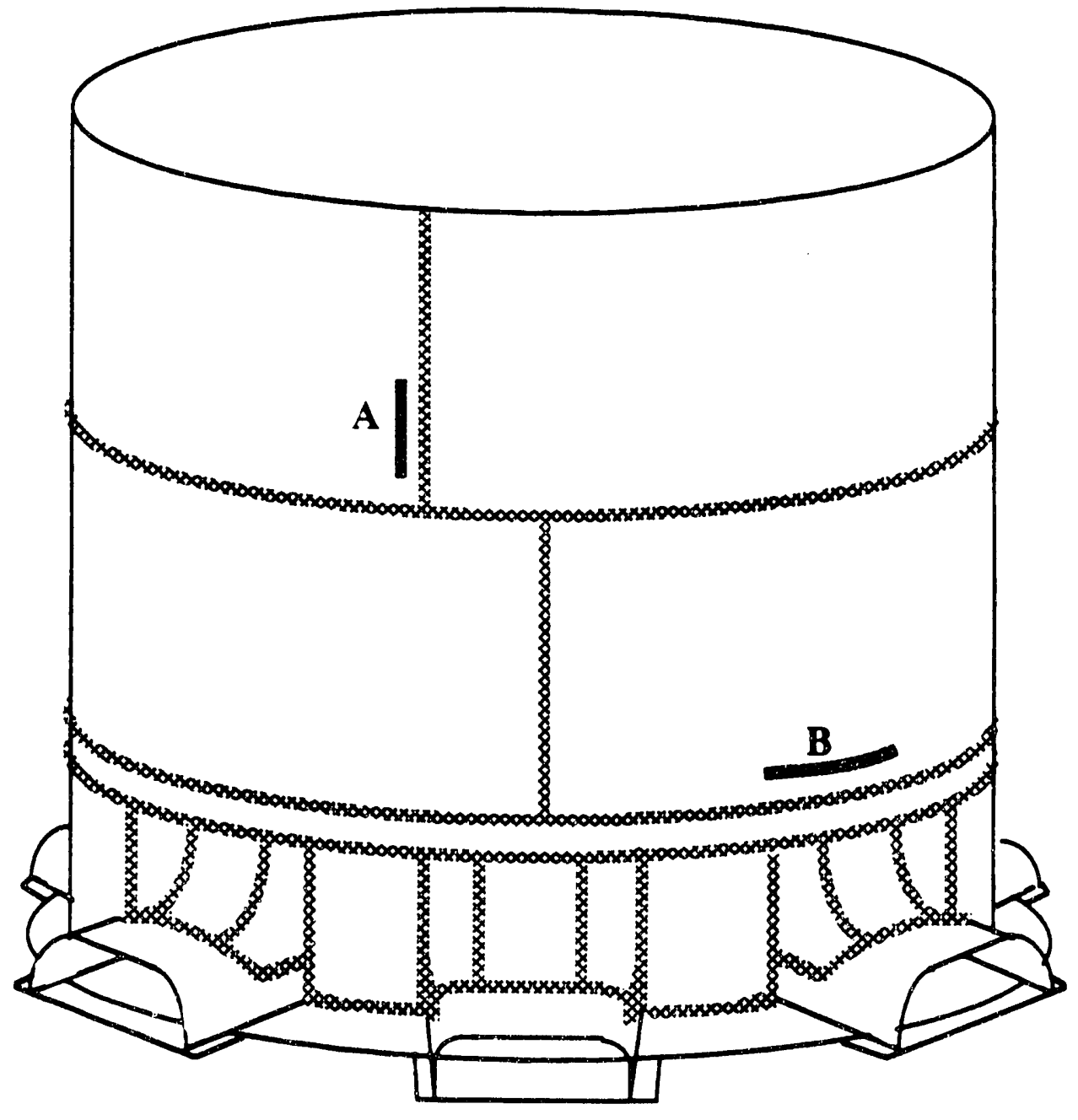

Figure 6. Postulated Crack Locations 


\section{APPENDIX A.}

\section{SAMPLE CALC̄ULATIONS OF REACTOR TANK ALLOWABLE CRACK LENGTHS}

Sample calculations are shown for two postulated through wall cracks Figure Al shows the locations of these postulated cracks. Crack $A$ is oriented in the arial direction and crack $B$ is circumferentially oriented.

Three steps involved in the calculation are:

1. determine the applied and residual stresses,

2. determine the appropriate irradiated condition J-Resistance and J-T curves, and

3. calculate the instability and allowable crack lengths.

\section{Determine the Applied and Residual Stresses}

The load states considered in the fracture assessment were: (i) normal operations, (ii) normal operation + design basis earthquake (DBE) and (iii) accident condition. The last two load states fall under the faulted or Level D condition defined by the ASME Boiler and Pressure Vessel Code. Since simultaneous occurrence of these two events is highly unlikely, these two faulted events are considered independent of each other. Nevertheless, calculations for such a case were also conducted for information. For the axial crack (location $A$ ) the accident condition stresses are more limiting than the normal operation $+\mathrm{DBE}$ case. On the other hand, normal operation $+\mathrm{DBE}$ condition stresses are more limiting for the circumferential crack (location B). The loadings during both the normal and accident conditions are pressure, thermal gradient and the residual stress.

Based on a review of the technical literature, a self-equilibrated weld residual stress distribution was assumed. For this distribution, the peak stress magnitude occurs as a tensile stress at both surfaces of the wall, and as a compressive stress at mid-wall. For points in between. linear interpolation is used to get the residual stress (A 5). This distribution applies to the main tank shell, away from the $T$-weld and nozzles. Table Al summarizes the applied and weld residual stress values used in the evaluation.

\section{Determine the Material J-Resistance and J-T Curves $\left(J_{\text {mat }}, T_{\text {mat }}\right)$}

The J-Resistance curves used in this evaluation were generated by MEA from tests on HFIR-irradiated SRP material. A review of the J-Resistance curve data from all of the specimens irradiated in the HFIR $4 \mathrm{M}$ assembly, showed that the specimen 7HAH5 exhibited the lowest toughness. Therefore, the J-Resistance curve data (Figures A2a and A2b) from this specimen were conservatively used in the fracture evaluation. The $J$-Integral values in Figure A2a are based on deformation $\mathrm{J}\left(\mathrm{J}_{\mathrm{D}}\right)$ while the values in Figure $\mathrm{A} 2 \mathrm{~b}$ are based on modified $\mathrm{J}\left(\mathrm{J}_{M}\right)$. Both the figures also show the power law fits to the data.

A review of Figure A2a shows that the J-Resistance curve appears to go through as inflection point after which its slope appears to increase with crack extension. The inflection point appears to be at a $J_{D}$ of $\sim 113 \mathrm{~kJ} / \mathrm{m}^{2}$ or $646 \mathrm{in}-\mathrm{lb} / \mathrm{in}^{2}$. Therefore, only the data up to a $\mathrm{J}_{D}$ value of 646 in-lb/in (the corresponding $\mathrm{J}_{M}$ value was $815 \mathrm{in}-\mathrm{lb} / \mathrm{in}^{2}$ ) were used in determining the material J-T curves for instability analysis. Figure $A 3$ shows the $J_{D}-T$ and $J_{M}-T$ curves based on the data in Figures $\mathrm{A} 2 \mathrm{a}$ and $\mathrm{A} 2 \mathrm{~b}$. 
The expected values of applied tearing modulus, $\mathrm{T}_{\text {applied, }}$, will be considerably smaller than the lowest tearing modulus values on the material J-T curves shown in Figure A3. Therefore, the extrapolation of these material J-T curves was necessary in onder to determine the intersection of the material and applied J-T curves. Two extrapolation procedures were used as shown in Figure A3. In the first procedure the extrapolation consisted of extending a horizontal straight line from the highest $\mathrm{J}_{\mathrm{D}}$ or $\mathrm{J}_{M}$ value. This is the most conservative procedure. A tangent straight line is used in the second pros dure. This extrapolation procedure is recommended in NUREG-1061. Although the evaluation. was performed using both extrapolation procedures, only the crack lengths based on the first procedure were used in developing the tank flaw acceptance criteria.

Extensive discussion is ongoing among the fracture mechanics specialists on the technical basis for $J_{M}$. Therefore, the instability and allowable crack lengths based on the $J_{M}-T$ curve are presented for information only. The tank flaw acceptance criteria are based on the $J_{D}-T$ curve.

\section{Calculate the Instability and Allowable Crack Lengths}

Procedures for the determination of the stress intensity factor, $\mathrm{K}$, or the J-integral, $\mathrm{J}$, for the various load cases and the tearing stability evaluation based on elastic-plastic fracture mechanics are first described. Calculatinn results for instability and allowable crack lengths are then presented.

\section{Calculate the Applied J-Integral for Pressure Loading}

This discussion concentrates on the axial flaw. For this case the J-integral can be calculated by using the formulas for a crack in an infinite plate with suitable shell correction factor to account for the curvarure effects (A1, A2). These formulas are summarized below.

$$
\begin{aligned}
\frac{J}{Y^{2} \sigma_{0} \varepsilon_{0} a} & =\pi\left[1+\frac{1}{2}\left(\frac{n-1}{n+1}\right)\left(\frac{Y \sigma}{\sigma_{0}}\right)^{2}\right]\left(\frac{\sigma}{\sigma_{0}}\right)^{2} \\
& +\alpha\left[3.85 \sqrt{n}\left(1-\frac{1}{n}\right)+\frac{\pi}{n}\right]\left(\frac{\sigma}{\sigma_{0}}\right)^{n+1}
\end{aligned}
$$

For circumferential cracks:

$$
\begin{array}{rlr}
Y^{2} & =\left(1+0.3225 \lambda^{2}\right) & (0<\lambda<1) \\
& =\left(0.9+0.25 \lambda^{2}\right) \quad(1<\lambda<5)
\end{array}
$$

For longitudinal cracks:

$$
\begin{array}{rlrl}
Y^{2} & =1+1.25 \lambda^{2} & & (0<\lambda<1) \\
& =(0.6+0.9 \lambda)^{2} & & (1<\lambda<5) \\
\lambda & =\sqrt{\mathrm{Rt}} &
\end{array}
$$


December 20, 1989

where $\quad \mathrm{a}=$ half crack length

$\lambda=-$ shell parameter

$\mathbf{R}=$ vessel radius

$t=$ vessel thickness

The material stress-strain behavior was characterized in the Ramberg-Osgood format as follows:

$$
\left(\frac{\varepsilon}{\varepsilon_{0}}\right)=\left(\frac{\sigma}{\sigma_{0}}\right)+\alpha\left(\frac{\sigma}{\sigma_{0}}\right)^{n}
$$

Ramberg-Osgood Parameters ( A 6):

$$
\begin{aligned}
& \alpha=4.2 \\
& n=8.9 \\
& \sigma_{0}=90000 \mathrm{psi} \\
& \varepsilon_{0}=\frac{\sigma_{0}}{\mathrm{E}}, \mathrm{E}=28 \times 10^{6} \mathrm{psi}
\end{aligned}
$$

\section{Calculate the Applied J-Integral for Thermal Gradient Loading}

The stress due to thermal gradient loading is essentially pure bending. Therefore, standard formulas for calculating $K$ due to a bending stress were used (A3).

\section{Calculate the Applied J-Integral for Residual Stress}

Due to the self-equilibrated nature of the residual stress distribution, standard solutions for stress intensity factors in the literature cannot be directly used to calculate the applied $\mathbf{K}$. Therefore, finite element analyses were used to determine the $\mathrm{K}$ values. The correct singularity at the crack tip in the finite element models was assured by using isoparametric urick elements with quarter point nodes.

A cylinder representing the tank was modeled by two layers of 20 node brick elements. The residual stress distribution was applied in the form of nodal loads on the nodes at the crack surface. The following $\mathrm{K}$ values were obtained for two axial cracks analyzed.

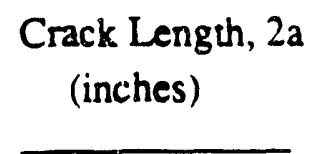

3

\section{Stress Intensity Factor, $\mathrm{K}$}

ksi $\sqrt{ }$ in

$12 \quad 27$

The peak magnitude of the stress in these analyses is $45 \mathrm{ksi}$. It is seen that the calculated $\mathrm{K}$ values do not follow the conventional dependence of $\mathrm{K}$ and $\sqrt{\mathrm{a}}$. This is due to the fact that the assumed through thickness stress distribution is unusual in the sense that it produces zero net force on the 
crack face. Based on energy considerations, it is logical to expect that as the through-wall crack lengthens, the stress intensity factor does not continue to increase. The calculated $\mathrm{K}$ values are consistent with this. The $K$ values for other crack lengths were obtained by fitting a curve to the calculated values. The curve fit function was selected such that as the crack length increases, the $K$ value asymptotically reaches a constant value.

\section{Combine the Applied J-Integral from Various Loadings}

Based on the fast fluence level. the yield strength of the material at both the locations analyzed is expected to be no greater than $85 \mathrm{ks}$. Thus, for the given loadings the material fracture behavior is expected to be in the linear elasuc fracture mechanics (LEFM) regime or at most in the small scale yielding regime. Therefore, it is reasonable to add the $\mathrm{K}$ values from various loadings to obtain a $\mathrm{K}_{\text {total. }}$. The addition of the individual $\mathrm{K}$ values is needed since the $\mathrm{J}$ values are nonlinear functions of stress and are not additive. Since the pressure loading is the only primary loading, a plastic zone size correction was applied to the calculated $\mathrm{K}$ values for this case. The $\mathrm{K}_{\text {total }}$ was then converted into an equivalent $J_{\text {total }}$ value by the usual relationship. $J=K^{2} / E$.

The calculation sequence is as follows:

(i) Compute the $\mathrm{J}$ value due to pressure. Calculate the corresponding $\mathrm{K}_{\text {pressure }}$

(ii) Compute the $\mathrm{K}$ values due to thermal gradient and residual stress using LEFM.

(iii) Determine $K_{\text {total }}=K_{\text {pressure }}+K_{\text {thermal }}+K_{\text {resid }}$.

(iv) Calculate $\mathrm{J}_{\text {total }}=\left(\mathrm{K}_{\text {total }}\right)^{2 / \mathrm{E}}$.

\section{Tearing Stability Evaluation}

The elastic-plastic fracture mechanics based concepts developed by Paris and Hutchinson were used to determine the instability crack lengths at both the locations. Figure A4 schematically illustrates the procedure. The applied J-integral, $J_{\text {app }}$, ( $J_{\text {total }}$ in the preceding subsection) was calculated as a function of crack length for normal and accident condition loads. The applied iearing modulus, $T_{\text {app }}$, is defined as,

$$
T_{\text {app }}=\frac{E}{\sigma_{0}^{2}} \frac{d J_{\text {app }}}{d a}
$$

The intersection of $\left(J_{\text {app }}, T_{\text {app }}\right)$ and the $\left(J_{\text {mat }}, T_{\text {mat }}\right)$ curve gives the instability point. From the $J_{\text {app }}$ value at instability, the crack length corresponding to instability can be determined. A check on this approach is available from the $\mathrm{J}$ vs a curve analysis illustrated in Figure 1 of Reference A4.

\section{Safety Factors to Obtain Allowable Crack Lengths}

Pressure vessels designed to the ASME Code provide, in general, a safety factor of 3 on pressure against failure due to vessel rupture under normal operating conditions. For faulted conditions (or Level D) the Code provides a safety factor of 1.41 . For linear elastic fracture mechanics behavior, assuming linear dependence of $\mathrm{K}$ on the square root of the flaw size, the factor of 3 and 1.41 on stress translates to a factor of $\left(3^{2}\right)$ or close to 10 and $\left(1.41^{2}\right)$ or close to 2 on the flaw size. Section $\mathrm{XI}$ of the ASME Code allows the user the choice of the safety factor on stress or the flaw size. 
Except for some simple cases the two criteria do not lead to the same allowable flaw size. This is largely due to the fact that $\mathrm{K}$ is not proportional to the square root of the flaw size, but in fact depends on a geometncal magnification factor in addition to the square root term.

In this evaluation, safety factors of 3 and 1.41 on applied stress are used for normal and faulted conditions respectively. Thus, the safety factors were only applied to the pressure and seismic str. $s$ ses. This is realistic since the objective is to provide safety factors that provide margins on applied loading. Applying a factor on flaw size is not meaningful since it uses geometric factors that are not dependent on the current flaw size but on a much larger flaw size that may never occur in future service. Furthermore, a factor on flaw size would apply the same margin on both the residual stress and the applied siresses. In reality, margins are needed on the applied loading, not on the as-built stresses in the unloaded condition.

\section{Instability and Allowable Crack Lengths}

Figures A5a through A5d show the applied $J$ and $T$ values as a function of crack length for various load combinations. The crack length on the applied J-T curve at the intersection with the material $\mathrm{J}-\mathrm{T}$ curve, is the instability crack length. Table A2 shows the instability crack lengths at the two postulated crack locations.

The results for the accident condition + DBE case in Table A2 are shown for information only since the likelihood of the simultaneous occurrence of these two events is extremely low. The instability crack lengths for the accident condition and the accident condition + DBE at location $A$ are identical because the DBE does not produce any circumferential stress at this location. The applied stress (i.e. pressure stress) at location B during normal operation is very low (see Table Al) and. therefore, instability crack length calculations were not performed for this case.

The allowable crack lengtiss were determined by essentially following the same method as that used in determining the instability crack lengths. In this case, the pressure and seismic stresses were multiplied by the appropriate safety factors. Figures A6a through A6d show the applied J and T values for different load combinations and locations. The allowable crack lengths are shown in Table A3. Allowable crack lengths at location A are smaller than those at location B. The lowest allowable crack length at location $A$ is 28 inches. This crack length can be conservatively used in development of tank flaw acceptance criteria.

\section{References}

A1. C. F. Shih and J. W. Hurchinson, Transactions, American Society of Mechanical Engineers, Journal of Engineering Materials and Technology, Series H, Vol. 98, 1976, pp. 289-295.

A2. P. C. Paris and H. Tada, "The Application of Fracture Proof Design Methods Using Tearing Instability Theory to Nuclear Piping Postulating Circumferential Through-Wall Cracks." L". S. Nuclear Regulatory Commission Repor,. NLREG/CR-3464, Washington D.C.. September 1983.

A3. D. P. Rooke and D. J. Cartwright, "Compendium of Stress Intensity Factors," Her Majesty's Stationary Office, London, September 1974.

A4. EDG-89.47, "Procedure for Evaluation of Reactor Tank Inspection Results," J. A. Begley et al.. May 1989.

A5. SASR\#86-64, Fracture Mechanics Evaluation of Potential Flaw Indications in the Savannah River L, P and K Tanks," General Electric, October 1989.

A6. SASR \# 85-94, GE Design Record File No. 137-0010. December 1985. 
TABLE A1

STRESS MAGNITUDES AT POSTULATED CRACK LOCATIONS

\begin{tabular}{clrr} 
Location & Load Source & \multicolumn{2}{c}{$\begin{array}{c}\text { Stress (psi) } \\
\text { Bembrane }\end{array}$} \\
\hline & & & \\
A & Pissure, NO & 2525 & 0 \\
& Pressure, Acc. & 5228 & 0 \\
& Th. Gradient, NO & 0 & 3240 \\
& Th. Grad., Acc. & 0 & 6480 \\
& & & \\
& Pressure, NO & 500 & 1000 \\
& Th. Gradient, NO & 0 & 0 \\
& Seismic (DBE) & 5000 & 0
\end{tabular}

Note: A self equilibrated weld residual stress distribution was assumed at both locations. The peak stress magnitude was $30000 \mathrm{psi}$ at location A and $45000 \mathrm{psi}$ at location B.

NO $=$ Normal Operation 
TABLE A2

CALCULATED INSTABILITY CRACK LENGTHS

\begin{tabular}{|c|c|c|c|c|c|}
\hline \multirow[b]{2}{*}{$\begin{array}{l}\text { Postulated } \\
\text { Crack Location }\end{array}$} & \multirow[b]{2}{*}{$\begin{array}{l}\text { Load } \\
\text { State }\end{array}$} & \multicolumn{2}{|c|}{ Based on $J_{D}$} & \multicolumn{2}{|c|}{ Based on $\mathrm{J}_{\mathrm{M}}$} \\
\hline & & $\begin{array}{l}\text { Horiz. } \\
\text { Extrap. }\end{array}$ & $\begin{array}{l}\text { Tang. St } \\
\text { Line Extrap. }\end{array}$ & $\begin{array}{l}\text { Horiz. } \\
\text { Extrap. }\end{array}$ & $\begin{array}{l}\text { Tang. St } \\
\text { Line Extrap }\end{array}$ \\
\hline \multirow{3}{*}{$\mathbf{A}$} & NO & 58 & 62 & 65 & 72 \\
\hline & $A \infty$ & 32 & 34 & 36 & 40 \\
\hline & $A C c+D B E$ & 32 & 34 & 36 & 40 \\
\hline \multirow{3}{*}{ B } & NO & $\cdots$ & $\cdots$ & $\cdots$ & $\cdots$ \\
\hline & $\mathrm{NO}+\mathrm{DBE}$ & 50 & 54 & 56 & 61 \\
\hline & $A c c+D B E$ & 46 & 48 & 50 & 55 \\
\hline
\end{tabular}

Notes: All crack lengths are in inches

NO - Normal Operation

Acc - Accident Condition

DBE - Design Basis Earthquake 
TABLE A3

CALCULATED ALLOWABLE CRACK LENGTHS

\begin{tabular}{clcccc}
$\begin{array}{l}\text { Postulated } \\
\text { Crack Location }\end{array}$ & $\begin{array}{l}\text { Load } \\
\text { State }\end{array}$ & $\begin{array}{c}\text { Boriz. } \\
\text { Extrap. }\end{array}$ & $\begin{array}{l}\text { Tang. St } \\
\text { Line Extrap. }\end{array}$ & $\begin{array}{c}\text { Based on } \mathrm{J}_{\mathrm{M}} \\
\text { Horiz. } \\
\text { Extrap. }\end{array}$ & $\begin{array}{c}\text { Tang. St } \\
\text { Line Extrap. }\end{array}$ \\
\hline \multirow{4}{*}{ A } & NO & 26 & 27 & 29 & 32 \\
& Acc & 25 & 26 & 28 & 31 \\
& Acc + DBE & 25 & 26 & 28 & 31 \\
& & & & & \\
B & NO & $\ldots$ & $\ldots$ & $\ldots$ & $\ldots$ \\
& NO + DBE & 40 & 42 & 44 & 48 \\
& Acc + DBE & 36 & 38 & 40 & 44 \\
\hline
\end{tabular}

Notes: All crack lengths are in inches

NO - Normal Operation

Acc - Accident Condition

DBE - Design Basis Earthquake 


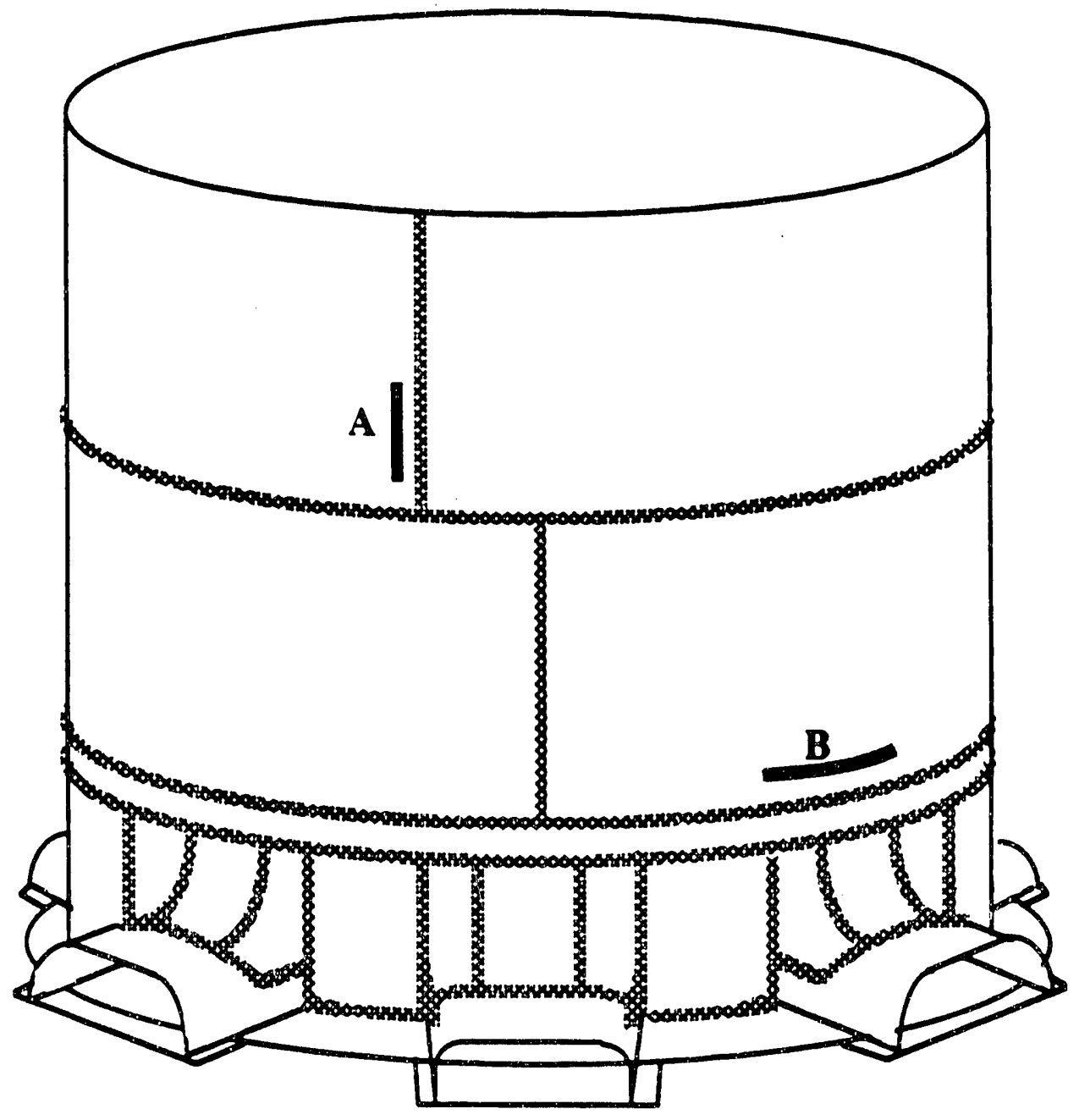

Figure A1. Postulated Crack Locations 
Crack Extension (inch)

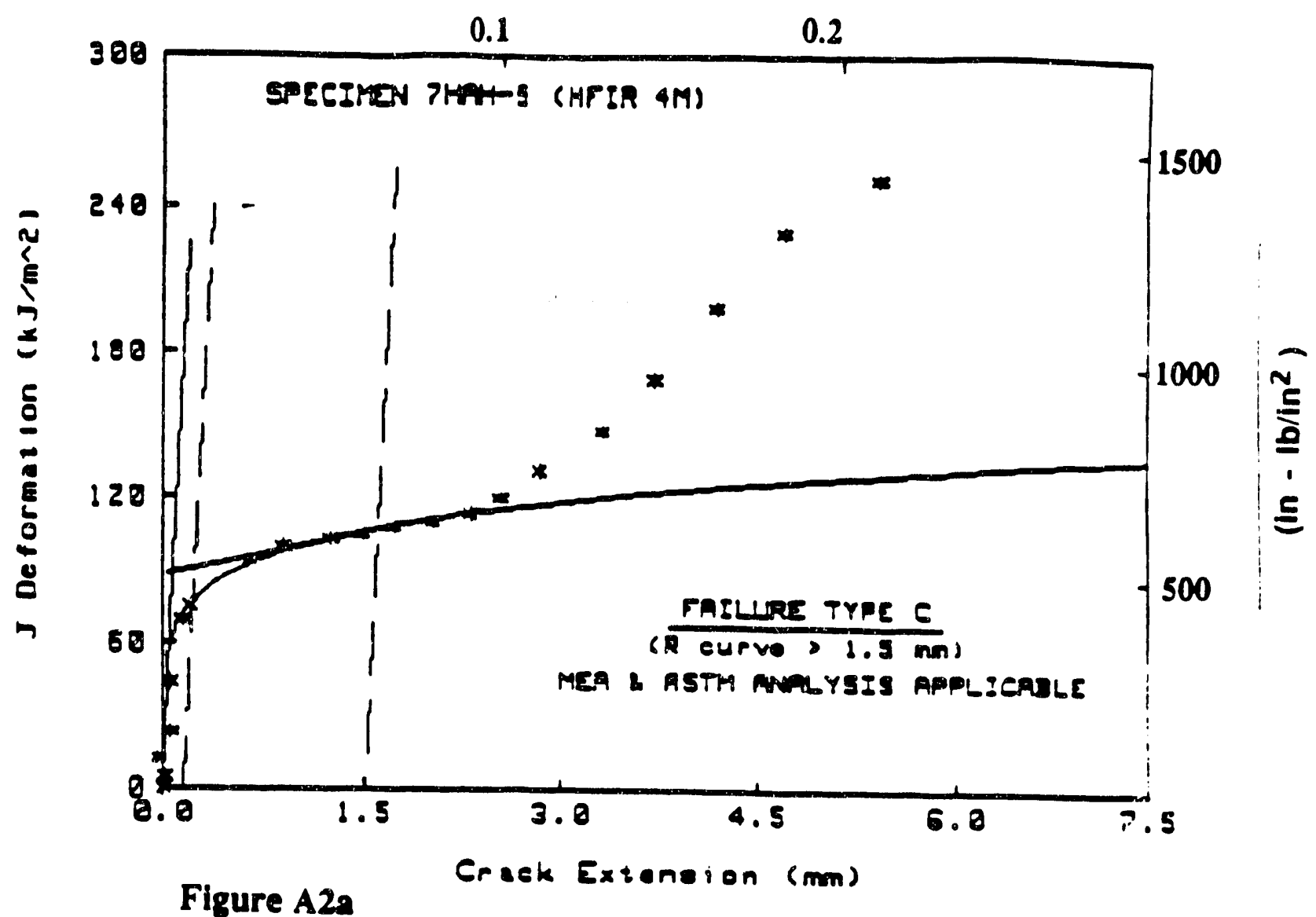

Crack Extension (inch)

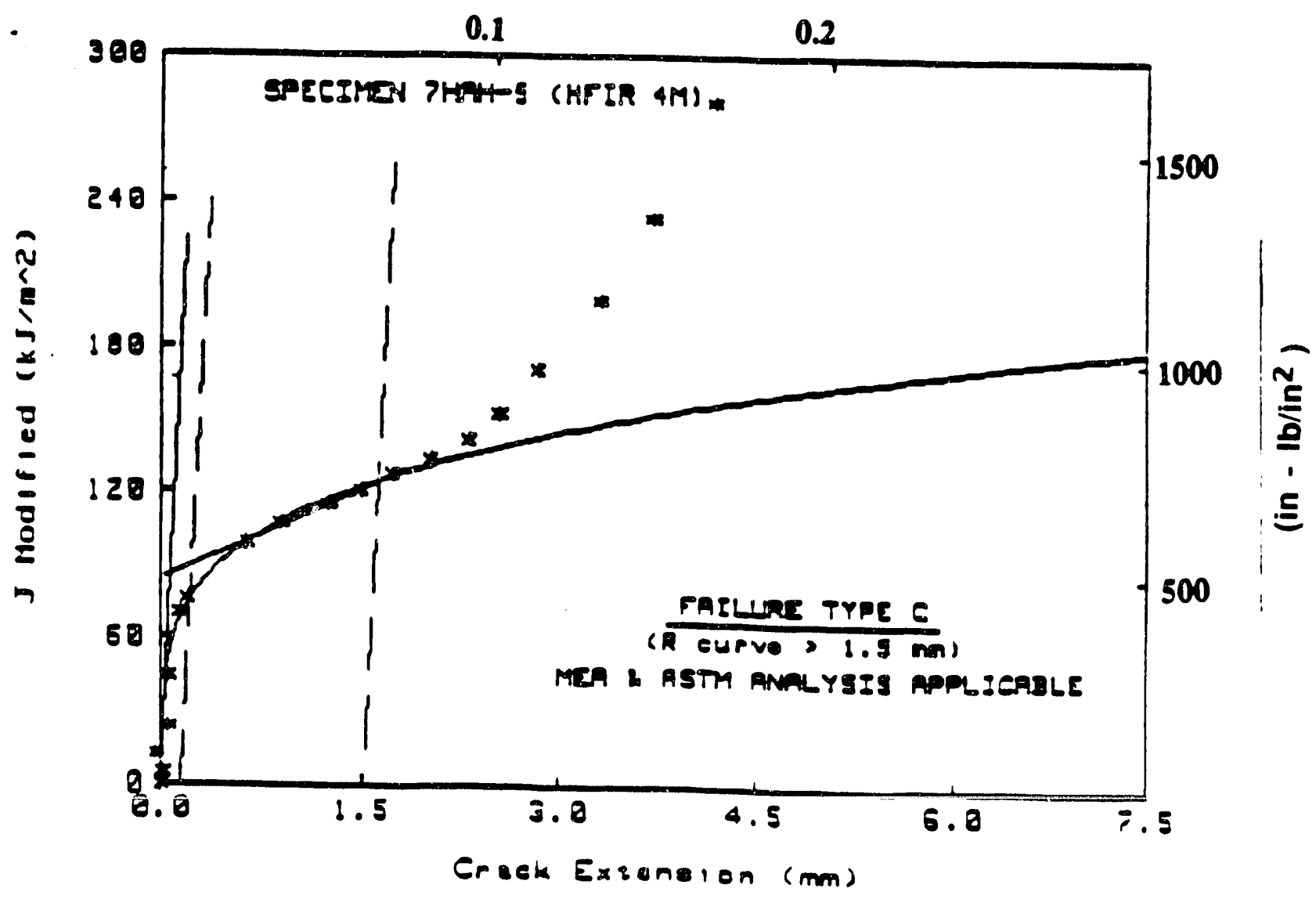

Figure A2b 


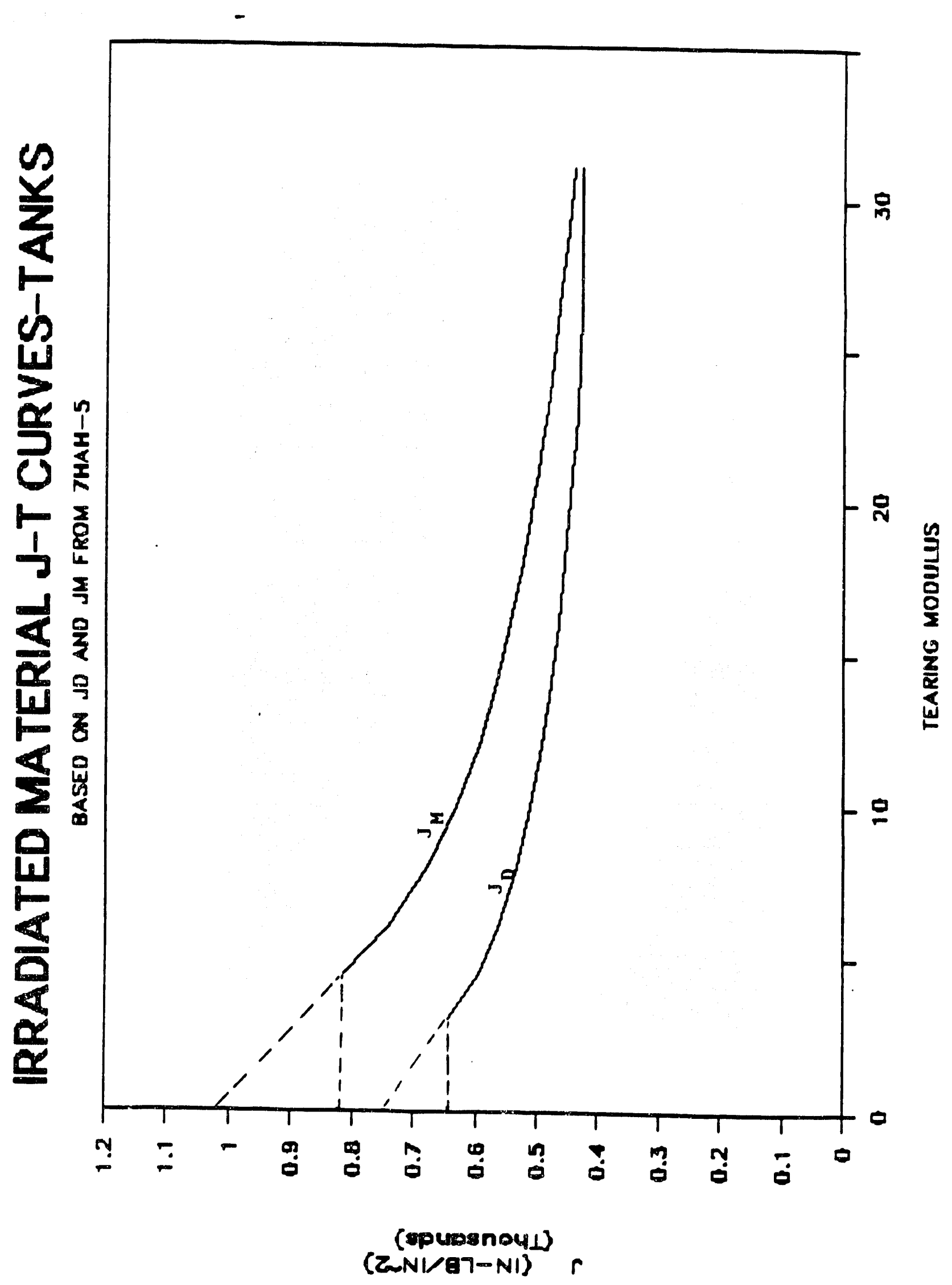

2
$\sum$
$\vdots$ 


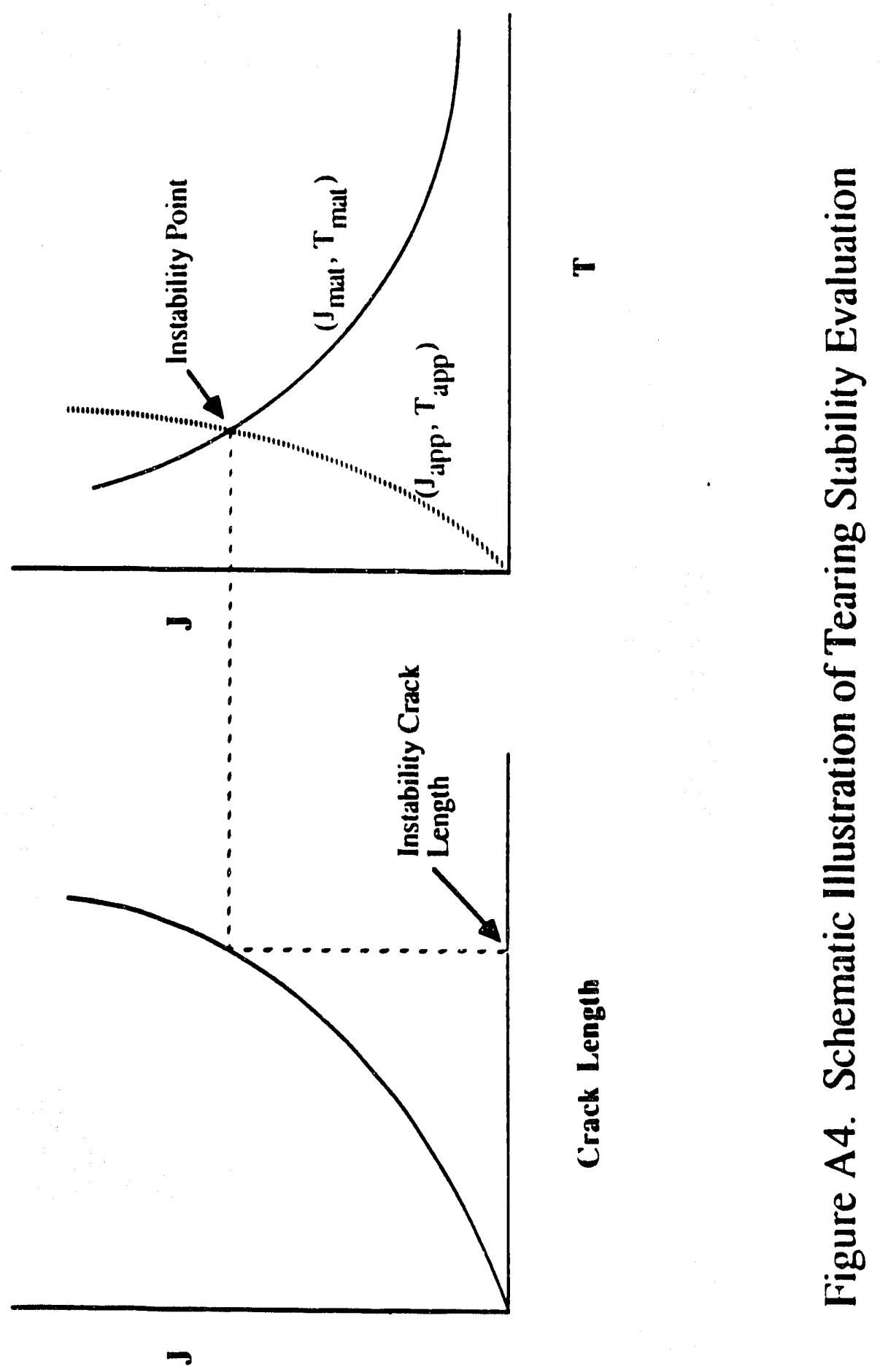




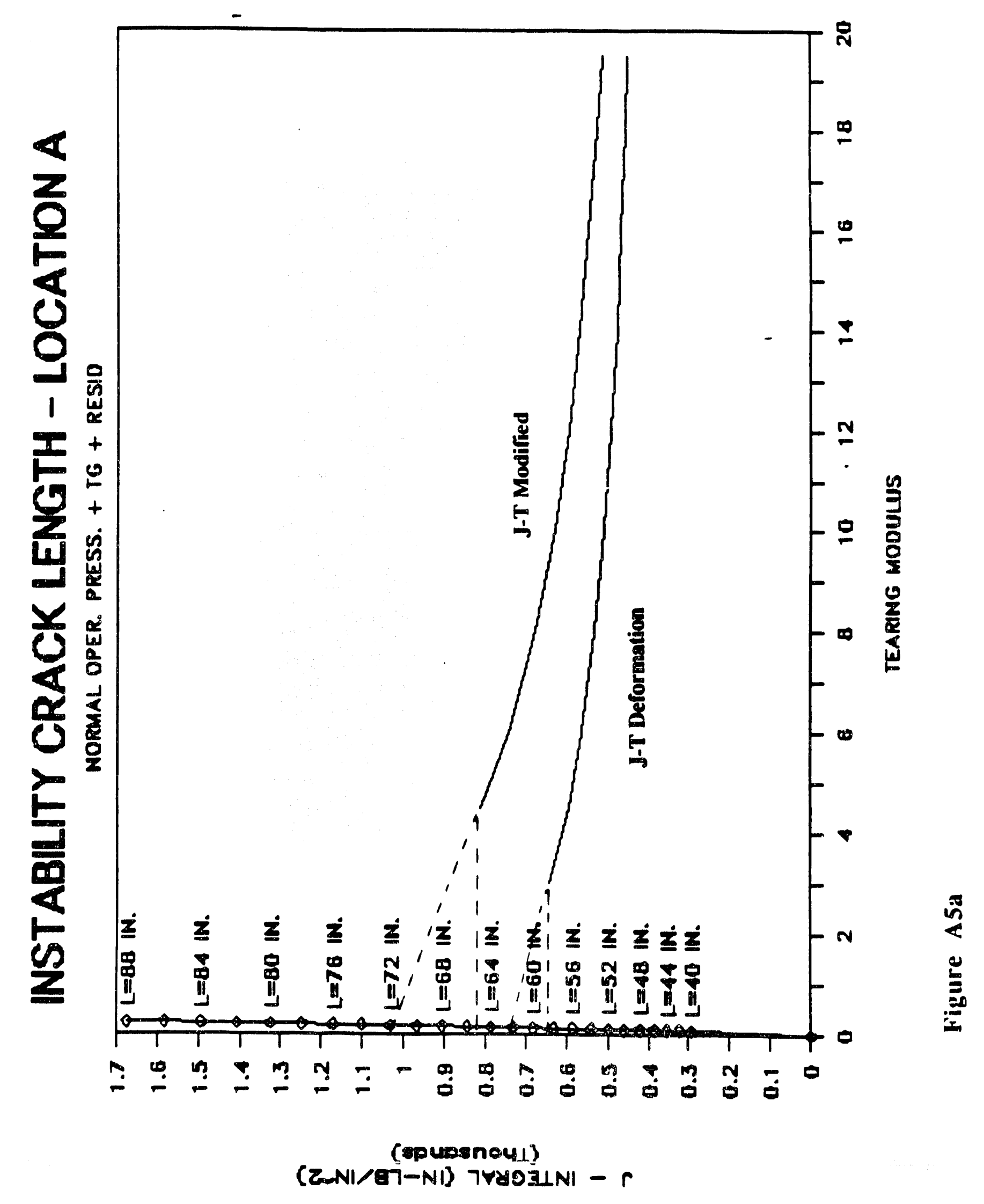




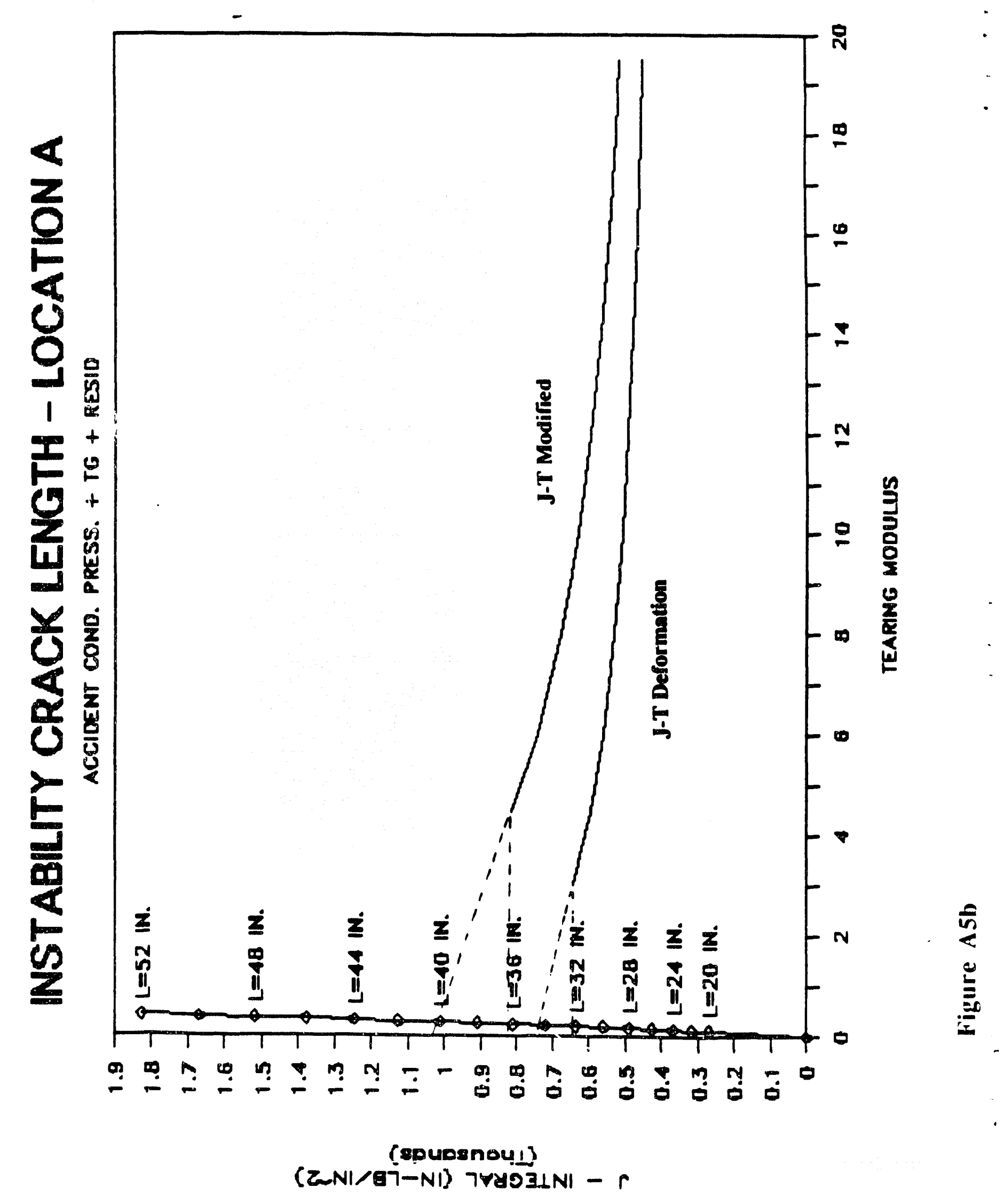




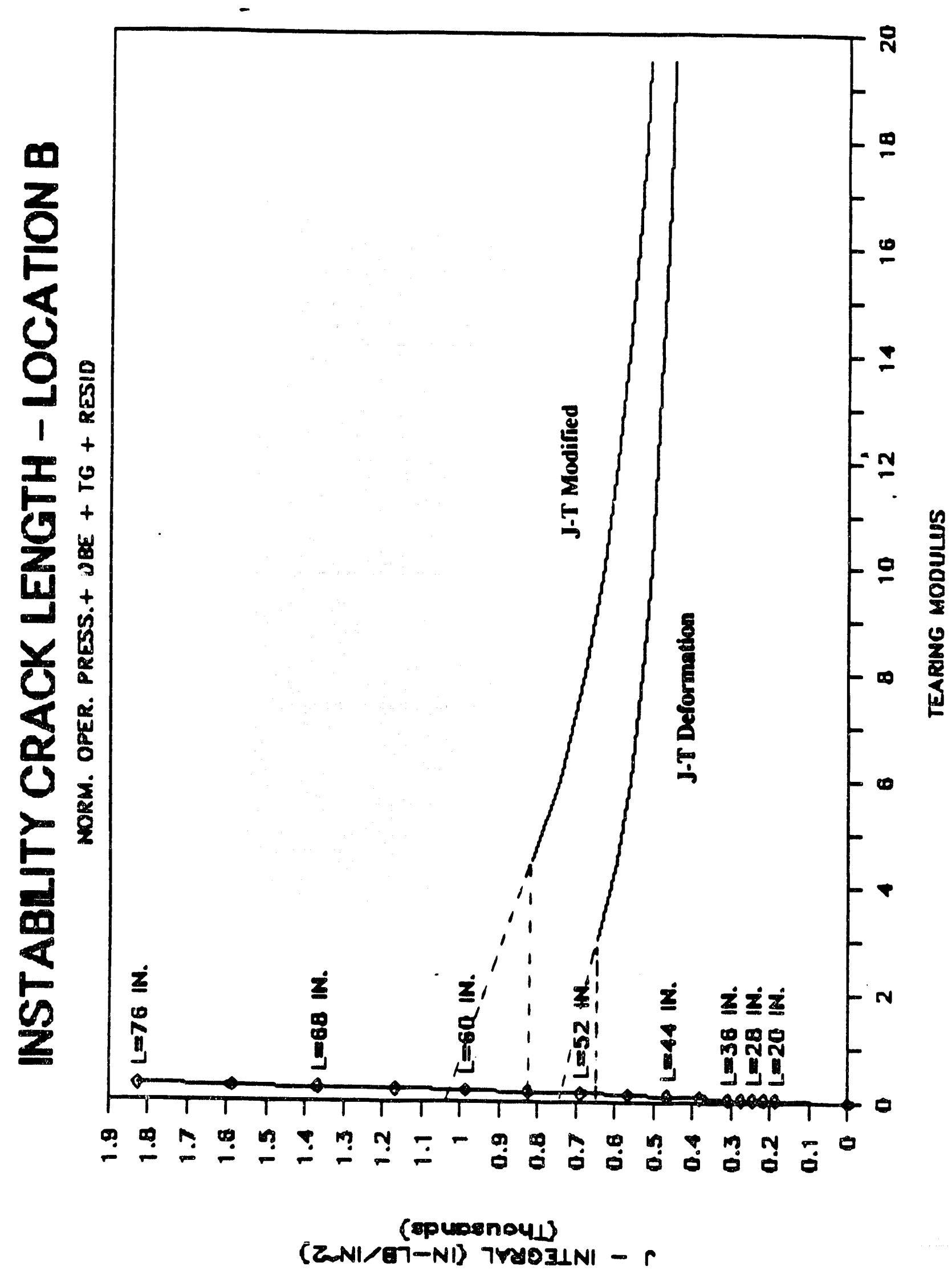

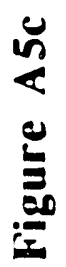




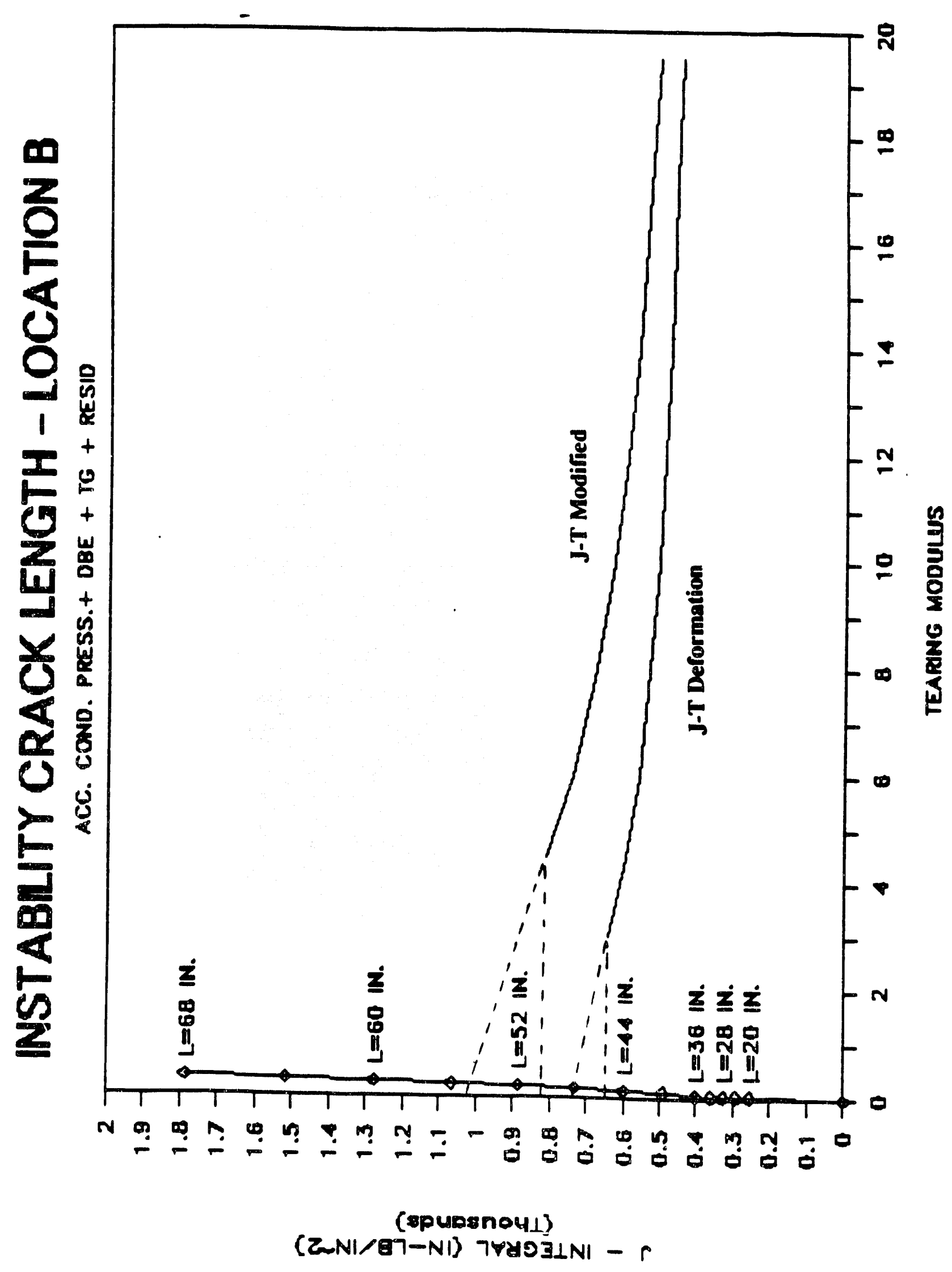

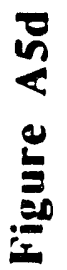




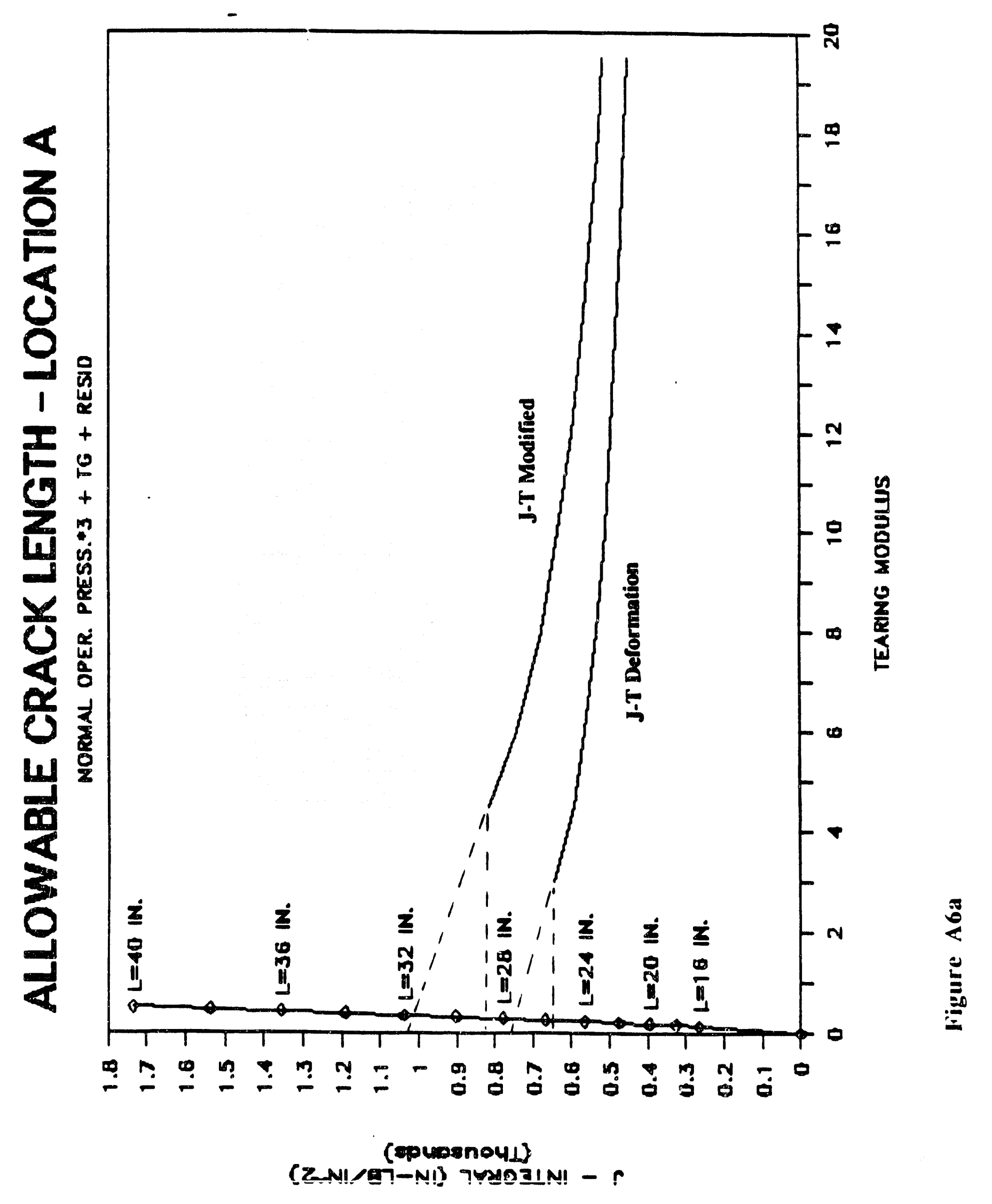




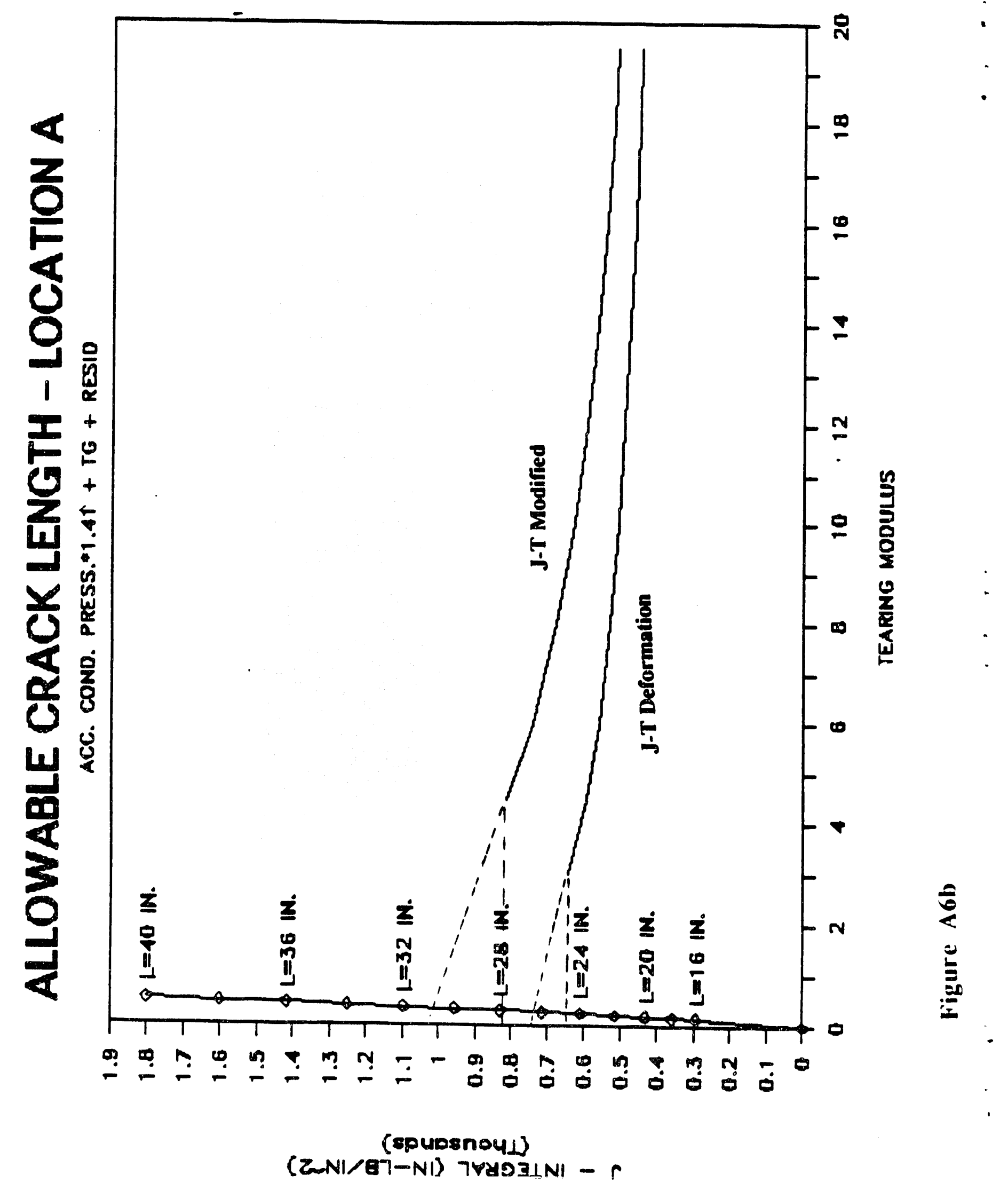




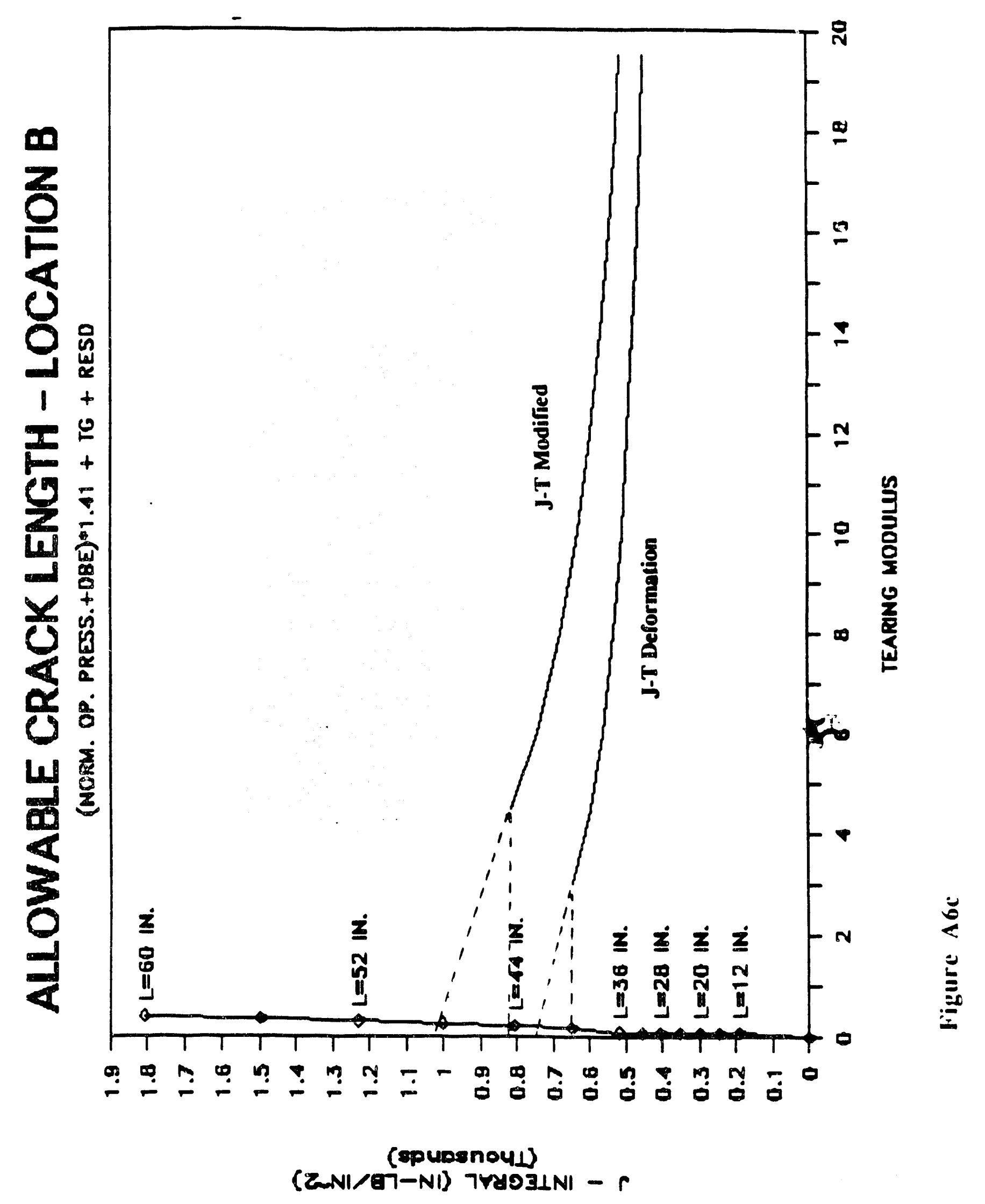




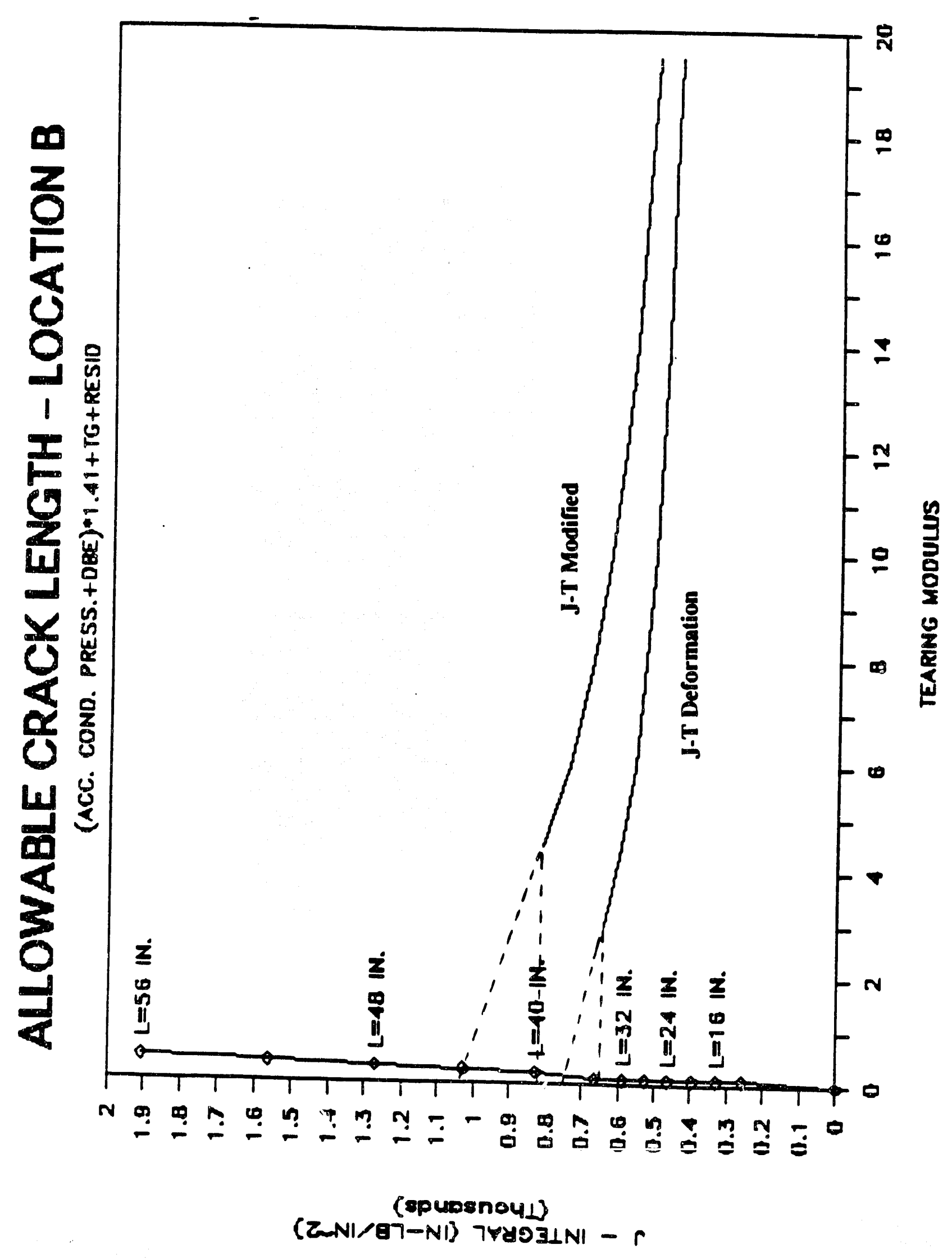

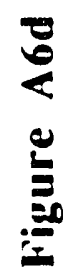


J. M. Stone

Page 6

January 30,1990
WSRC-RP-89-208-Revision 2

Task Number 88-001-A-1

ATTACHMENT NO. 3 
EDG-89.49-REVISION 1

\section{BEACTOR TANK UT PROGRAM - SAMPLING PLAN (IU)}

\section{DECEMBER 1989}

\section{Patent Status}

This internal management report is being transmitted without DOE patent clearance. and no further dissemination or publication shall be made of the report without prior approval of the DOE-SR patent counsel.

Westinghouse Savannah River Company Savannah River Laboratory

P. O. Box 616 Aiken, SC 29802 


\section{IULE: BEACTOR TANK UT PROGRAM- SAMPLING PLAN (U)}

DOCUMENT: EDG-89.49-REVISION 1

REVISION1

PREPARED BY:

$\omega L$ Dewhents is Dore 87
W. L. DAUGHERTY
WESTINGHOUSE, SRL

BEVISION

REVIEWED BY:

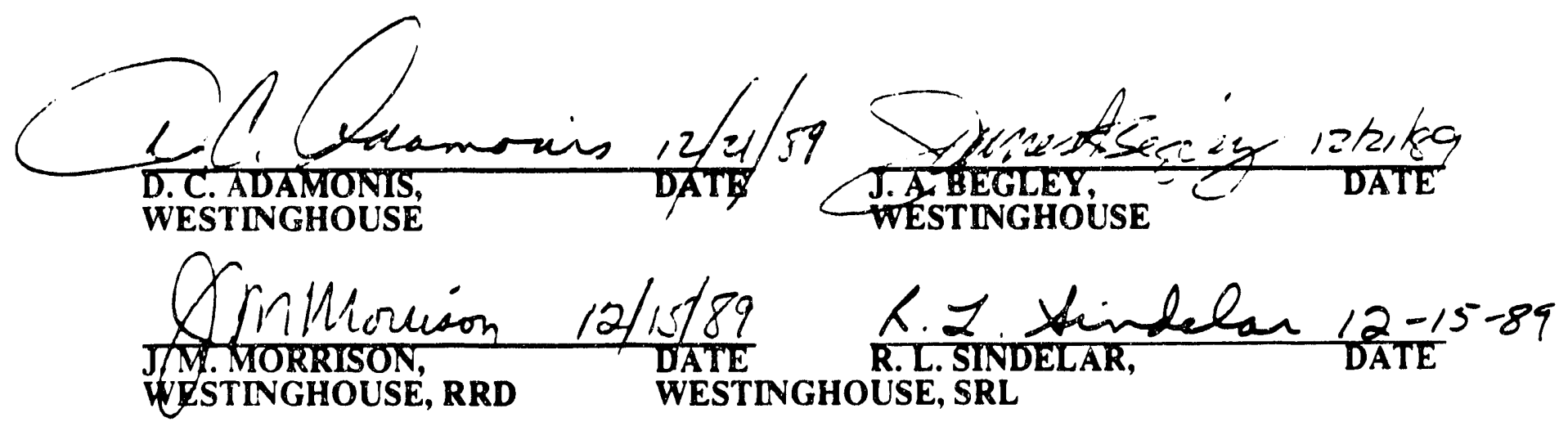


This approval page from the original issue of the Reactor Tank LT Acceptance Criteria by the Tank Acceptance Criteria Working Group is included in Revision as a record of the technical expertise behind these acceptance criteria. Revision 1 to this document was made to clarify the criteria and not to alter the technical contents.

TILE: REACTOR TANK LT PROGRAM. SAMPLING PLAN

PREPARED BY:

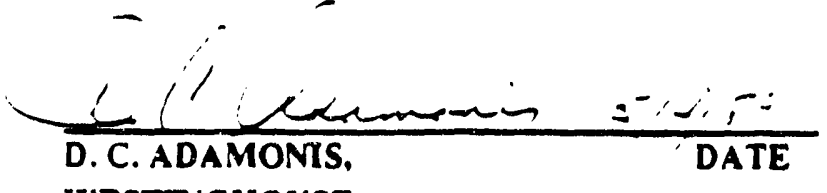

WESTINGHOUSE

REVIEWED BY:
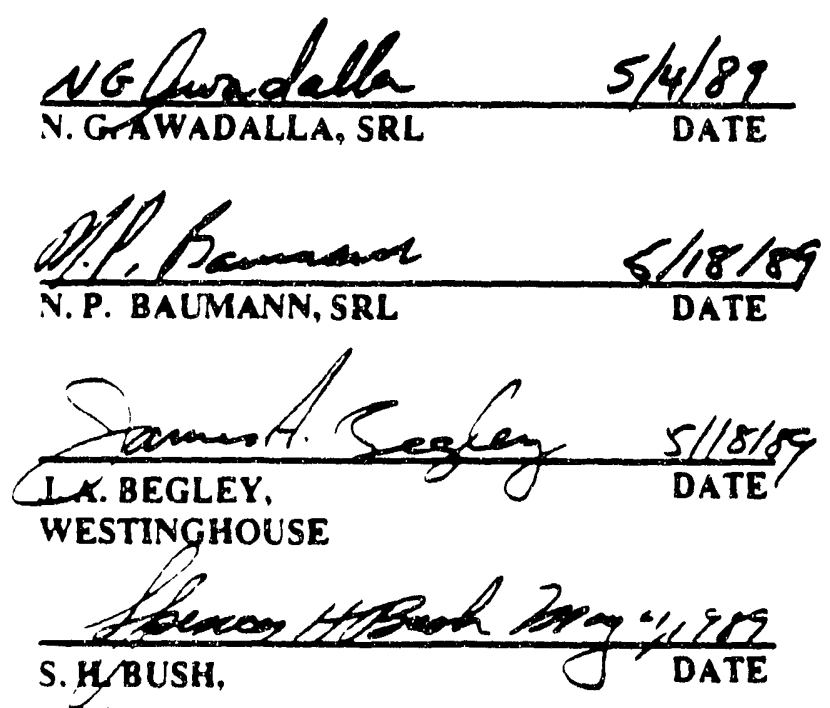

REVIEW \& SYNTHESIS ASSOCIATES
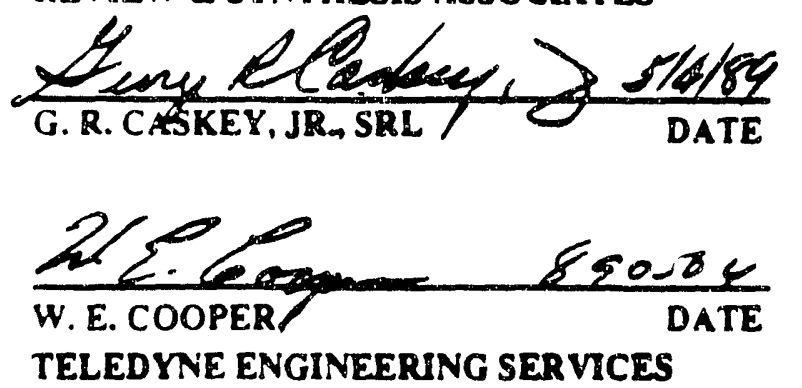

TELEDYNE ENGINEERING SERVICES

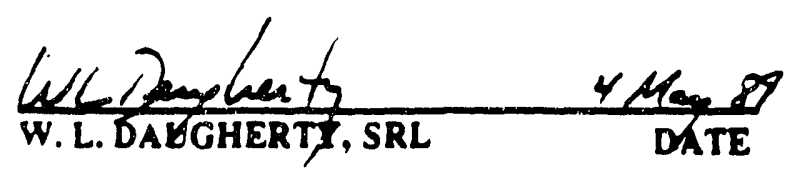

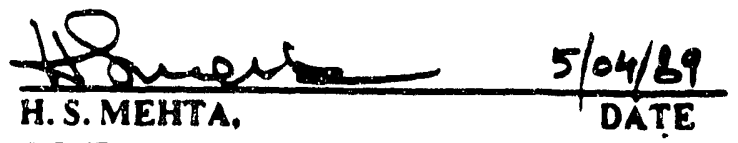

GENERAL ELECTRIC COMPANY

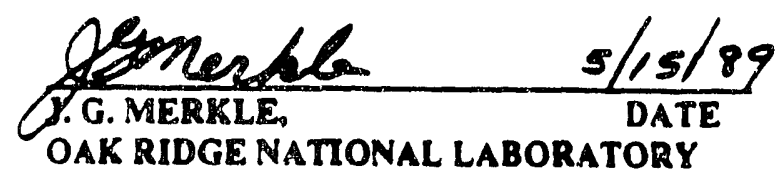

OAK RIDGE NATIONAL LABORATORY $\frac{\text { LRauganate } \frac{5 / 4 / 89}{\text { S.RANGANATH, }}}{\text { DATE }}$ GENERAL ELECTRIC COMPANY
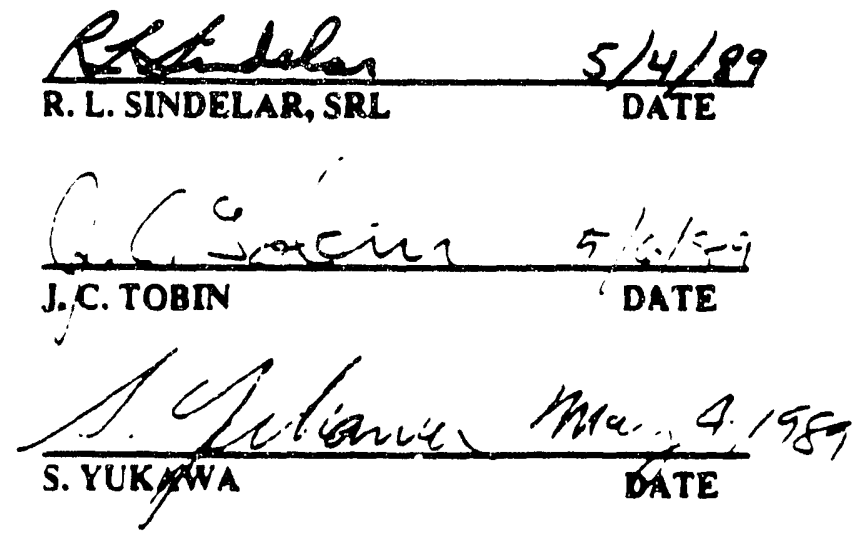


\section{Revision Summary Page}

Document No. ED̄G-89.49

Rev. No. 1 Issue Date: $12 / 20 / 89$

Task ID No. 88-001-A-1

Effective Date: 12/20/89

Page No.

Description of Revision

1

Summary: "bearing ring" corrected to "expansion ring"

2

3rd paragraph;

Additional information added to clarify geometric similarity of tanks.

Figure 1

Added "Typical" to caption.

Figures $3-5$

Added to revision 1. 


\section{INTRODUCTION}

An ultrasonic in-service inspection program has been developed for the Savannah River Site (SRS) reactor tanks. The rationale for implementation of this program is to 1 ) provide information concerning tank status necessary for life extension studies and planning preventive maintenance and 2) provide additional assurance concerning the continued safe and reliable operation of the tank over and above that already established by design, analysis, prior examinations and operating experience. The philosophy of this periodic in-service inspection program is consistent with Section XI of the AS.MIE Boiler and Pressure Vessel Code and the "ISI Plan for the Savannah River Production Reactors Process Water System". A "baseline" examination will be accomplished during scheduled outages over the next five years of operation and "in-service" examinations will be performed during subsequent five year intervals.

\section{SCOPE}

This document describes a recommended sampling plan for the initial UT inspection of the SRS reactor tanks. The scope of subsequent inspections to complete the baseline examination will depend in part on the outcome of the initial inspection.

\section{SUMMARY}

A recommended sampling plan has been developed for the initial UT inspection of the SRS reactor tanks. The areas targeted for this initial inspection will be selected based on parameters such as fabrication and operating history, material chemistry, UT equipment flexibility and stress levels. This sampling plan will target the following coverage during the initial inspection:

- $100 \%$ of the tank shell longitudinal weld heat affected zones,

- $33 \%$ of the tank shell circumferential weld heat affected zones,

- $33 \%$ of the effluent nozzle-to-tank weld heat affected zones,

- Portions of the T-weld and tank-to-expansion ring weld heat affected zones that are accessible,

- Regions of the tank base metal, and

- Regions of previous repair work.

\section{DISCUSSION}

Examinations will be accomplished from the tank wall inside diameter surfaces utilizing an inspection robot with six degrees of freedom. The only entry to the inside of the tank is through $4-3 / 8^{\prime \prime}$ diameter universal sleeve housings (USH's) through the upper plenum. Each USH position allows for access to a limited sector of the tank circumference. As illustrated in Figure 1, it is necessary to position the tool in 18 different USH locations to achieve $360^{\circ}$ coverage of the tank.

Ultrasonic examinations will be performed using dual element $45^{\circ}$ shear wave, $2.0 \mathrm{MHz}$ transducers in a full vee application with reference sensitivity established on notches having depths equal to $5 \%$ of the tank wall thickness. Scanning will be conducted in two directions parallel to the welds and two directions perpendicular to the welds where access permits. This technique was used successfully during examinations of the C Tank "sidewall" region in 1985. All ultrasonic test data will be digitized and recorded using an Amdata IntraSpect/98 Automated Ultrasonic Imaging System for off-line analysis and archival storage of examination results. The entire examination system, including inspection personnel, will be qualified for detection and sizing on representative samples containing intergranular stress corrosion cracks. This qualification program is modeled after the Boiling Water Reactor piping inspection requirements and will be administered by personnel from the EPRI NDE Center. Any changes requiring subsequent requalification will also use samples containing intergranular stress corrosion cracks. 
Since the "baseline" examination is accomplished over a series of outages during the next five years of reactor tank operation, a sample plan is recommended which provides emphasis on tank areas of particular interest in the early phase of implementation. This plan provides guidance for selection of approximately $40 \%$ of all accessible tank weld heat affected zones during the initial examination. No specific guidance is provided for the remainder of the baseline period. These selections may be based on duration of outage and compatibility with other scheduled work. However, the baseline work must be completed within the specified five year interval.

Selection of inspection areas for this initial examination is based on the following considerations:

- accumulated fluence

- applied stress

- residual stress

- base metal chemistry

- shop welds versus field welds

- prior examination results

- minimize repositioning of inspection equipment

- repair areas

The extent of examination coverage targeted by the recommended examination plan is illustrated by the four $30^{\circ}$ sectors shown in Figures 1 and 2. Weld heat affected zones and a sample of adjacent base material which fall in the crosshatched area of Figure 2 are identified for examination. Figures 1 and 2 , specific to $\mathrm{K}$ tank, provide a general view of the weld locations and regions to be inspected. The figures are generic in the sense that detailed weld locations are not specified. The shell weld locations including number and length of longitudinal (axial) and circumferential segments differs for each tank (Figures $3-5$ for the $P, K$ and $L$ tank shells, respectively). The detailed procedures for the inspection of each individual reactor tank are developed by the Equipment Engineering Section. The following discussion directs the selection of weld regions to be examined in the initial inspection.

It is the intent that the initial examination include the following areas. All longitudinal weld heat affected zones in the tank shell section will be examined. These zones represent areas of high fluence and are limiting in terms of instability flaw size. In addition, 33\% of the length of the tank upper-to-lower shell circumferential weld heat affected zones will be examined to account for azimuthal variations in fluence. Areas selected on the basis of applied stress include $33 \%$ of the effluent nozzle-to-tank weld heat affected zones. Axial, circumferential, and nozzle-to-tank welds included in the examination program provide a variety of anticipated residual stress levels. Thirty-three percent of the field weld joining the nozzle assembly to the main tank will be examined. Presently, techniques are not available for examination of the weld joining the tank to the bottom tubesheet (T-joint) and examinations of the tank-to-bearing ring weld may be limited to single sided access. Developmental efforts are in progress for examination of these areas and will be phased into the examination program as they become available. Accomplishing the examination coverage recommended for the initial inspection would require the remote inspection tool be positioned in only six USH locations. 


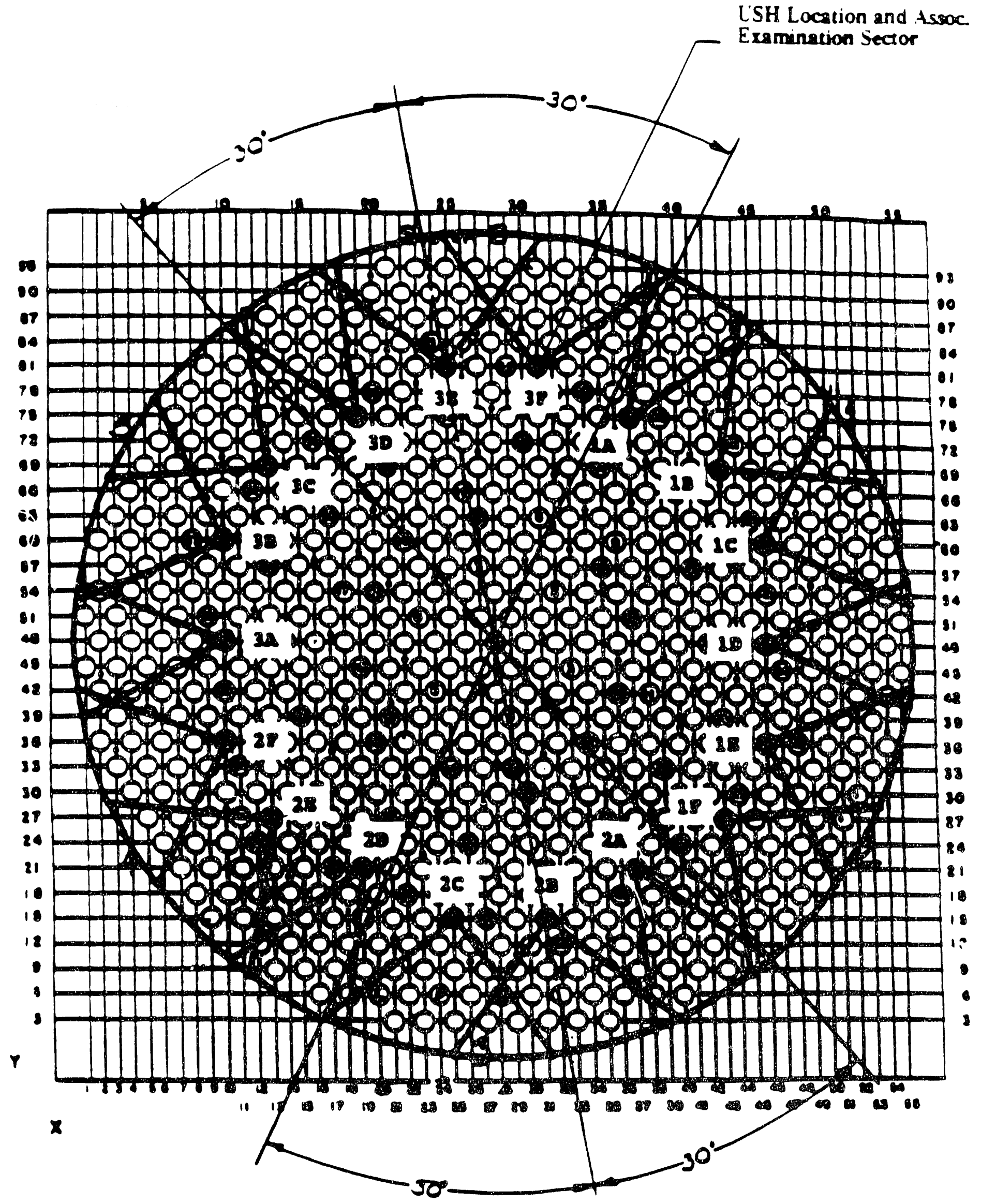

Figure 1. A top view of the reactôn tanth shôning typical $6 \theta^{\circ}$ inspection quadrant with its corresponding examination range. 


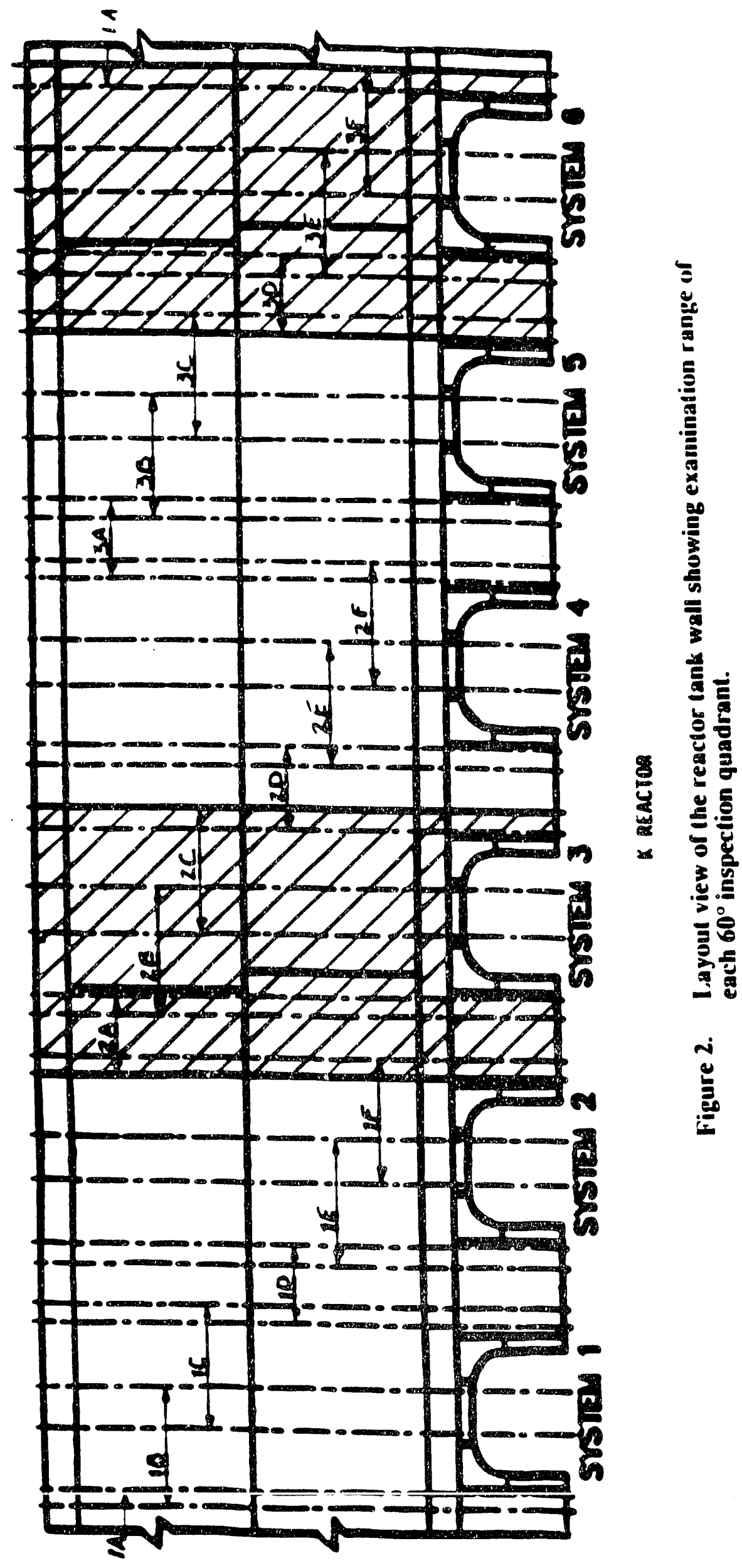



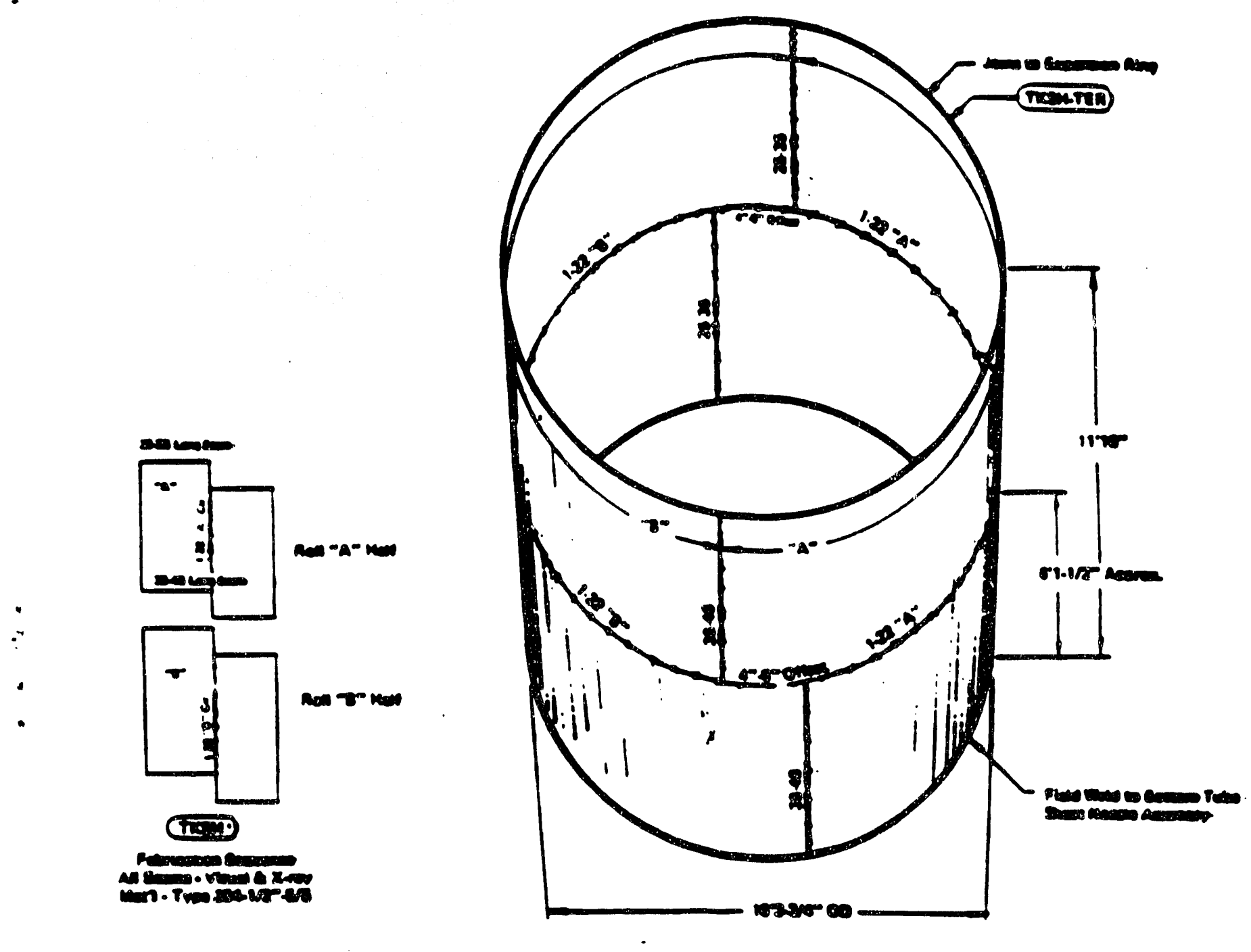

FIGURE 3. MAIN TANK SHELL "P" 

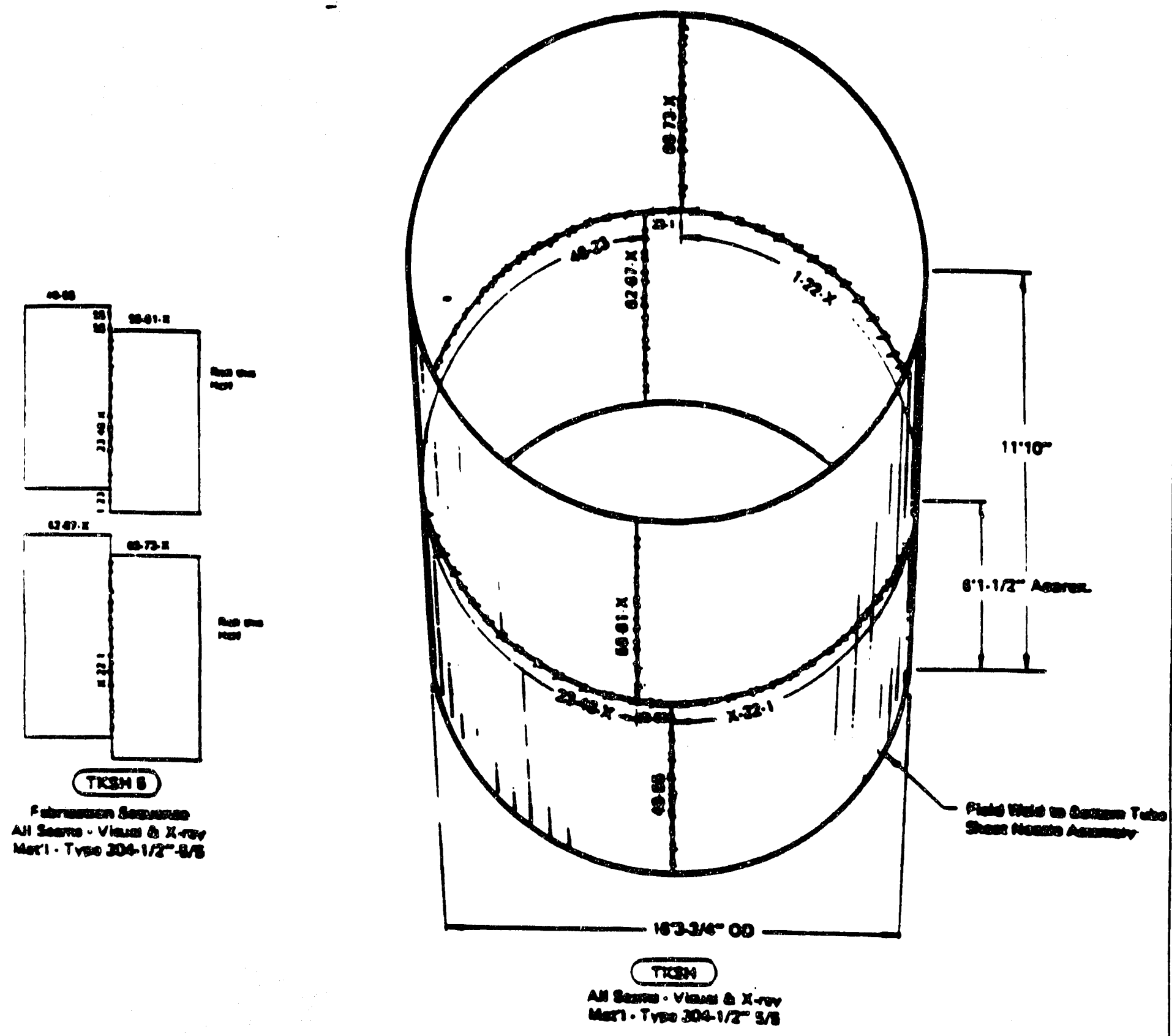

FIGURE 4. MAIN TANK SHELL " $K "$ 

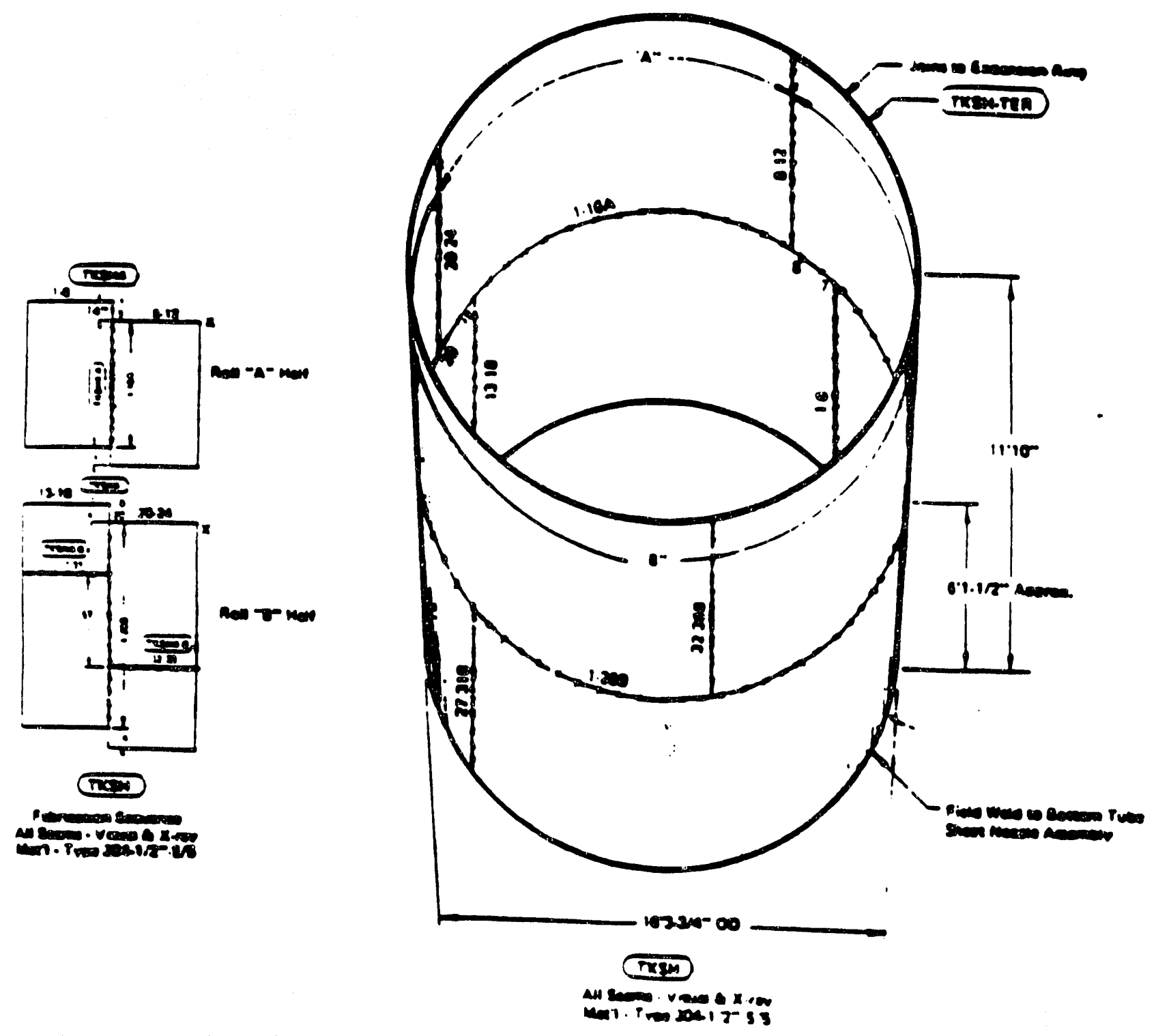

FIGURE 5. MAIN TA.IK SHELL "L" 

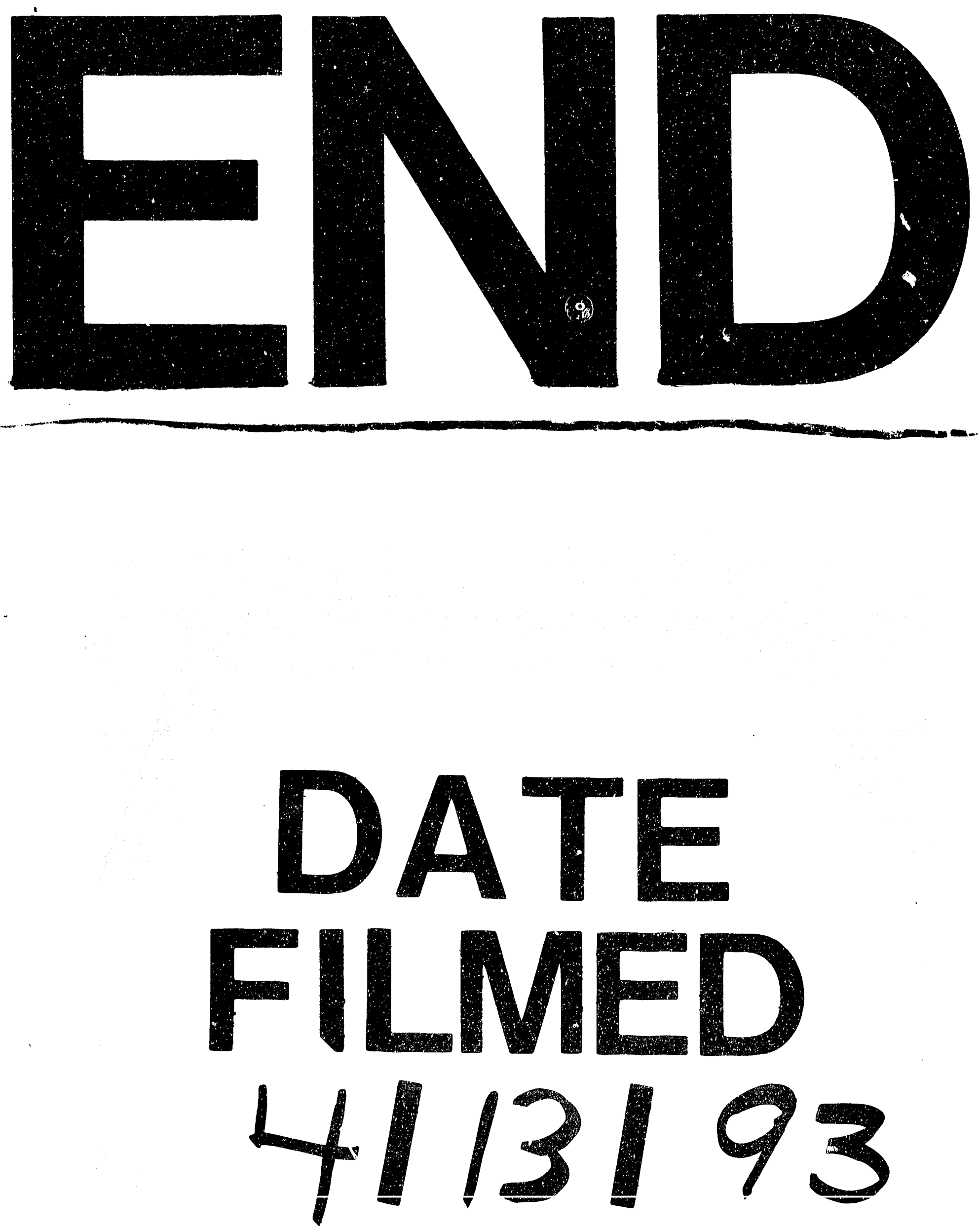

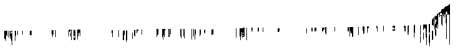


1 